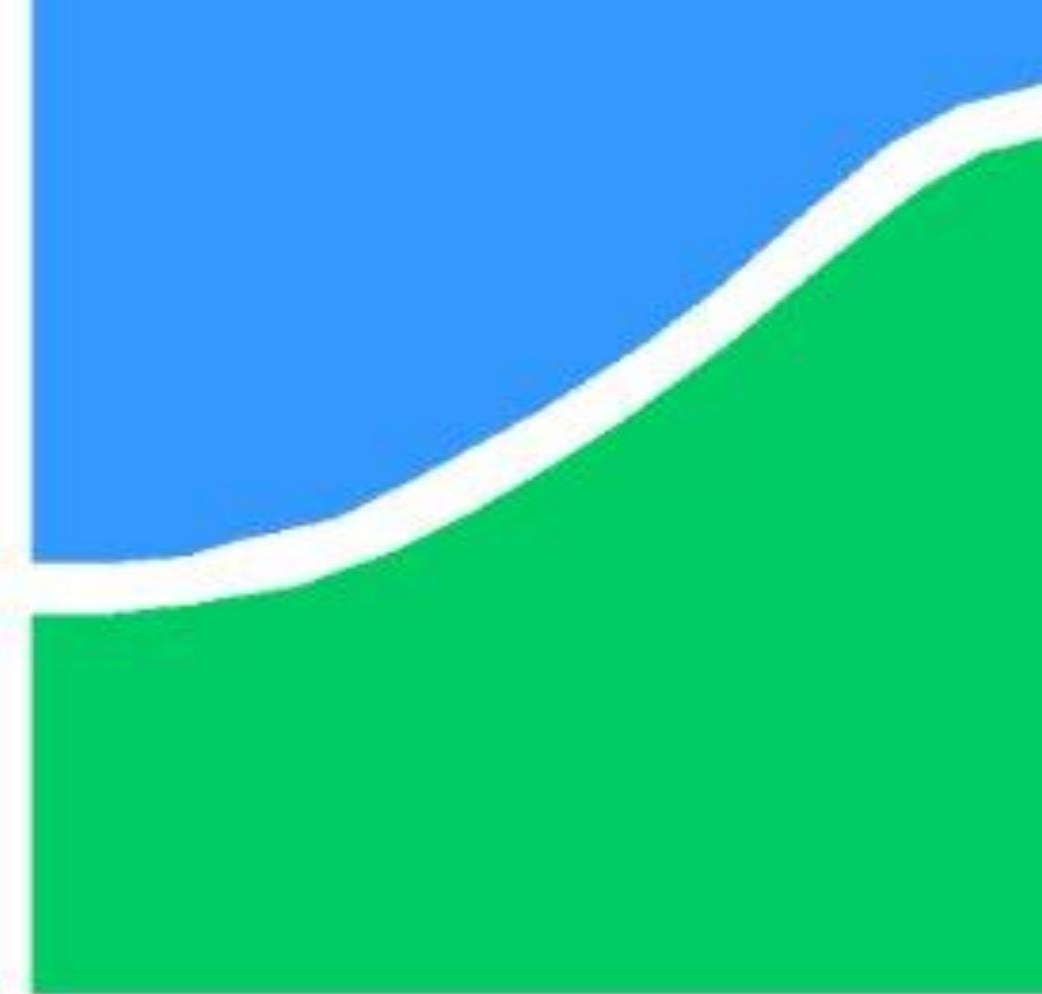

DISSERTAÇÃO DE MESTRADO

\title{
OXÍMETRO DE PULSO COM COMUNICAÇÃO VIA BLUETOOTH
}

MARCOS AURÉLIO LIMA NEVES

Brasília, 08 de Dezembro de 2015

UNB - UNIVERSIDADE DE BRASÍLIA

$$
\text { FGA - FACULDADE GAMA }
$$

PROGRAMA DE PÓS GRADUAÇÃO EM

ENGENHARIA BIOMÉDICA 


\author{
UNB - UNIVERSIDADE DE BRASÍLIA \\ FGA - FACULDADE GAMA \\ PROGRAMA DE PÓS-GRADUAÇÃO EM ENGENHARIA \\ BIOMÉDICA
}

\title{
OXÍMETRQ DE PULSO COM COMUNICAÇÃO VIA BLUETOOTH
}

Marcos Aurélio Lima Neves

Orientador: Dr. Georges Daniel Amvame Nze

DISSERTAÇÃO DE MESTRADO EM ENGENHARIA BIOMÉDICA

PUBLICAÇÃO: 42A/2015

Brasília, 08 de Dezembro de 2015 


\title{
UNIVERSIDADE DE BRASÍLIA \\ FACULDADE UNB GAMA \\ ENGENHARIA BIOMÉDICA
}

\section{OXÍMETRO DE PULSO COM COMUNICAÇÃO VIA BLUETOOTH}

\author{
MARCOS AURÉLIO LIMA NEVES
}

DISSERTAÇÃO DE MESTRADO SUBMETIDA À FACULDADE UNB GAMA DA UNIVERSIDADE DE BRASÍLIA, COMO PARTE DOS REQUISITOS NECESSÁRIOS PARA A OBTENÇÃO DO TÍTULO DE MESTRE EM ENGENHARIA BIOMÉDICA.

APROVADA POR:

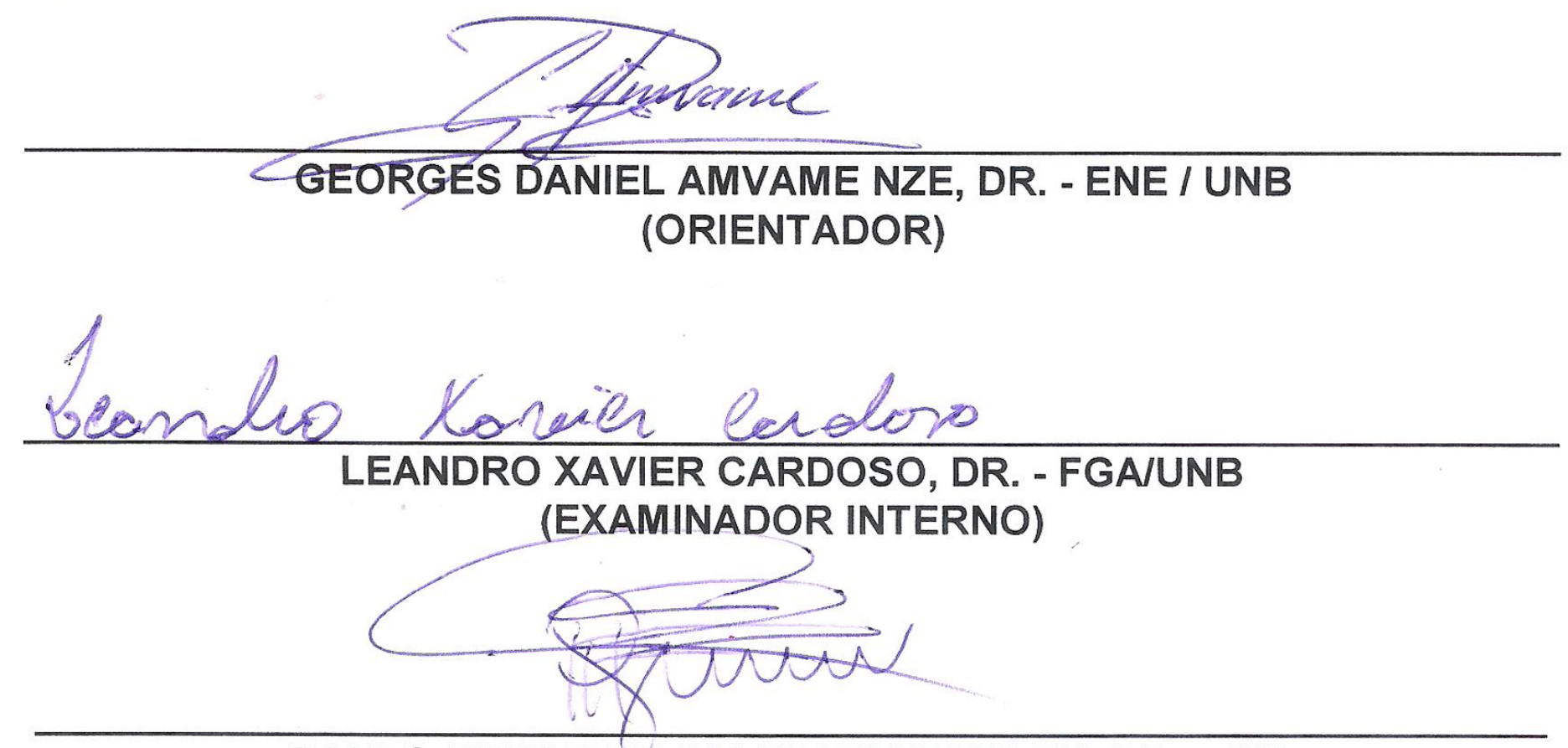

PAULO HENRIQUE SALES WANDERLEY, DR. - IFB

(EXAMINADOR EXTERNO) 


\section{Brasília, 08 de Dezembro de 2015.}

\section{FICHA CATALOGRÁFICA}

NEVES, MARCOS AURÉLIO LIMA

OXÍMETRO DE PULSO COM COMUNICAÇÃO VIA BLUETOOTH,

[Distrito Federal] 2015.

71 p.,210 x 297mm (FGA/UnB Gama, Mestre, Engenharia Biomédica, 2015).

Dissertação de Mestrado - Universidade de Brasília. Faculdade Gama.

Programa de Pós-Graduação em Engenharia Biomédica.

1. Condicionamento do sinal 2. Processamento do sinal

3. Bluetooth

4. Sensor

I. FGA GAMA/UnB

II. Título série

\section{REFERÊNCIA BIBLIOGRÁFICA}

NEVES, M. A. L. (2015). Oxímetro de pulso com comunicação via bluetooth. Dissertação de Mestrado em Engenharia Biomédica, Publicação n ${ }^{\circ}$ 042A /2015, Programa de Pós-Graduação em Engenharia Biomédica, Faculdade Gama, Universidade de Brasília, Gama, DF, 70.p.

\section{CESSÃO DE DIREITOS}

AUTOR: Marcos Aurélio Lima Neves

TÍTULO: Oxímetro de pulso com comunicação via bluetooth.

GRAU: Mestre

ANO: 2015

É concedida à Universidade de Brasília permissão para reproduzir cópias desta dissertação de mestrado e para emprestar ou vender tais cópias somente para propósitos acadêmicos e científicos. O autor reserva outros direitos de publicação e nenhuma parte desta dissertação de mestrado pode ser reproduzida sem a autorização por escrito do autor.

Marcos Aurélio Lima Neves.

Área Especial de Indústria Projeção A Brasília.

Cep: 72.444-240 - Gama - Brasília/DF - Brasil. 


\section{DEDICATÓRIA}

Por toda a compreensão e apoio recebido no desenvolvimento desta dissertação, dedico a minha querida esposa Luciana e filhas: Carina, Kelly e Luana. Também em especial, a meu Pai, minha Mãe, Irmão, Familiares e Amigos que acreditaram no meu objetivo.

Marcos Aurélio. 


\section{AGRADECIMENTOS}

Primeiramente, a Deus por ter me dado força e coragem para superar todos os desafios envolvidos ao longo desta dissertação, sem Ele nada teria conseguido!

Em especial, com grande carinho e respeito, ao prof. Dr. e orientador Georges Daniel Amvame Nze pela condução, contribuição e confiança a mim estabelecida ao longo desta pesquisa. Com certeza, um dos grandes motivadores e apoiadores deste trabalho!

Aos prof.(s) Dr.(s): Euler de Vilhena Garcia, Marcelino Monteiro de Andrade, Marilia Miranda Forte Gomes, Gerardo Antonio Idrobo Pizo, Sergio Ricardo Menezes Mateus e Vera Regina Fernandes da Silva Marães por todo apoio e conhecimento transferido nas disciplinas ministradas ao longo do curso.

A prof.(a) Dr. Lourdes Brasil por todo profissionalismo empregado e comprometimento com o nível de qualidade acadêmica do curso, onde sempre atuou com muita competência.

A professores, Dr. Leandro Cardoso e Dr. Fábio Mesquita, pelas considerações apresentadas na fase de qualificação da dissertação, fazendo enriquecer o trabalho desenvolvido.

Aos colegas e amigos Edson Miranda, Willian Daniel de Mattos, Luiz Rodrigo, Jorge Luiz da Silva Lustosa e João Paulo Silveira pelas contribuições no desenvolvimento conceitual, técnico e prático deste projeto.

A direção da Escola Técnica de Brasília por ter cedido suas instalações laboratoriais para desenvolvimento do projeto eletrônico e aos professores Gabriel, Dornelas, Júlio e Sandoval por todo o apoio incondicional.

A equipe da secretaria UnB/Gama pelo apoio administrativo na condução e divulgação dos processos vinculados ao curso.

Enfim, a todos aqueles que de alguma forma contribuíram pelo sucesso deste trabalho e por algum motivo eu tenha esquecido de formalizar. Assim, finalizo meus agradecimentos manifestando com muito orgulho o meu ...

MUITO OBRIGADO! 


\title{
RESUMO
}

\section{OXÍMETRO DE PULSO COM COMUNICAÇÃO VIA BLUETOOTH}

\author{
Autor: Marcos Aurélio Lima Neves. \\ Orientador: Dr. Georges Daniel Amvame Nze. \\ Programa de Pós-Graduação em Engenharia Biomédica. \\ Brasília, 08 de dezembro de 2015.
}

O oxímetro é um equipamento médico não invasivo que extrai dados percentuais de oxigenação (SpO2) e frequência cardíaca (FC) do ser humano. O processo fisiológico se manifesta por meio do fluxo respiratório e sanguíneo. A troca gasosa que ocorre nos alvéolos dos pulmões faz com que a corrente sanguínea transporte o oxigênio através das moléculas de hemoglobina oxigenada ( $\mathrm{HbO} 2)$ que estão presentes no sangue arterial. Com isso, a maior parte do oxigênio é absorvido pelos tecidos corporais e um pequeno percentual retorna como uma parcela de impurezas por meio das moléculas de hemoglobinas desoxigenadas, presentes no sangue venoso. A periodicidade em que se repete tal processo permite aferir o ritmo cardíaco. Atualmente, os oxímetros existentes no mercado nacional não disponibilizam, ao paciente ou à equipe médica, as informações de frequência cardíaca e percentual de oxigenação por meio de um serviço de telecomunicação. No mercado internacional, em particular nos países desenvolvidos, este cenário já é uma realidade. Com a inserção do conceito de Telemedicina, dispositivos eletrônicos de comunicação sem fio foram inseridos em equipamentos da área de Engenharia Biomédica, possibilitando o envio dos dados coletados para a equipe médica por meio de terminais portáteis (celulares, tablets e notebooks). Com isso, o objetivo dessa dissertação é apresentar a descrição analítica de um projeto, em nível de hardware e software, na área da oxímetria direcionando seus resultados para o campo da Telemedicina. O envio das informações coletadas pelo oxímetro foi realizada via comunicação bluetooth. Um servidor móvel foi inserido para registro e gerenciamento dos dados enviados pelo equipamento, facilitando assim, o monitoramento e reduzindo as fronteiras existentes no acompanhamento de sinais biomédicos. Esse trabalho pode contribuir para a melhoria no tratamento dos pacientes reduzindo a distância entre o monitoramento de seus sinais vitais e o envio dos dados para a equipe médica.

Palavras chaves: Sinais Biocondutivos, Sensores, Condicionamento, Amplificadores, Microprocessador, Bluetooth e Monitoramento. 


\title{
ABSTRACT \\ Pulse Oximeter whith Communication Bluetooth
}

\author{
Author: Marcos Aurélio Lima Neves. \\ Supervisor: Dr. Georges Daniel Amvame Nze. \\ Post-Graduation Program in Biomedical Engineering. \\ Brasília, December 08 of 2015.
}

\begin{abstract}
The oximeter is a noninvasive medical device which extracts data percentage oxygenation ( $\mathrm{SpO} 2)$ and heart rate (HR) from human being. The physiological process happens by the respiratory and blood flow. Gas exchange occurring in the alveoli of the lungs causes the blood oxygen transport through the oxygenated hemoglobin molecule (HbO 2) present in the arterial blood. Thus, oxygen is absorbed by body tissues resulting in a portion of impurities that returns through deoxygenated hemoglobin molecules existing in venous blood. The periodicity which this process is repeated allows to extract the heart rate. Nowadays, Brazilian market oximeters do not provide the heart rate information nor percentage of oxygenation through telecommunications service. In developed countries this scenario is already a reality, concepts of telemedicine and wireless communication devices has been inserted on Biomedical Engineering equipment allowing to send patient's data to medical staff over portable terminals as mobile phone, tablets and notebooks. Thereby, this dissertation presents an analytical description of a project about hardware and software on oximetry field concentrated its results on telemedicine area. Bluetooth technology was chose to transmit the data collected by the oximeter and a mobile server was inserted to manage and record all data received by the portable device. This work may contribute to improve patient's treatment reducing the distance between monitoring their signals and the information to medical staff.
\end{abstract}

Key words:: Sensors, conditioning, Amplifiers, Microprocessor, Bluetooth, Signs Bio Conductive and Monitoring. 


\section{SUMÁRIO}

1 INTRODUÇÃO 1

1.1 Contextualização e Formulação do Problema . . . . . . . . . . . . . . . 1

1.2 Motivação . . . . . . . . . . . . . . . . . . . 2

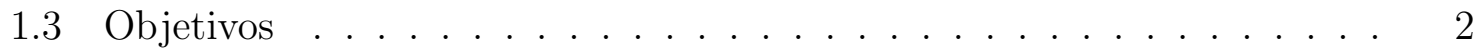

1.3.1 Objetivo Geral .................... 2

1.3.2 Objetivo Específico . . . . . . . . . . . . . 2

1.4 Revisão da Literatura . . . . . . . . . . . . . . . . . . . . . 3

1.5 Trabalhos Relacionados . . . . . . . . . . . . . . . 4

1.6 Organização do Trabalho . . . . . . . . . . . . . . . . . . 5

2 FUNDAMENTAÇÃO TEÓRICA 6

2.1 Processo Fisiológico . . . . . . . . . . . . . . . . . . 6

2.2 Princípio da Oximetria . . . . . . . . . . . . . . . . . 10

2.3 Sensoriamento . . . . . . . . . . . . . . . . . . . 12

2.3.1 Funcionamento ...................... 14

2.3.2 Erros de Leitura . . . . . . . . . . . . . . . . . . . 15

2.3.3 NBR IEC 60601-1 e ISO 10993-1 . . . . . . . . . . . 15

2.4 Condicionamento . . . . . . . . . . . . . . . . . . . . 16

2.4.1 Circuito de Transimpedância . . . . . . . . . . . . . . 16

2.4.2 Filtro Passsa Baixa (FPB) . . . . . . . . . . . . . 17

2.4.3 Circuito de Amplificação . . . . . . . . . . . . . . . . 18

2.4 .4 Circuito de Off-Set . . . . . . . . . . . . . . . . 19

2.5 Processamento do Sinal . . . . . . . . . . . . . . . . . . . . . . . . . 19

2.6 Comunicações sem Fio . . . . . . . . . . . . . . . . . . . . . . . . . 22

2.6.1 WI-FI (Wireless Fidelity) . . . . . . . . . . . . . . 22

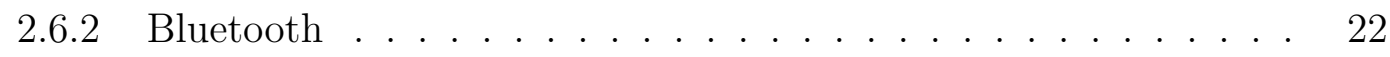

2.6.3 UWB (Ultra Wide Band) . . . . . . . . . . . . . . . 22

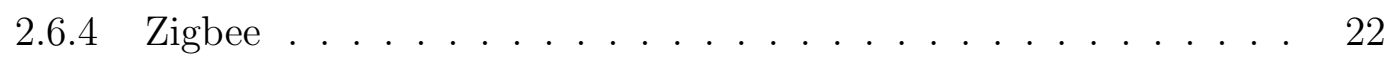

2.7 ThingSpeak - Internet das Coisas . . . . . . . . . . . . . . . 23 
3 METODOLOGIA

3.1 Diagrama de Blocos . . . . . . . . . . . . . . . . . 24

3.2 Sensor . . . . . . . . . . . . . . . . . . . 24

3.3 Simulação Eletrônica . . . . . . . . . . . . . . . . . . . . . . 26

3.4 PIC C Compiler e Software Microborn _ . . . . . . . . . . . . . . . . 29

3.5 Módulo Bluetooth . . . . . . . . . . . . . . . . . . . . . . . . . 30

3.6 APP - Android . . . . . . . . . . . . . . . . 31

3.7 Disponibilização dos dados - WEB . . . . . . . . . . . . . 35

3.7 .1 Configuração . . . . . . . . . . . . . . . . 35

3.7.2 Criação do canal . . . . . . . . . . . . . . . . 35

4 RESULTADOS E DISCUSSÕES $\quad 38$

4.1 Sensor de Dedo . . . . . . . . . . . . . . . . . . . . . 38

4.2 Protótipo . . . . . . . . . . . . . . . . . . . 39

4.3 Comunicação sem Fio e Aplicativo Android . . . . . . . . . . . . . . 39

4.4 Internet das Coisas . . . . . . . . . . . . . . . . . . . . . . . . . 41

4.5 Coleta e Análise de Dados . . . . . . . . . . . . . . . . . . . . . . . 42

4.5.1 Média Aritmética da Amostra . . . . . . . . . . . . . . 42

4.5.2 Mediana da Amostra . . . . . . . . . . . . . . . . . . 43

4.5.3 Variância e Desvio Padrão . . . . . . . . . . . . . . . . 43

5 CONCLUSÃO E TRABALHOS FUTUROS 45

REFERÊNCIAS BIBLIOGRÁFICAS $\quad 46$

$\begin{array}{ll}\text { A Artigo Publicado } & 49\end{array}$

A.1 Simpósio Engenharia Biomédica - Uberlândia/2015 . . . . . . . . . . . 49

B Diagrama do projeto $\quad 53$

B.1 Oxímetro de Pulso com Comunicação Sem Fio . . . . . . . . . . . . . . 53

C Especificações Técnicas

C.1 Foto-Diodo BPW34 . . . . . . . . . . . . . . . . . 55

D CÓDIGO - PIC18F452 56

D.1 Main . . . . . . . . . . . . . . . . . . 56

E CÓDIGO - Visualização e Conexão Bluetooth 62

E.1 device_list.xml . . . . . . . . . . . . . . . . . . . . 62

E.2 DeviceListActivity.java . . . . . . . . . . . . . 63 
F CÓDIGO - Main APP

F.1 MainActivity.java . . . . . . . . . . . . . . . 66 


\section{LISTA DE TABELAS}

4.1 Custos do Sensor de Dedo . . . . . . . . . . . . . . . . . . . . . . . . . 39

4.2 Coleta de dados . . . . . . . . . . . . . . . . . . . . . . 42

4.3 Média Aritmética da Coleta de dados . . . . . . . . . . . . . . 43

4.4 Disposição ordenada das amostras para cálculo da mediana . . . . . . . 43

4.5 Variância e Desvio Padrão FC . . . . . . . . . . . . . . . . . . . . . 44

4.6 Variância e Desvio Padrão $\% \mathrm{SPO}_{2} \ldots \ldots \ldots$. . . . . . . . . 44 


\section{LISTA DE FIGURAS}

2.1 Imagem da Face do Nariz . . . . . . . . . . . . . . . . 6

2.2 Septo Nasal, Narinas e Coanas . . . . . . . . . . . . . . . . . 7

2.3 Faringe . . . . . . . . . . . . . . . . . 7

2.4 Laringe . . . . . . . . . . . . . . . . . . . . . . . . . 7

2.5 Traquéia . . . . . . . . . . . . . . . . . . 8

2.6 Brônquios . . . . . . . . . . . . . . . . . . . . . . . . . 8

2.7 Pulmões . . . . . . . . . . . . . . . . . . . . . . . . . . . . . 9

2.8 Sistema Cardiovascular . . . . . . . . . . . . . . . . . . . . . . . 10

2.9 Coeficientes de absorção versus do comprimento de onda - com adaptações 11

2.10 Relação entre a taxa $(\mathrm{R})$ e o SpO2 - Com adaptações . . . . . . . . . . 12

2.11 Curva Pletismográfica . . . . . . . . . . . . . . . . . . . 13

2.12 Modelo Fotovoltaico - Com Adaptações . . . . . . . . . . . . . . . . . . 15

2.13 Amplificador de Transimpedância . . . . . . . . . . . . . . . . . . 16

2.14 FPB Butterworth de $4^{\mathrm{o}}$ Ordem . . . . . . . . . . . . . . . 18

2.15 Circuito de Amplificação . . . . . . . . . . . . . . . . . . . . . . . . 19

2.16 Circuito Off-Set . . . . . . . . . . . . . . . . 20

2.17 Microcontrolador PIC 18F452 . . . . . . . . . . . . . . . . 21

2.18 Canal de dados ThingSpeak . . . . . . . . . . . . . . . 23

3.1 Projeto Oxímetro com Comunicação Bluetooth . . . . . . . . . . 25

3.2 Esquemático de Ligação - Com Adaptações . . . . . . . . . . . . . . . . 26

3.3 Condicionamento $-1^{\circ}$ Estágio . . . . . . . . . . . . . . 26

3.4 Condicionamento - $2^{\mathrm{o}}$ Estágio . . . . . . . . . . . . . 27

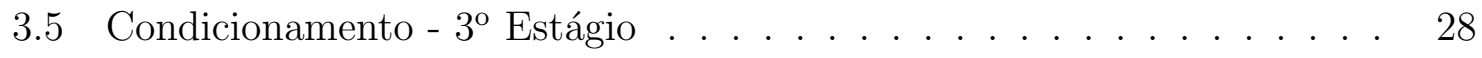

3.6 Condicionamento - $4^{\mathrm{o}}$ Estágio . . . . . . . . . . . . . . 28

3.7 Microcontrolador e LCD - Proteus . . . . . . . . . . . . . . . . . 29

3.8 Hardware Picburner Usb K150 . . . . . . . . . . . . . . . . . . . 29

3.9 Software Microborn . . . . . . . . . . . . . . . . . . . 30

3.10 Módulo Bluetooth - HC05 . . . . . . . . . . . . . . . . . . . 31

3.11 Dimensões da Placa HC05 . . . . . . . . . . . . . . . . . . . . . . . 31

3.12 Design Aplicativo Android . . . . . . . . . . . . . . . . . . . 32 
3.13 Design Conexão Bluetooth . . . . . . . . . . . . . . . . . . 33

3.14 Configura o Canal ThingSpeak . . . . . . . . . . . . . . 35

3.15 Configurando os parâmetros de leitura . . . . . . . . . . . . 36

3.16 Print do canal thingspeak configurado . . . . . . . . . . . . . . . . 37

4.1 Curva pletismográfica vista na tela do osciloscópio . . . . . . . . . . 38

4.2 Circuito montado em Protoboard . . . . . . . . . . . . . . . . . . . . . 39

4.3 Comunicação Bluetooth . . . . . . . . . . . . . . . . . . . 40

4.4 Comparação com Finger Pulse Oximeter - Comercial . . . . . . . . . . 40

4.5 Imagem do site: https://thingspeak.com/channels . . . . . . . . . . . 41

B.1 Diagrama do projeto - Condicionamento e Processamento . . . . . . . 53

B.2 Diagrama do projeto - Fonte Simétrica . . . . . . . . . . . . . . . . . . 54

C.1 Dimensões do Fotodiodo BPW34 . . . . . . . . . . . . . . . . 55 


\section{INTRODUÇÃO}

\subsection{Contextualização e Formulação do Problema}

Notoriamente, sabe-se que a tecnologia, de uma forma ou de outra, atua sempre em favor da saúde. Com isso, a exploração por aplicações que busquem aperfeiçoar o controle e acompanhamento médico em relação ao paciente são cada vez mais prioritários para os pesquisadores e profissionais das áreas afins [1].

Recentes avanços nos sistemas da área de TELEMEDICINA levaram ao surgimento de uma tecnologia que se encontra em franca expansão, sendo conhecida como: " rede de sensores sem fio para aplicações médicas ". Tratam-se de pequenos equipamentos eletrônicos alimentados através de baterias e com capacidade de comunicação limitada em potência e tráfego, que tem o objetivo de captar os sinais bioelétricos dos seres humanos.

Atualmente, os grandes centros de tecnologia mundial desenvolvem e implementam uma série de sensores médicos sem fio com base em plataformas de hardware e softwares com códigos abertos (open source). Um bom exemplo é aplicado na área de oximetria, onde oxímetros operam com transmissão sem fio, coletando dados importantes da freqüência cardíaca (FC) e a saturação de oxigênio $\left(\mathrm{SpO}_{2}\right)$. A transmissão dos dados é direcionada para uma determinada área de cobertura para dispositivos que recebam as informações, incluindo laptops, tablets, dentre outros. O importante é que os dados possam ser visualizados em tempo real e com isso, serem tratados de forma mais efetiva.

O oxímetro de pulso com comunicação via BLUETOOTH é um dispositivo eletrônico com módulo transmissor e receptor de baixa potência. O protocolo de transmissão é compatível com IEEE 802.15.1, no que opera na faixa de frequência de 2,45 GHz. Também pode ser classificado de acordo com a distância de cobertura nas classes $1(100 \mathrm{~m}), 2(10 \mathrm{~m})$ e $3(1 \mathrm{~m})$.

O desenvolvimento de projetos na área de sensores biomédicos permite que os sinais vitais possam ser registrados, controlados e monitorados com maior precisão, permitindo diversas opções para o diagnóstico médico. Através da medicina a distância é possível diagnosticar, prevenir, acompanhar, fiscalizar e monitorar diversos procedimentos médicos, fazendo com que o sistema se torne mais eficiente.

O fato é que uma rede de sensores sem fio de oximetria aperfeiçoará os recur- 
sos no atendimento aos pacientes e aos profissionais de clínicas e redes hospitalares. Desse modo, a pesquisa tem como objetivo apresentar uma solução de projeto de um oxímetro sem fio com comunicação via bluetooth para operação centralizada do controle e monitoração utilizando softwares de código aberto.

\subsection{Motivação}

Inicialmente, a proposta de melhoria nos projetos ou equipamentos médicos na área Engenharia possibilita colaborar com a evolução da tecnologia, principalmente com a relação custo/benefício, seja para usuários comum ou empreendedores do sistema.

Trabalhar integrando áreas como saúde e tecnologia remete ao estudante ou profissional de engenharia a necessidade de atualização conceitual com as novidades do mercado de equipamentos médicos, seja eles, invasivos ou não invasivos.

As vantagens da inserção de comunicação sem fio nos dispositivos biomédicos garantem benefícios satisfatórios, tanto para o paciente como a equipe médica envolvidas no acompanhamento e controle dos dados. Cita-se como exemplos de ganhos: a flexibilidade de locomoção, a redução na instalação de fios ao longo do corpo.

\subsection{Objetivos}

\subsubsection{Objetivo Geral}

Desenvolver um OXÍMETRO com comunicação Bluetooth capaz de monitorar e avaliar os sinais de frequência cardíaca e oxigenação do sangue através de aplicativo android utilizado em smartphone e servidor web.

\subsubsection{Objetivo Específico}

Os objetivos específicos desta dissertação estão concentrados nas seguintes áreas de interesse:

1. Área clínica (fisiologia)

Nesta especialidade, este trabalho propõe conceituar os fundamentos básicos de fisiologia voltada para a geração dos sinais de frequência cardíaca e oxigenação do sangue do ser humano.

2. Engenharia Biomédica

- Identificar as principais tecnologias de rede de sensores sem fio utilizadas atualmente; 
- Desenvolver um projeto de hardware e software de um oxímetro sem fio com comunicação via bluetooth, envolvendo as seguintes etapas: sensoriamento, condicionamento, processamento (tratamento da informação), implementação do dispositivo bluetooth e criação do aplicativo (interface de comunicação) android.

- Disponibilização dos dados via web.

\subsection{Revisão da Literatura}

A pesquisa da base bibliográfica utilizada nesse trabalho considerou a busca por livros, teses, monografias e artigos nas seguintes fontes especializadas: PubMed, ACM (Association for Computing Machinery), IEEE (Institute of Electrical and Electronics Engineers), RadiologySource, Radiographics, USP (Universidade de São Paulo), UFSC (Universidade Federal de Santa Catarina).

O PubMed é uma base de dados que permite a pesquisa bibliográfica de artigos publicados em revistas de grande circulação da área médica. Ele foi desenvolvido pelo NCBI (National Center for Biotechnology Information), sendo mantido pela NLM (National Library of Medicine). A pesquisa foi realizada utilizando a palavra-chave " Oximetry Bluetooth "como referência retornou 08 trabalhos, apresentando relevância ao tema em estudo. Destes, apenas três foram selecionados como temas relevantes ao estudo desta dissertação.

Outra base bibliográfica pesquisada foi o IEEE, que é uma organização profissional sem fins lucrativos com trabalhos editados e publicados no em jornais, congressos e revistas internacionais. A pesquisa realizada utilizando a palavra-chave "Oximetry Bluetooth", com limitação por período de 2002 à 2015, retornou 23 trabalhos com relevância ao tema em estudo. Destes, apenas onze foram selecionados como temas relevantes ao estudo desta dissertação.

O cruzamento dos dados em combinação com os registros desta dissertação possibilitou o desenvolvimento de um artigo de interesse, intitulado como "BLUETOOTH PULSE OXIMETER A TELEMEDICINE ORIENTED EQUIPMENT". Este artigo foi aceito e publicado nos Anais do Simpósio de Engenharia Biomédica ocorrido na cidade de Uberlândia no mês de agosto de 2015 e está disponível no apêndice A desta dissertação. 


\subsection{Trabalhos Relacionados}

Em [2] é proposto o desenvolvimento de um oxímetro de pulso para medição da oxigenação periférica e pulsação cardíaca com interface via web. Tal aplicação foi desenvolvida com base na plataforma Raspberry Pi cujos resultados se demostraram satisfatórios. No entanto, ficou registrado que o tempo de processamento se mostrou lento comparado a outros oxímetros.

Em [3], Felix Adochiei et al., apresenta um artigo baseado em pesquisas sobre um oxímetro wireless de baixo custo para a telemonitoração do nível de $\mathrm{SpO} 2$ e frequência cardíaca (FC). O uso do sistema proposto é adequado para o monitoramento de pacientes que precisam de algum diagnóstico. A arquitetura utiliza microcontroladores de baixa potência e transceptores de RF que se comunicam utilizando a rede Wi-Fi ou a comunicação móvel 3G (GSM / GPRS). Tal protótipo foi concebido, implementado e testado. O hardware utilizou dispositivos disponíveis no mercado.

Em [4], Kejia Li et al., propõem uma avaliação da taxa de oxigenação $\left(\mathrm{SpO}_{2}\right)$ e da frequência cardíaca através do envio dos dados da curva pletismográfica (PPG). A proposta do artigo reduz a transmissão de dados desnecessários possibilitando o aumento da vida útil da fonte de energia (baterias) do oximetro de pulso sem fio. Isso foi possível devido a utilização de algoritmos inteligentes que detectavam as características de bordas dos PPGs. Todo o tratamento da informação também foi feito no host receptor. Os dados conclusivos mostram que os resultados do algoritmo obtiveram uma eficiência de até $99 \%$ nas interpretações dos PPGs utilizáveis.

Em [5], Yitzhak Mendelson, apresenta a defesa de um projeto de oxímetro de pulso utilizando o conceito de telemedicina. Sua pesquisa consiste no desenvolvimento de sensores de oximetria de tecnologia sem fio, que possam ser empregados na monitoração e controle dos sinais vitais dos profissionais de salvamento de vidas (bombeiros), cujas atividades estão expostas a alto níveis de cargas extenuantes de curto prazo e esforço excessivo, bem como, o iminente perigo da inalação de dióxido de carbono $(\mathrm{CO})$ com alto risco da perda de consciência e morte.

Em [6], María J. Morón, apresenta uma arquitetura de acompanhamento médico utilizando oximetros sem fio descrevendo os diversos cenários de utilização. O sistema permite receber e processar em um nó único concentrador (por exemplo, um laptop ou um simples dispositivo portátil), os sinais de pulso-oximetria de um ou vários pacientes monitorados sem o uso de qualquer infra-estrutura cabeada. O sistema é baseado numa rede de sensores Bluetooth (piconet), sendo que os sinais possam ser retransmitidos pela rede WLAN e GPRS. 


\subsection{Organização do Trabalho}

Este trabalho está organizado em cinco capítulos, incluindo este.

No capítulo dois, é apresentada uma visão geral do referencial teórico. Objetivando a compreensão do processo fisiológico, o princípio da oximetria e os tipos de tecnologias sem Wireless.

O capítulo três detalha a metodologia utilizada no estudo.

O capítulo quatro descreve os resultados e discussões obtidos nesta dissertação.

O capítulo cinco apresenta as conclusões finais, bem como, discorre sobre propostas de trabalhos futuros que possam ser desenvolvidos a partir das idéias apresentadas neste projeto. 


\section{FUNDAMENTAÇÃO TEÓRICA}

\subsection{Processo Fisiológico}

Em termos gerais, o oxigênio é oferecido ao corpo humano com a colaboração de dois processos fisiológicos detalhados as seguir:

1. Sistema Respiratório: responsável pela inalação dos gases oriundos da atmosfera terrestre. Seu principal objetivo é garantir permanentemente a concentração de oxigênio no sangue e reduzir ou eliminar a presença de outros gases oriundos do gás carbônico $\left(\mathrm{CO}_{2}\right)$. Tem sua composição formada pelos seguintes órgãos: cavidade nasal, boca, faringe, laringe, traqueia, brônquios: esquerdo/ direito, e os pulmões formando sua estrutura. A seguir, será apresentado o conceito e a função de cada órgão.

- Cavidade Nasal: são as escavações (direita e esquerda) que existem no interior do nariz, sendo localizado no centro da face do rosto humano. Externamente o nariz possui uma raiz, um dorso, duas narinas, duas asas (esquerda e direita) e um ápice. Estes detalhes podem ser visto através da figura 2.1[7].

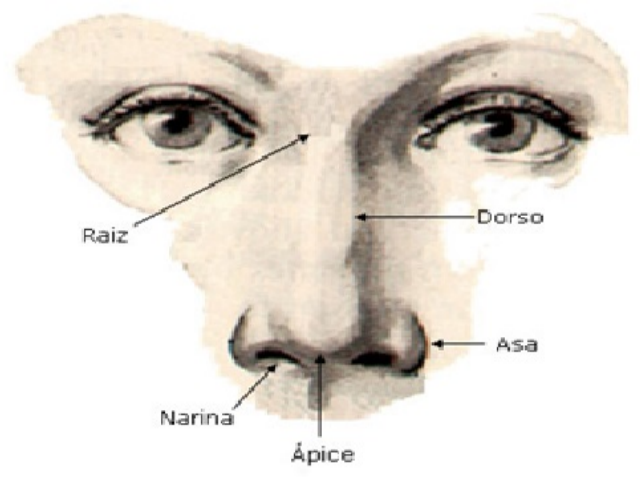

Figura 2.1: Imagem da Face do Nariz

O septo envolve a parte anterior externa (narinas) e a posterior interna (coanas), esta última é responsável pela comunicação entre cavidade nasal e a faringe. A demonstração deste órgão pode ser vista na figura 2.2[7]. 


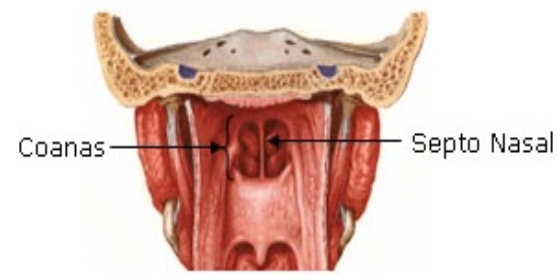

Figura 2.2: Septo Nasal, Narinas e Coanas

- Faringe: é um tubo que se inicia nas coanas e estende-se para baixo do pescoço. Sua estrutura pode ser conhecida visualizando o corte lateral e posterior visto na figura 2.3[7].

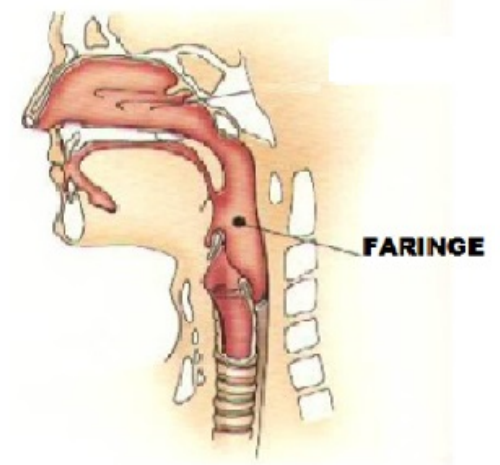

Figura 2.3: Faringe

- Laringe: é considerada um órgão que interliga a faringe com a traquéia. Executa funções especiais como: passagem de ar durante o ciclo respiratório, os sons produzidos e emitidos pela voz e também impede que alimentos ou objetos estranhos entrem nas estruturas respiratórias. A figura 2.4[7] apresenta sua estrutura.

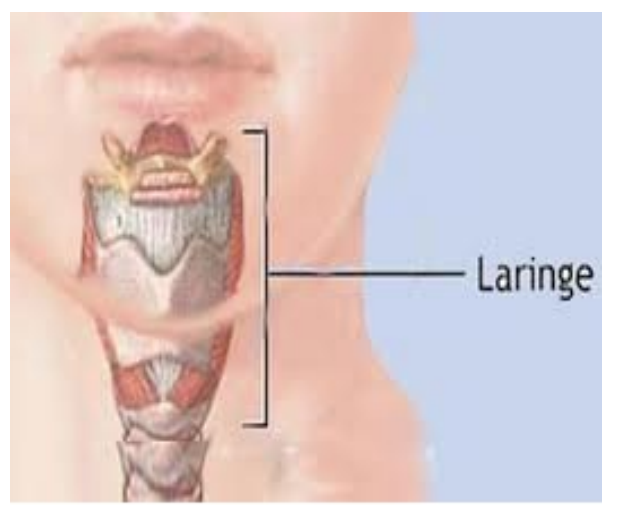

Figura 2.4: Laringe 
- Traquéia: é um tubo que possui dimensões entre 10 a 12,5 cm de comprimento, e 2,5 cm de diâmetro. Fisicamente, a traquéia (ver figura 2.5[7]) interliga a laringe aos dois brônquios principais direito e esquerdo.

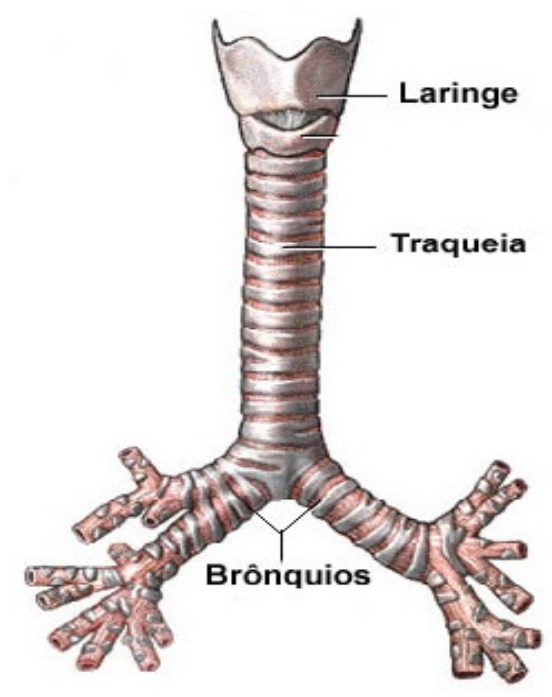

Figura 2.5: Traquéia

- Brônquios: responsável por interligar a traquéia com os pulmões. Constituído de anéis incompletos, sua estrutura se divide em túneis cada vez menores chamados de bronquíolos, que terminam em uma estrutura microscópia conhecida como Alvéolos. A figura 2.6[7] detalha a estrutura dos brônquios.

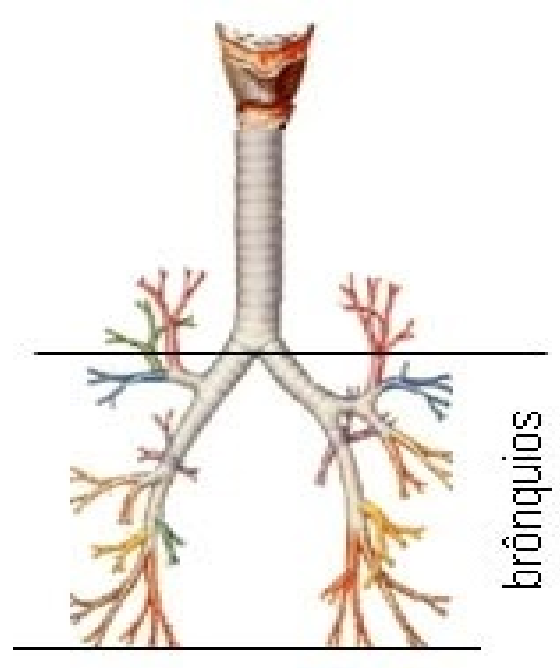

Figura 2.6: Brônquios

- Pulmões: são os órgãos principais no processo de respiração. Seu principal 
objetivo é realizar o encontro do oxigênio com o sangue circulante, denominando a chamada Hematose (troca gasosa). A estrutura pulmonar é vista na figura 2.7[7].

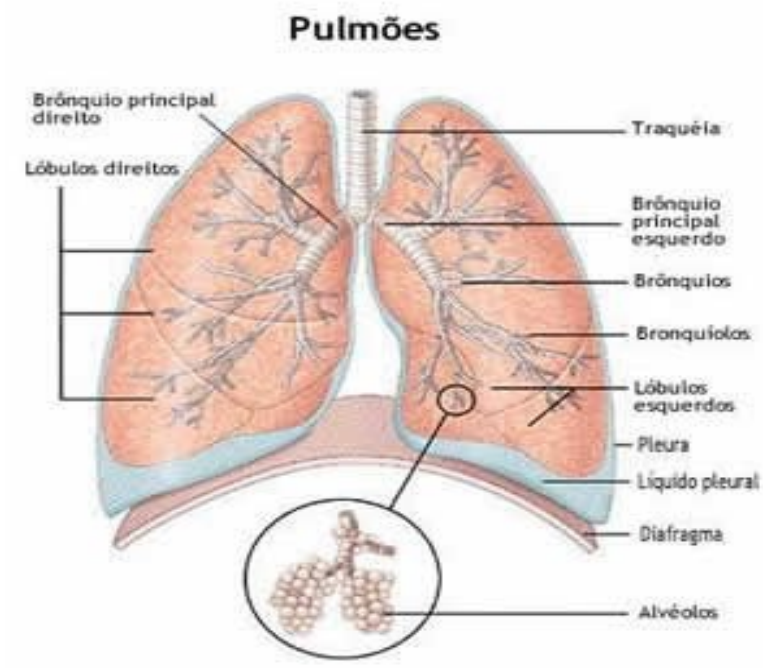

Figura 2.7: Pulmões

Na circulação pulmonar, o fluxo de oxigênio é encaminhado pelo coração através do ventrículo direito. Pelo átrio esquerdo, retorna o dióxido de carbono que são os elementos impuros extraídos pelas células corporais.

2. Sistema Cardiovascular: a corrente sanguínea possui a função de levar materiais nutritivos e oxigênio até as células ao longo do corpo humano. É um sistema fechado constituído por tubos, chamados também de vasos, e por uma bomba percursora que impulsiona o sangue vermelho pela rede cardiovascular. Faz parte da sua composição: o sangue, os vasos sanguíneos e o coração.

A circulação sistêmica é responsável por levar o sangue para todo o organismo, juntamente com os nutrientes e o oxigênio necessários. Também, acumula a função de captar o dióxido de carbono $\left(\mathrm{CO}_{2}\right)$, que é o sangue pobre em oxigênio, chegando no átrio esquerdo do coração.

Em resumo, pode-se concluir que o sangue é constituído pela seguinte estrutura:

- Plasma: responsável por transportar os nutrientes;

- Hemácias: são os glóbulos vermelhos responsáveis por transportar oxigênio até os tecidos corporais.

- Leucócitos: são os glóbulos brancos responsáveis pela defesa do corpo humano; 
- Plaquetas sanguíneas: responsáveis pela coagulação.

É importante ressaltar, que a falta de oxigênio pode levar a problemas relacionados a hipoxemia (baixa concentração de oxigênio no sangue arterial) e a hipóxia (baixa disponibilidade de oxigênio para determinado órgão).

A figura 2.8[7] detalha o sistema cardiovascular.

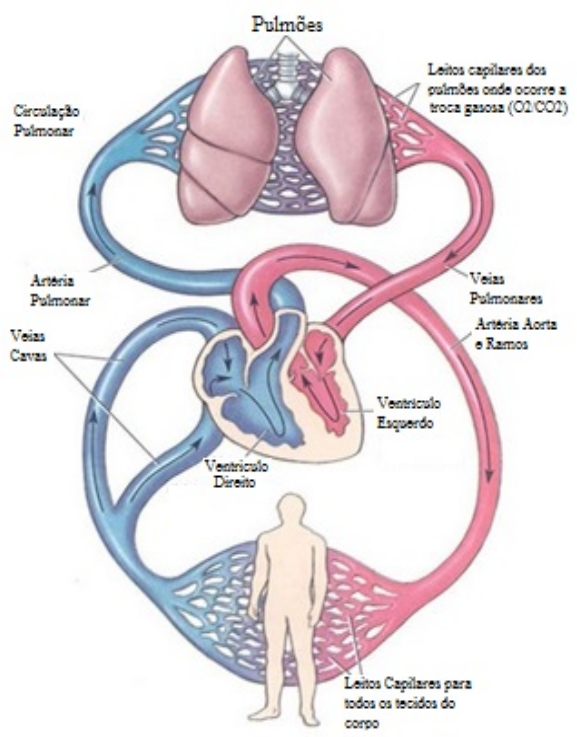

Figura 2.8: Sistema Cardiovascular

\subsection{Princípio da Oximetria}

A monitoração da taxa de saturação de oxigênio (SpO2) do corpo humano é aferida por um equipamento médico chamado oxímetro de pulso. Seu funcionamento é baseado no processo da fotocondução, por que utiliza a luz como o processo responsável pela captação dos dados de oxigenação e frequência cardíaca. Para isso, são utilizados os comprimentos de luz que melhor respondem ao processo de absorção da hemoglobina oxigenada e desoxigenada. Os leds são identificados pelas cores Vermelha (faixa de 600$750 \mathrm{~nm}$ ) e Infravermelha (faixa 850-1000 nm).

Com base na Lei de Beer-Lambert [8] dada pela equação 2.1, a espectrofotometria relaciona a absorção da luz por uma substância específica e pela distância percorrida por determinado feixe luminoso através daquele corpo[9].

$$
\begin{gathered}
I_{1}=I_{0} \cdot e^{-\alpha \cdot l} \\
\alpha=\epsilon(\lambda) \cdot c
\end{gathered}
$$

Em que: 
(a) $I_{0}=$ Intensidade da luz incidente $\left(W / m^{2}\right)$;

(b) $I_{1}=$ Intensidade da luz transmitida emergindo do meio $\left(\mathrm{W} / \mathrm{m}^{2}\right)$;

(c) $\alpha=$ Coeficiente de extinção de determinado feixe luminoso $\left(\mathrm{cm}^{-1}\right)$;

(d) l= Distância percorrida pela luz no meio, dado em metros (m);

(e) c= Concentração da substância no meio $\left(\frac{m m o l}{\text { litro }}\right)$;

(e) $\epsilon(\lambda)=$ Variável de extinção de determinado feixe luminoso.

Utilizando a equação 2.1 é possível traçar graficamente o modelo das curvas de absorção do oxigênio pela hemoglobina oxigenada e desoxigenada, fazendo referência aos seus respectivos comprimentos de ondas (ver figura 2.9[3]). O encontro das duas curvas é chamado de ponto isobéstico.

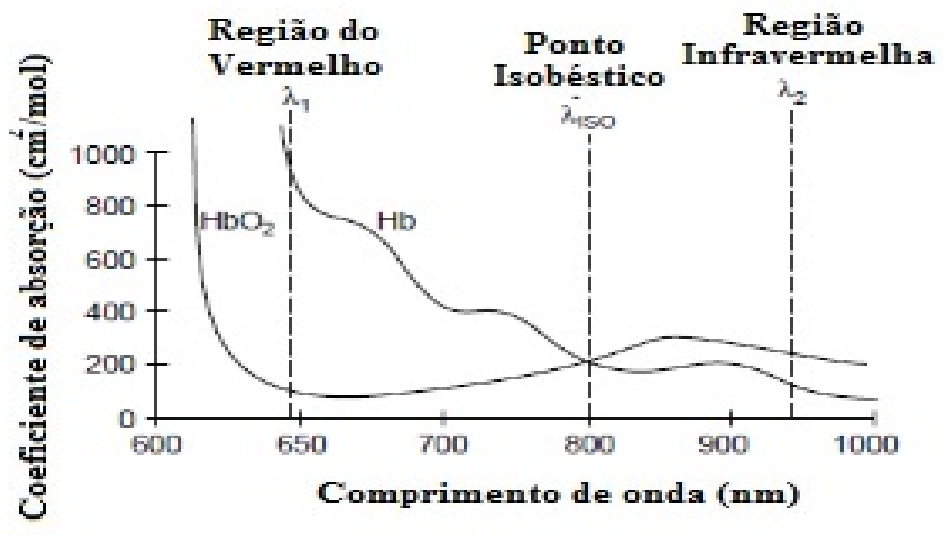

Figura 2.9: Coeficientes de absorção versus do comprimento de onda - com adaptações

Relacionando logaritmicamente as variáveis das intensidades dos sinais vermelho e infravermelho recebido no receptor por um dispositivo conhecido como fotodiodo, é possível extrair uma razão equivalente $\mathrm{R}$ (ver equação 2.3) capaz de relacionar em um determinado intervalo de medidas os valores das taxas de saturação de oxigenação (0-100\%) recebida pelo corpo humano.

$$
R=\log \frac{I_{(0)}}{I_{(1)}}=\frac{\log \frac{R_{(R M S)}}{R_{(D C)}}}{\log \frac{I R_{(R M S)}}{I R_{(D C)}}}
$$

Os primeiros oxímetros de pulso utilizavam a curva de Beer-Lambert como referência na obtenção dos valores de oxigenação do sangue. No entanto, foi observado que para taxas abaixo de $85 \%$, tais valores não apresentavam precisão na medida. Com 
o intuito de contornar este problema, uma curva empírica foi estabelecida, a partir de medições realizadas em pacientes saudáveis, resultando em valores mais precisos para o cálculo da taxa de oxigenação do corpo humano. A equação 2.4 modela matematicamente a curva empírica.

$$
S p O_{2}=10,0002 \cdot R^{3}-52,887 \cdot R^{2}+26,87 \cdot R+98,293
$$

A variável " $\mathrm{R}$ " introduzida na equação 2.4 é a taxa descrita pela equação 2.3. O gráfico apresentado na figura 2.10[9] detalha as curvas (Beer-Lambert e Empírica) envolvidas no processo de oxigenação. Basicamente, a taxa $\mathrm{R}$ varia entre um intervalo de 0,5 à 2,5. Respectivamente, os valores de oxigenação variam de forma inversa, ou seja, quando a taxa apresentar o valor extremo inferior, ter-se-á um valor de oxigenação de $100 \%$. Em contra partida, ao atingir o valor próximo a 2,2 ter-se-á uma oxigenação próximo a $0 \%$.

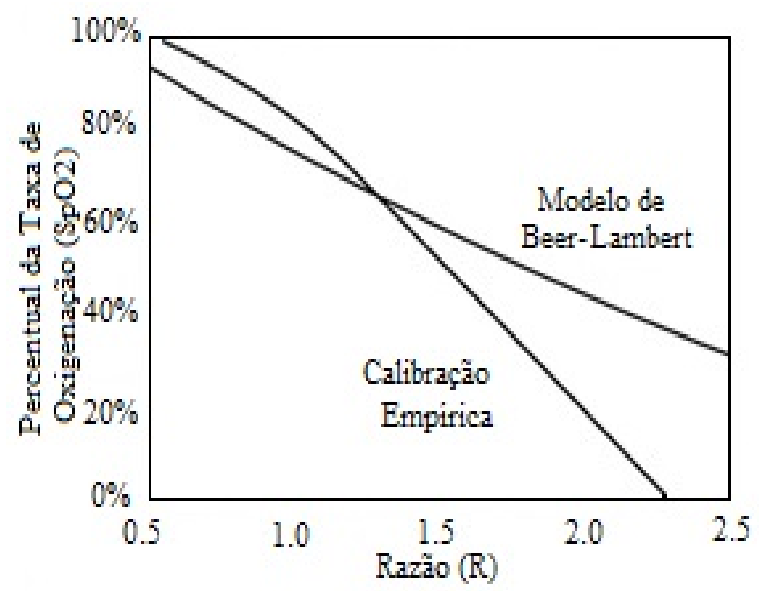

Figura 2.10: Relação entre a taxa (R) e o SpO2 - Com adaptações

É importante resaltar que a insuficiência respiratória pode ser diagnostigada para valores abaixo de $90 \%$. No entanto, casos por volta de $70 \%$ ou até mesmo $80 \%$ podem levar o paciente a internação e controle de forma imediata.

\subsection{Sensoriamento}

$\mathrm{Na}$ área de tecnologia, especificamente na Engenharia Biomédica, o linguajar técnico sensoriamento deriva da palavra "Sensor ", cujo conceito está extremamente empregado nos equipamentos da instrumentação médica.

Em termos gerais, sensor é um dispositivo que através do processo de transdução capta as variações dos sinais bioelétricos ou biocondutivos do corpo humano. Por de- 
finição sensores são transdutores cuja função é realizar as entradas das informações do mundo externo para o sistema, e atuador é o elemento responsável pelas ações de saída do sistema para o mundo externo. Esta definição é bastante apropriada para quem trabalha com sistemas de controle [10].

Em um oxímetro, o sensor é responsável por identificar as variações da frequência cardíaca e oxigenação do corpo humano. O sinal resultante do processo fotocondutivo é classificado como analógico e continuo. Graficamente é possível gerar uma reposta das variações de intensidades tensão máxima e mínima dos sinais captados pelo fotodiodo, este processo é conhecido como curva plestimográfica. A figura 2.11[9] apresenta um modelo teórico da curva pletismográfica.

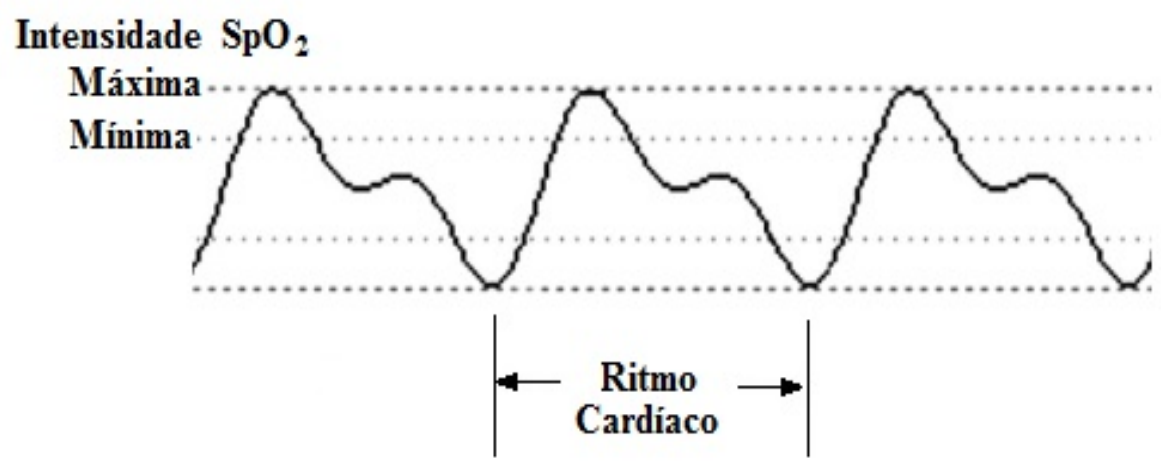

Figura 2.11: Curva Pletismográfica

Segundo Seippel, um transdutor é um dispositivo capaz de converter algum tipo de energia em outra forma de energia. O engenheiro Katsuhiko Ogata, em seu livro de Dinâmica de Sistema, classifica o processo de transdução da seguinte forma:

- Transdutores analógicos: são transdutores nos quais os sinais de entrada e saída de função contínua ao longo do tempo. Ou seja, as amplitudes dos sinais podem assumir quaisquer valores dentro das limitações físicas do sistema.

- Transdutores de dados amostrados: são transdutores nos quais os sinais e saída ocorrem apenas em instantes discretos de tempo, normalmente periódicos. As amplitudes do sinal são não-quantizáveis.

- Transdutores digitais: são aqueles nos quais os sinais de entrada e saída são discretos e a amplitude dos mesmos são quantificáveis, ou seja, podem assumir apenas certos valores discretos.

- Transdutores analógico-digital: são transdutores nos quais o sinal de entrada é uma função contínua do tempo e o sinal de saída é um sinal quantizável que 
pode assumir apenas certos valores discretos.

- Transdutores digital-analógico: são aqueles nos quais o sinal de entrada é um sinal quantizado e o sinal de saída é uma função contínua do tempo.

\subsubsection{Funcionamento}

O modo de funcionamento do sensor de oximetria baseia-se no processo de , no qual leds na faixa do Vermelho (R-660nm) e Infravermelho (IR-950nm), emitirão intensidades luminosas que atravessarão as partes translúcidas do corpo humano, como por exemplo, as orelhas e os dedos.

Antes de chegar ao fotodiodo, elemento considerado o receptor do sistema, parte das energias serão absorvidas pelo sangue humano e outra pequena parte captada pelo dispositivo. Este processo se repetirá a cada ciclo respiratório e de acordo com o ritmo cardíaco.

Na recepção, o modo de operação do fotodiodo pode ser discriminado através dos seguintes métodos relacionados com a forma de polarização:

1. Fotovoltaico: o dispositivo não necessita de polarização reversa e possui como característica linear, baixo ruído e geralmente é utilizado em aplicações que exijam precisão de medida;

2. Fotocondutivo: o dispositivo necessita de polarização reversa, possuindo características não lineares, alto ruído (térmico+shot) e geralmente é utilizado em aplicações que exijam alta velocidade.

No modelo fotovoltaico, o circuito de um fotodiodo pode ser modelado por um gerador de corrente em paralelo com uma resistência $R_{F T}$, na qual pode variar de algumas centenas de $k \Omega$ até alguns $G \Omega$, e um capacitor $C_{F T}$. A capacitância varia de acordo com o tamanho da área do diodo, ou seja, diodos de pequena área terão uma capacitância $C_{F T}$ variando até $50 \mathrm{pF}$. Já diodos de grande área terão uma capacitância com variação de até $300 \mathrm{pF}$.

Para baixas freqüências a impedância será determinada pela resistência $R_{F T}$, em altas freqüências será em função da capacitância $C_{F T}$. A figura 2.12 [11] apresenta a idealização do circuito do fotodiodo.

A corrente de curto circuito gerada por um fotodiodo pode variar significativamente em função da intensidade da luz sendo linear por 6 a 9 décadas de intensidade de luz. 


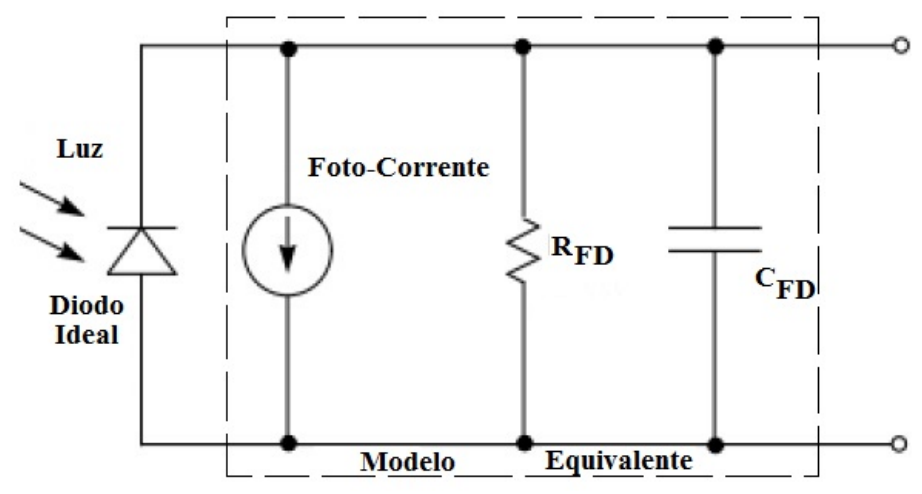

Figura 2.12: Modelo Fotovoltaico - Com Adaptações

\subsubsection{Erros de Leitura}

É importante ressaltar que os valores obtidos no momento da medição dos sinais de oxigenação $\left(\mathrm{SpO}_{2}\right)$ dependem das condições do fluxo sanguíneo, ou seja, em caso de situação de choque, hiportemia, uso de drogas vasoativas, anemia, dentre outros provocará alteração no ritmo cardíaco podendo provocar alterações também nas leituras de $\left(\mathrm{SpO}_{2}\right)$.

Algumas situações são elencadas a seguir que podem provocar erros de leitura no momento da medição da oxigenação do sangue, bem como, da frequência ou ritmo cardíaco.

a) Colocação incorreta do sensor;

b) Uso de esmaltes de unhas ou unhas postiças;

c) Fontes intensas de luz visível e infravermelha, como a luz direta do sol ou lâmpadas de bilirrubina;

d) Fontes eletromagnéticas intensas.

\subsubsection{NBR IEC 60601-1 e ISO 10993-1}

Em relação ao critério de classificação, os sensores atendem a série de normas NBR IEC 60601-1[12] apresentando como requisitos os seguintes ítens:

- Modo de operação: Operação Contínua;

- Classe de risco: Equipamento Classe II;

- Grau de proteção contra penetração nociva de água: IPX1; 
- Partes aplicadas à prova de desfibrilação, de Tipo BF;

- Não adequado a operar na presença de agentes anestésicos inflamáveis.

A questão da biocompatibilidade é avaliada de acordo com a ISO 10993-1[13], quanto à citotoxicidade, sensitização (reação alérgica) e irritação (reatividade intracutânea) potencial, causada na pele, pela exposição às partes aplicadas considerando a duração do contato como sendo limitada a até $24 \mathrm{~h}$.

\subsection{Condicionamento}

O condicionamento do sistema é responsável pelo tratamento do sinal analógico, tendo como objetivo deixar seus parâmetros adequados para ser analisado na etapa do processamento. Com o objetivo de facilitar a análise dos circuitos, o processo de condicionamento foi dividido em quatro estágios, a saber: (1) transimpedância, (2) amplificação, (3) filtragem e (4) off-set.

\subsubsection{Circuito de Transimpedância}

O amplificador de transimpedância possui características comuns ao amplificadores operacionais. No entanto, tal dispositivo é responsável por converter a intensidade de corrente captada pelo fotodiodo na entrada do circuito em uma intensidade de tensão na saída do seu estágio.

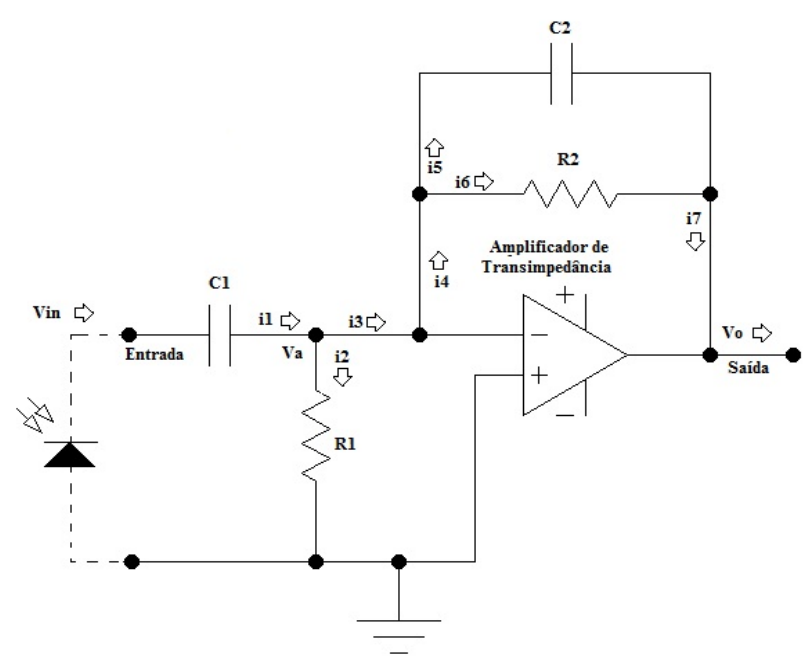

Figura 2.13: Amplificador de Transimpedância

Analisando o circuito da figura 2.13, observa-se que o sinal de entrada $V_{\text {in }}$ tem seu valor distribuído nos componentes $C_{1}$ e $R_{1}$, bem como, ao longo dos componentes 
$C_{2}$ e $R_{2}$ que estão presentes na realimentação negativa do amplificador. Esta configuração faz com que o ganho de amplificação dependa diretamente da relação entre as impedâncias de saída $\left(Z_{2}\right)$ e entrada $\left(Z_{1}\right)$ do estágio.

O ganho de amplificação da figura anterior é detalhado pela equação 2.5[14].

$$
G_{1}=\frac{V_{o}}{V_{\text {in }}}=-\frac{Z_{2}}{Z_{1}}
$$

As impedâncias de entrada $Z_{1}$ e saída $Z_{2}$ podem ser calculadas usando as fórmulas das equações 2.6 e $2.7[14]$.

$$
\begin{aligned}
& Z_{1}=\frac{\left(X C_{1} \cdot R_{1}\right)}{\left(X C_{1}+R_{1}\right)} \\
& Z_{2}=\frac{\left(X C_{2} \cdot R_{2}\right)}{\left(X C_{2}+R_{2}\right)}
\end{aligned}
$$

As reatâncias capacitivas $X C_{1}$ e $X C_{2}$ podem ser calculadas com base nas equações 2.8 e $2.9[14]$.

$$
\begin{aligned}
& X C_{1}=\frac{1}{2 \pi \cdot f_{o} \cdot C_{1}} \\
& X C_{2}=\frac{1}{2 \pi \cdot f_{o} \cdot C_{2}}
\end{aligned}
$$

Onde:

$\Rightarrow f_{o}$ é a frequência cardíaca do corpo humano.

\subsubsection{Filtro Passsa Baixa (FPB)}

A função do $2^{\circ}$ estágio é realizar a filtragem de sinais interferentes oriundos de outras fontes. O filtro desenvolvido deverá responder bem às frequências próximas da frequência de corte superior $f_{C S}$. Acima da mesma, o ganho do estágio deve cair para 0,707 de seu valor máximo, onde em dB, esta situação equivale a -3dB. Em referência ao projeto, a frequência de corte estabelecida foi de $3,7 \mathrm{kHz}$.

Com o objetivo de atender as demandas citadas no paragráfo anterior, um filtro passa baixa ativo Butterworth de quarta ordem foi desenvolvido. Ele pode ser visto através da figura 2.14[14].

O filtro passa baixa da figura 2.14 foi estruturado a partir da ligação em cascata de filtros de $2^{\circ}$ ordem, que apresentam em comum dois circuitos RC mais um amplificador operacional. Com base na frequência de corte apresentada anteriormente, 


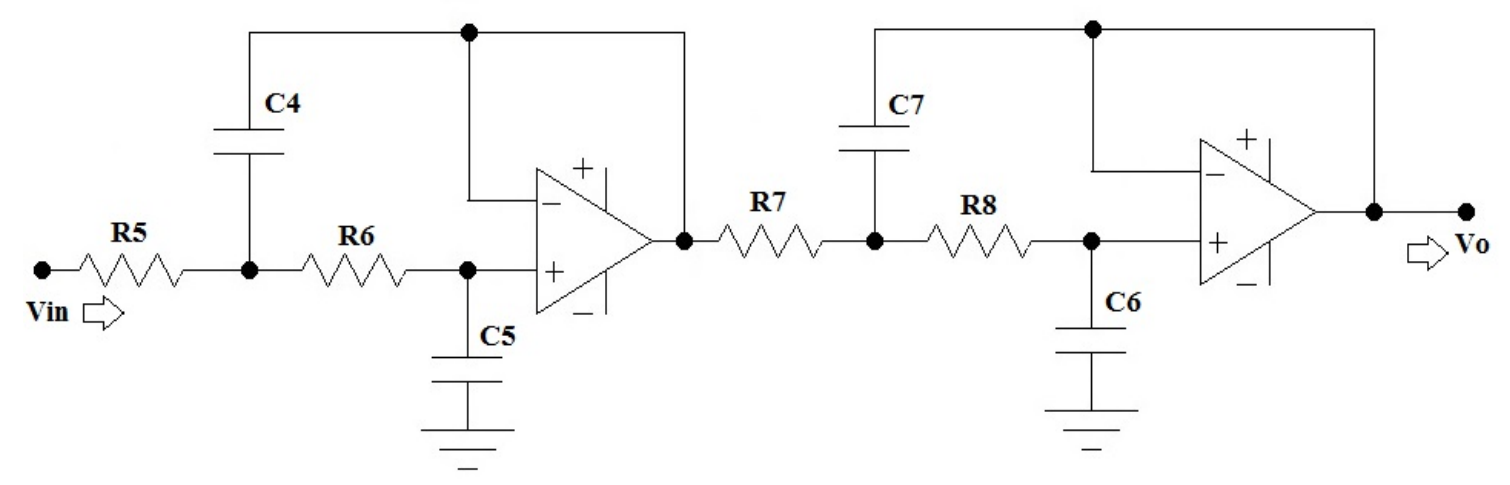

Figura 2.14: FPB Butterworth de $4^{\circ}$ Ordem

os elementos capacitivos e resistivos foram determinados utilizando como referência a equação 2.10[14].

$$
f_{c}=\frac{1}{2 \pi \cdot \sqrt{R_{5} \cdot R_{6} \cdot C_{4} \cdot C_{5}}}
$$

Igualando os valores dos resistores R5 e R6 e substituindo-os por R, juntamente com os capacitores C4 e C5 fazendo-os igual a C, temos uma forma simplificada vista por meio da equação 2.11 que foi utilizada como base de cálculo dos componentes [14].

$$
f_{c}=\frac{1}{2 \pi \cdot R \cdot C}
$$

Nota: Filtros de $4^{\circ}$ ordem possuem uma atenuação de amplitude para frequências acima da $f_{C S}$ na ordem de $40 \mathrm{~dB} /$ décadas.

\subsubsection{Circuito de Amplificação}

O circuito visto na figura 2.15 é responsável pela amplificação do sinal oriundo da saída do filtro passa baixa. Sua principal função é garantir um valor de tensão amplitude que tenha condições de ser interpretada pelo microcontrolador.

Devido as particularidades do sinal fotocondutivo no qual as amplitudes atingem valores próximos de algumas dezenas de milivolts, este estágio responderá por uma amplificação na ordem de centenas ou milhares de vezes em relação ao valor da tensão de entrada do circuito. As equações envolvidas nos cálculos do ganho do estágio de amplificação são demostradas a seguir[14].

$$
\frac{V_{o}}{V_{\text {in }}}=\frac{Z_{3}}{R_{3}}
$$

Onde $Z_{3}$ é uma impedância que pode ser calculado através da equação 2.13. 


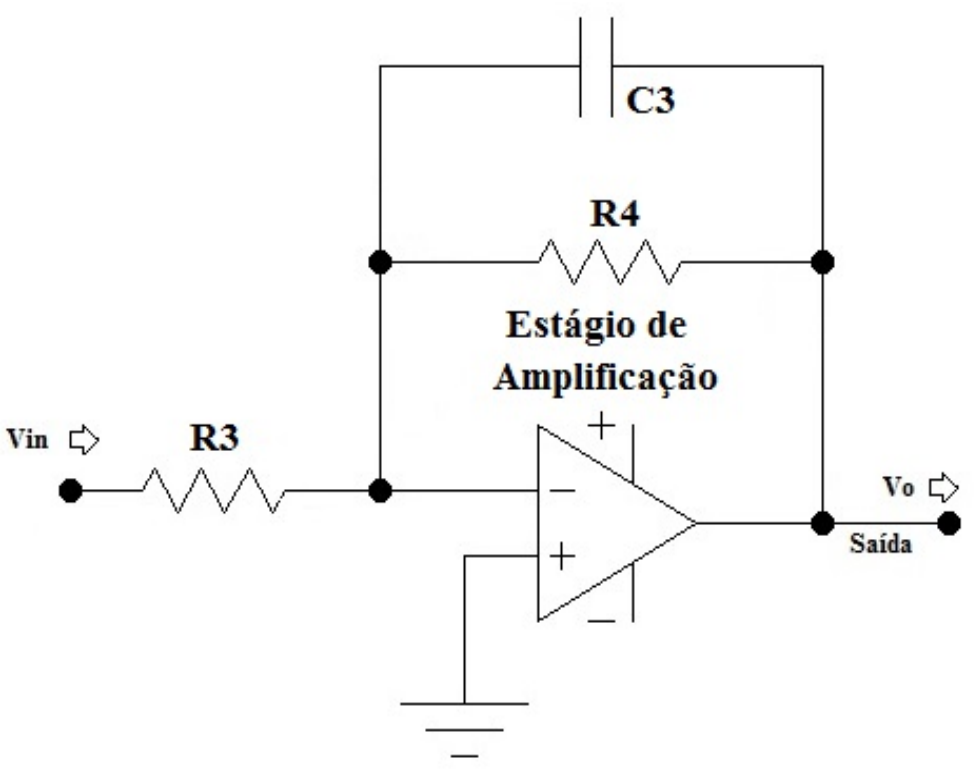

Figura 2.15: Circuito de Amplificação

$$
Z_{3}=\frac{\left(X C_{3} \cdot R_{4}\right)}{\left(X C_{3}+R_{4}\right)}
$$

No domínio da frequência, a frequência de corte pode ser derminada pela equação $2.14[14]$.

$$
f_{c}=\frac{1}{2 \pi \cdot C_{3} \cdot R_{4}}
$$

\subsubsection{Circuito de Off-Set}

Este estágio foi desenvolvido utilizando a configuração de um amplificador não inversor. Tem como objetivo realizar o deslocamento do sinal para acima do eixo de referência zero de tensão. Com isso, haverá uma compatibilidade positiva das amplitudes lidas na entrada do microcontrolador. Tal circuito pode ser visto através da figura 2.16 .

\subsection{Processamento do Sinal}

O processamento do sinal é uma das etapas mais específicas do projeto, pois através da estrutura do microcontrolador é que será possível aferir os parâmetros de entrada do sinal analógico para a realização do devido tratamento.

Os seguintes procedimentos serão executados pelo microcontrolodor: digita- 


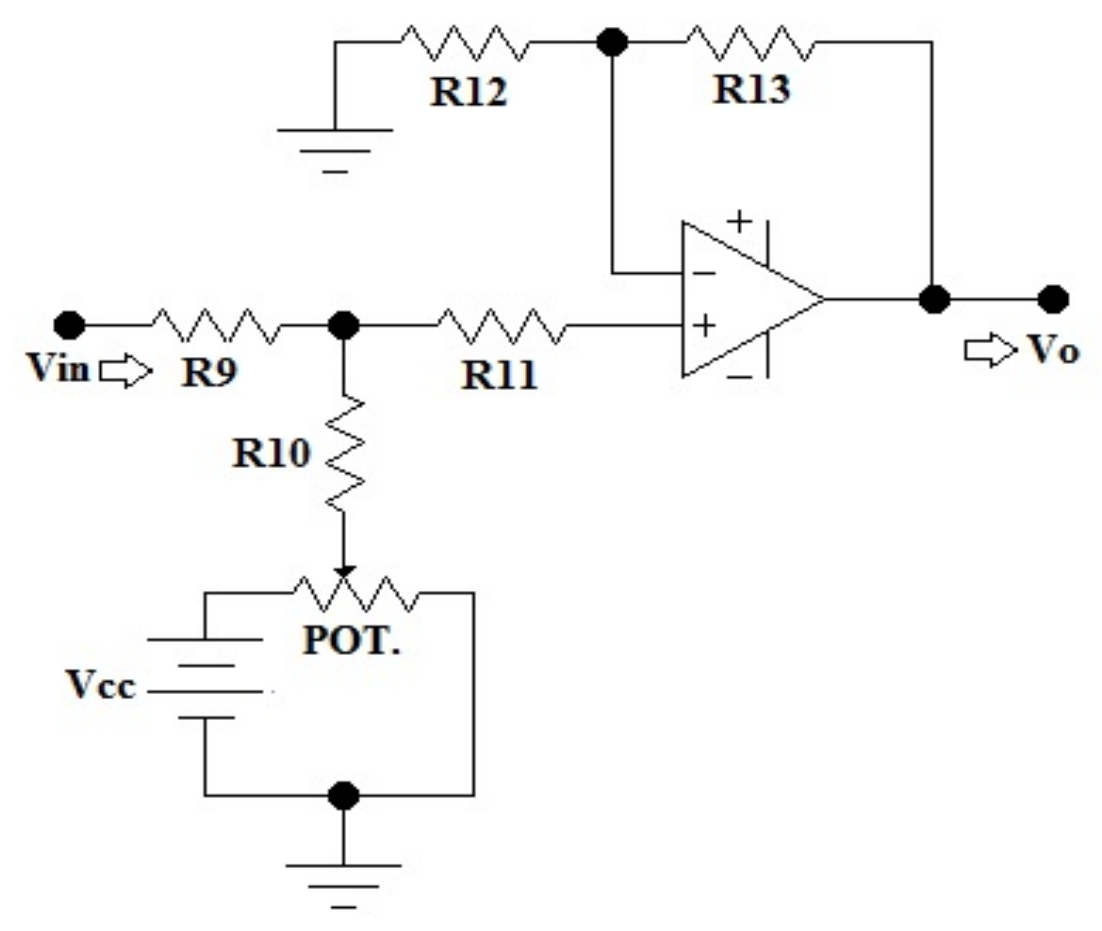

Figura 2.16: Circuito Off-Set

lização do sinal, controle de acendimento dos leds, cálculo da taxa de oxigenação do sangue $\left(\mathrm{SpO}_{2}\right)$ e do ritmo cardiaco (FC), envio das informações para o dispositivo de comunicação sm fio.

O microcontrolador é um hardware que possui uma arquitetura completa com CPU, memórias RAM (Random Access Memory) e ROM (Read Only Memory), clock interno e externo, portas $\mathrm{I} / \mathrm{O}$, entre outros.

Devido as exigências da grande rapidez na escrita e leitura dos dados recebidos e envidados pelo microcontrolador, neste projeto de oxímetro com comunicação sem fio, foi escolhido o microcontrolador PIC 18F452, no qual uma das suas grandes vantagens é possuir memória FLASH viabilizando o atendimento dos requisitos do projeto.

A figura 2.17[15] apresenta o modelo do microcontrolador PIC 18F453 com encapsulamento DIP, em seguida estão descritas suas principais características:

As principais característica do microcontrolador visto na figura 2.17 são:

1. 40 pinos podendo ter até $34 \mathrm{I} / \mathrm{O}$ (Input/Output digital);

2. 8 canais $\mathrm{A} / \mathrm{D}$ de 10 Bits;

3. 02 Módulos CCP (capture, compare e PWM); 


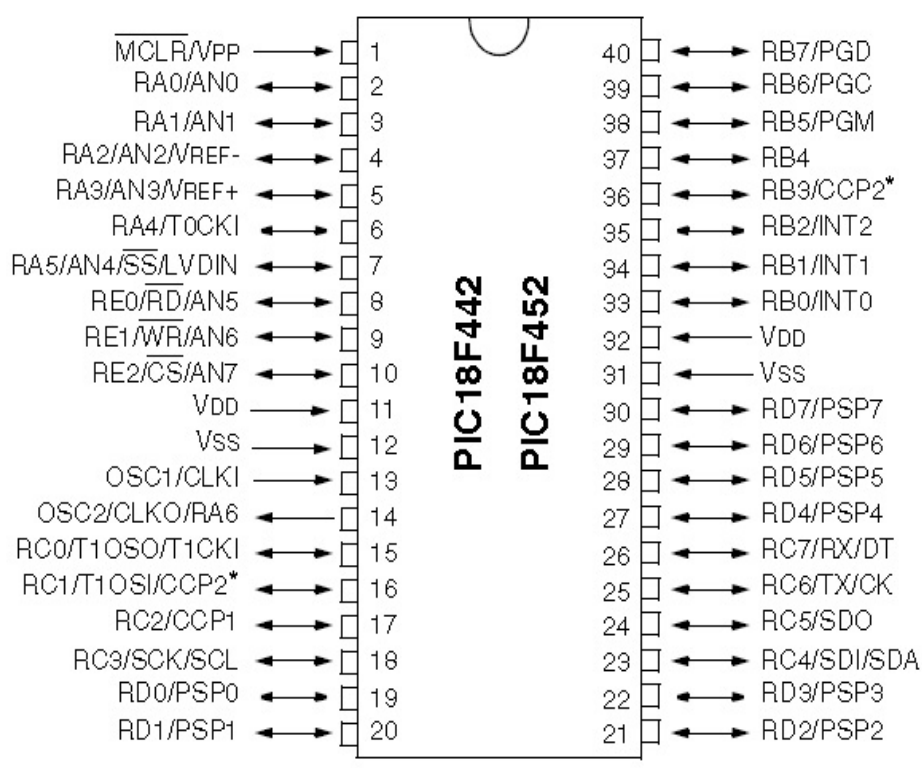

Figura 2.17: Microcontrolador PIC 18F452

4. Memória de Programa Flash (32K)

5. Memória RAM de 1536 bytes;

6. Memória EEPROM de 256 bytes;

7. Velocidade de processamento de até 10MIPS (milhões de instruções por segundo);

8. Módulo MSSP (Master Synchronous Serial Port);

9. Módulo USART;

10. Possibilita até 100.000 ciclos de escrita/leitura na memória de programa;

11. Possibilita 1.000.000 de ciclos de escrita/leitura na EEPROM;

12. Retenção dos dados na memória por até 40 anos;

13. Possibilita habilitação do Watchdog Timer;

14. Possibilita interrupção externa através de pinos do Microcontrolador;

15. Quatro Temporizadores/Contadores. 


\subsection{Comunicações sem Fio}

A comunicação sem fio permite a transmissão das informações sem o uso de uma infraestrutura cabeada, bem como, inclui a vantagem de romper distâncias quando o assunto é transmissão de dados. No campo da Engenharia Biomédica, os sensores sempre atuam próximo a alguma parte do corpo humano. Neste caso, redes pessoal sem fio (Wireless Personal Area Network) se conectarão a redes sem fio locais (Wireless Local Area Network) facilitando a propagação da informação.Uma rede WPAN pode ser definida como sendo uma rede composta por dispositivos pessoais usando tecnologias de comunicação sem fio de curto e médio alcance [16].

\subsubsection{WI-FI (Wireless Fidelity)}

É uma das redes mais utilizadas no mundo. Ela permite a comunicação por meio da internet ou através de um dispositivo para o outro. Em relação a segurança, possui boa criptografia. Trabalha em duas frequências $2.4 \mathrm{GHz}$ e $5.1 \mathrm{GHz}$. É regulamentada através do padrão IEEE 802.11[17].

\subsubsection{Bluetooth}

A tecnologia Bluetooth permite uma taxa máxima de transmissão de até 1 Mbps em Wireless Personal Area Network (WPAN). O Bluetooth é normatizado pelo padrão IEEE 802.15.1 e opera na faixa de freqüência ISM (Industrial, Scientific \& Medical) de 2,4 GHz que não precisa de autorização para ser utilizada agregando modulação Frequency Hopping Spread Spectrum (FHSS). Entre as principais aplicações para o Bluetooth estão as conexões sem fio a curtas distâncias de dispositivos como celulares, fones de ouvido, microfones, computadores, teclados, etc [16].

\subsubsection{UWB (Ultra Wide Band)}

Normatizado pelo padrão IEEE 802.15.3, permite uma taxa máxima de transmissão de até 100 Mbps. Opera dentro de um intervalo de freqüência entre $0 \mathrm{GHz}$ e $50 \mathrm{GHz}$ [18]. Tem grande aplicação em radares de curto alcance, transmissão de imagem/vídeo e sistemas de posicionamento e localização.

\subsubsection{Zigbee}

É uma tecnologia de comunicação sem fio cuja normatização é feita pelo padrão IEEE 802.15.4. Pode transmitir uma taxa de dados de até 250 Kbps e operar nas faixas 
de frequencia ISM de $868 \mathrm{MHz}, 910$ MHz e 2,4 GHz. Possui grande aplicação nas áreas industriais atuando no controle e automação, bem como, na área da saúde.

\subsection{ThingSpeak - Internet das Coisas}

O ThingSpeak é uma plataforma de aplicações para internet das coisas. Pode ser usada para o recolhimento de dados, enviados via smartphone, de sensores de campo. As características do ThingSpeak incluem coleta de dados de séries temporais, análise de dados usando MATLAB, armazenamento e envio de dados, entre outros. O conceito de internet das coisas permite coletar, analisar e comandar qualquer evento que esteja sob sua responsabilidade. As coisas são dispositivos que atuam como sensores (algo que se deseja monitorar, exemplo temperatura) ou atuadores (algo que se deseja controlar, exemplo termostado) que informam as necessidades do meio a qual estão instalados. Dentre as características do ThingSpeak, incluem: análise de dados, visualizações, aplicações e Plugins usando MATLAB[19].

O envio de dados para a página do ThingSpeak é realizado através de um canal, onde pode ser montado até oito controles para até oito sensores diferentes com o status de cada medida. Usando o ThingSpeak é possivel criar um canal e coletar dados das coisas (sensores), analisar e visualizar dados, bem com, atuar nos dados através de aplicações. Qualquer pessoa pode configurar seu canal para monitorar os dados através da internet das coisas. Para isso, basta ir até o site https://thingspeak.com/ e começar seu trabalho. Um exemplo da visualização que o ambiente possibilita pode ser vista no gráfico da figura 2.18[19].

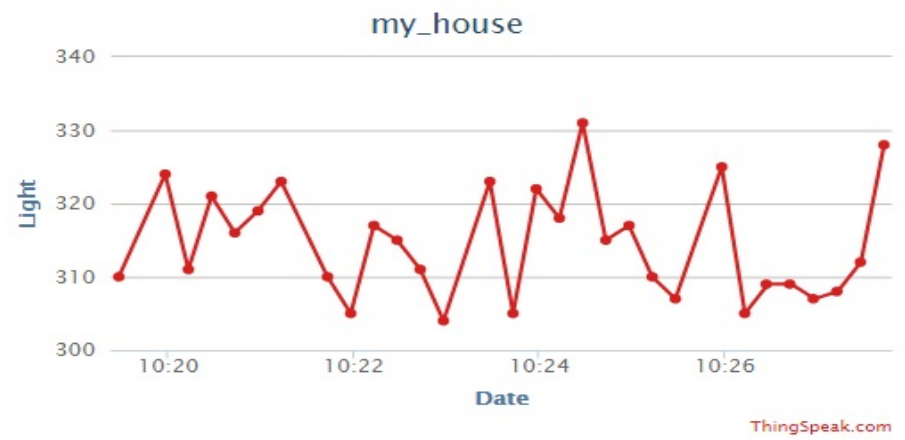

Figura 2.18: Canal de dados ThingSpeak 


\section{METODOLOGIA}

Os métodos de estudos abordados nesta dissertação foram fielmente seguidos e aplicados em cada fase do projeto. Os mesmos estão detalhados a seguir:

1. Modelamento e desenvolvimento do projeto com base em pesquisas realizadas;

2. Modelamento matemático de cada estágio;

3. Simulação do projeto através do Proteus (Simulador de Circuito Eletrônico);

4. Comprovação da teoria desenvolvida na prática utilizando recursos de laboratório, tais como: osciloscópio, gerador de sinais, fonte de alimentação, computador, entre outros.

É importante ressaltar que o projeto do oxímetro com comunicação sem fio foi desenvolvido com base em uma referência de sinal com pequena variação de amplitude, em torno de 1 milivolt, operando numa faixa de frequência de $0,4 \mathrm{~Hz}$ à $3,7 \mathrm{~Hz}$.

\subsection{Diagrama de Blocos}

A estrutura do projeto do oxímetro de pulso com comunicação sem fio é apresentado no diagrama de blocos da figura 3.1

O desenvolvimento do protótipo foi condicionado as seguintes etapas: sensor, condicionamento, processamento do sinal, controle dos Leds, comunicação Bluetooth e sistema de visualização Smartphone, LCD e gerência WEB.

\subsection{Sensor}

O esquemático equivalente adotado no desenvolvimento do sensor de dedo está idealizado na figura 3.2. 


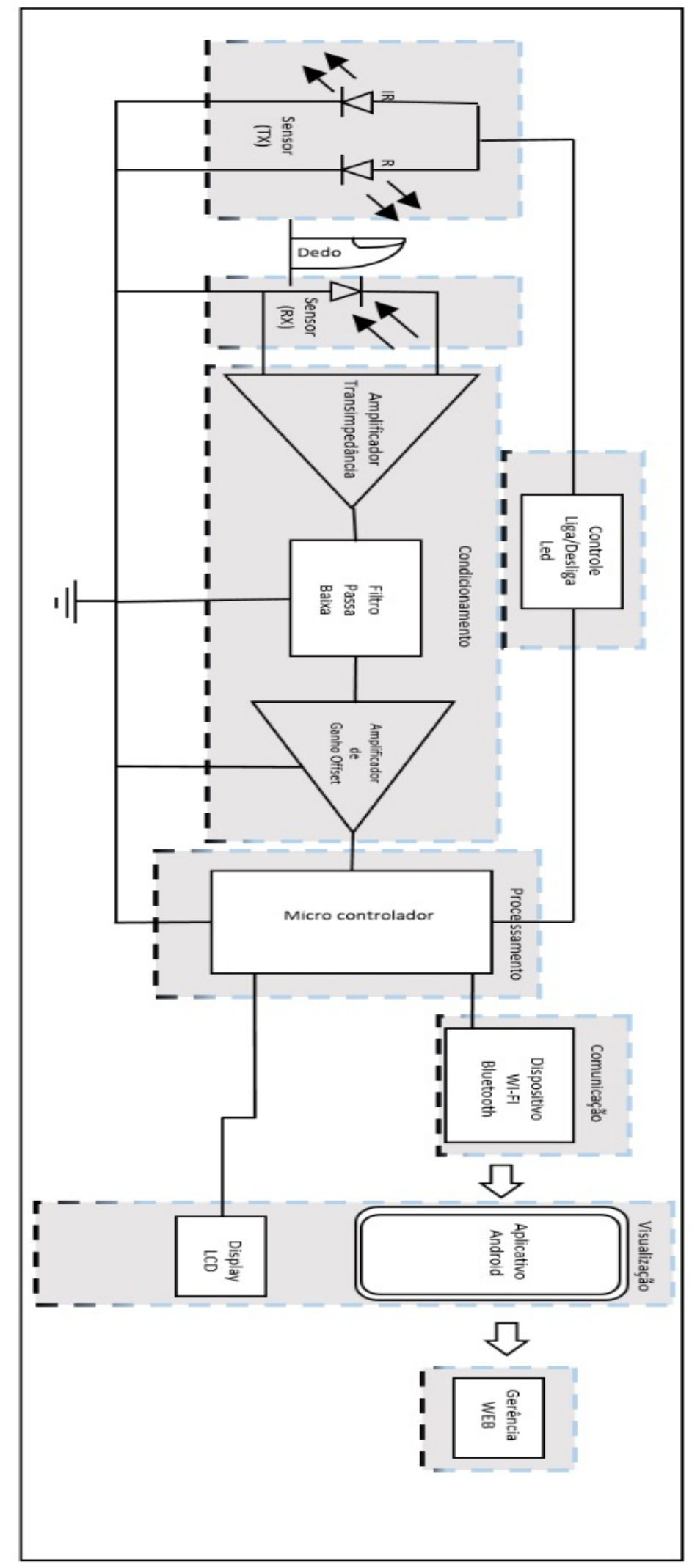

Figura 3.1: Projeto Oxímetro com Comunicação Bluetooth 


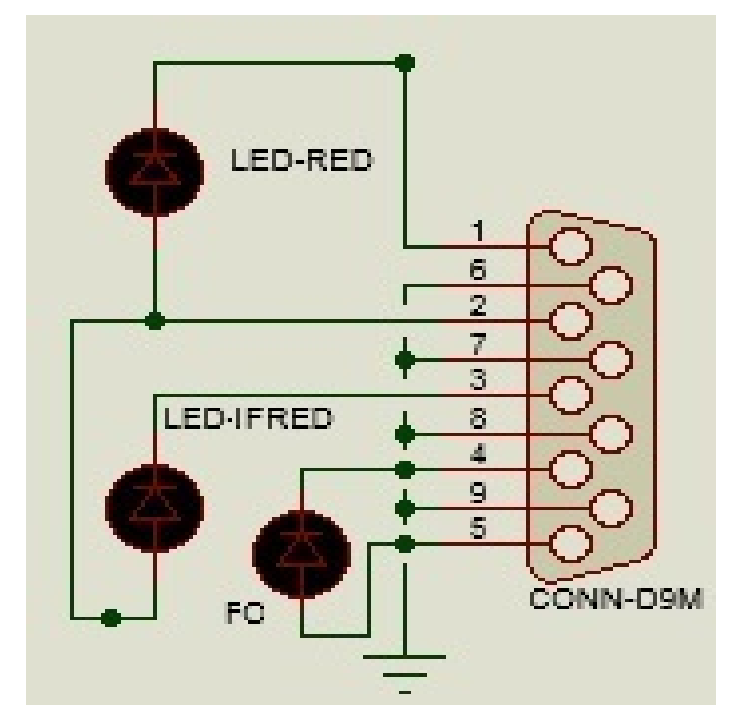

Figura 3.2: Esquemático de Ligação - Com Adaptações

\subsection{Simulação Eletrônica}

A seguir será mostrado o método de simulação eletrônica adotado e os cálculos dos componentes envolvidos em cada etapa. Veja que o $1^{\circ}$ estágio, visto na figura 3.3, também chamado de circuito de transimpedância, recebe o sinal do sensor.

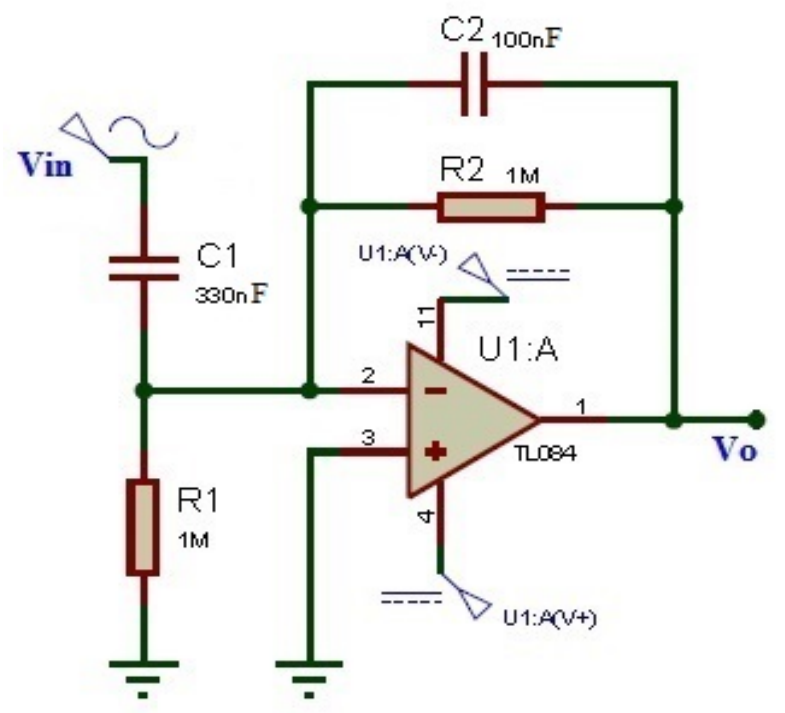

Figura 3.3: Condicionamento - $1^{\circ}$ Estágio

Utilizando como referência a frequência de operação $\left(f_{o}\right)$ de $3 \mathrm{~Hz}$, os cálculos das reatâncias capacitivas de entrada $\left(X C_{1}\right)$ e saída $\left(X C_{2}\right)$ são demonstrados a seguir: 


$$
\begin{gathered}
X C_{1}=\frac{1}{\left(2 \cdot \pi \cdot 3 \cdot 330 \cdot 10^{-9}\right)}=176,84 k \Omega \\
X C_{2}=\frac{1}{\left(2 \cdot \pi \cdot 3 \cdot 100 \cdot 10^{-9}\right)}=530,52 K \Omega
\end{gathered}
$$

Em relação aos valores das impedâncias de entrada e saída (realimentação), tem-se:

$$
\begin{gathered}
Z_{1}=\frac{\left(176,84 \cdot 10^{3} \cdot 1,0 \cdot 10^{6}\right)}{\left(176,84 \cdot 10^{3}+1,0 \cdot 10^{6}\right)}=150,3 k \Omega \\
Z_{2}=\frac{\left(530,52 \cdot 10^{3} \cdot 1 \cdot 10^{6}\right)}{\left(530,52 \cdot 10^{3}+1 \cdot 10^{6}\right)}=346,6 \mathrm{k} \Omega
\end{gathered}
$$

Fazendo a relação entre as equações 3.4 e 3.3 foi possível calcular o ganho do estágio, conforme demonstrado na equação 3.5.

$$
G_{1}=-\frac{V_{o}}{V_{\text {in }}}=-\frac{346,6}{150,3}=-2,3
$$

Os ruídos interferentes da rede de $60 \mathrm{~Hz}$ foram reduzidos com a construção de um filtro butterworth de quarta ordem, onde a sua configuração pode ser vista através da figura 3.4.

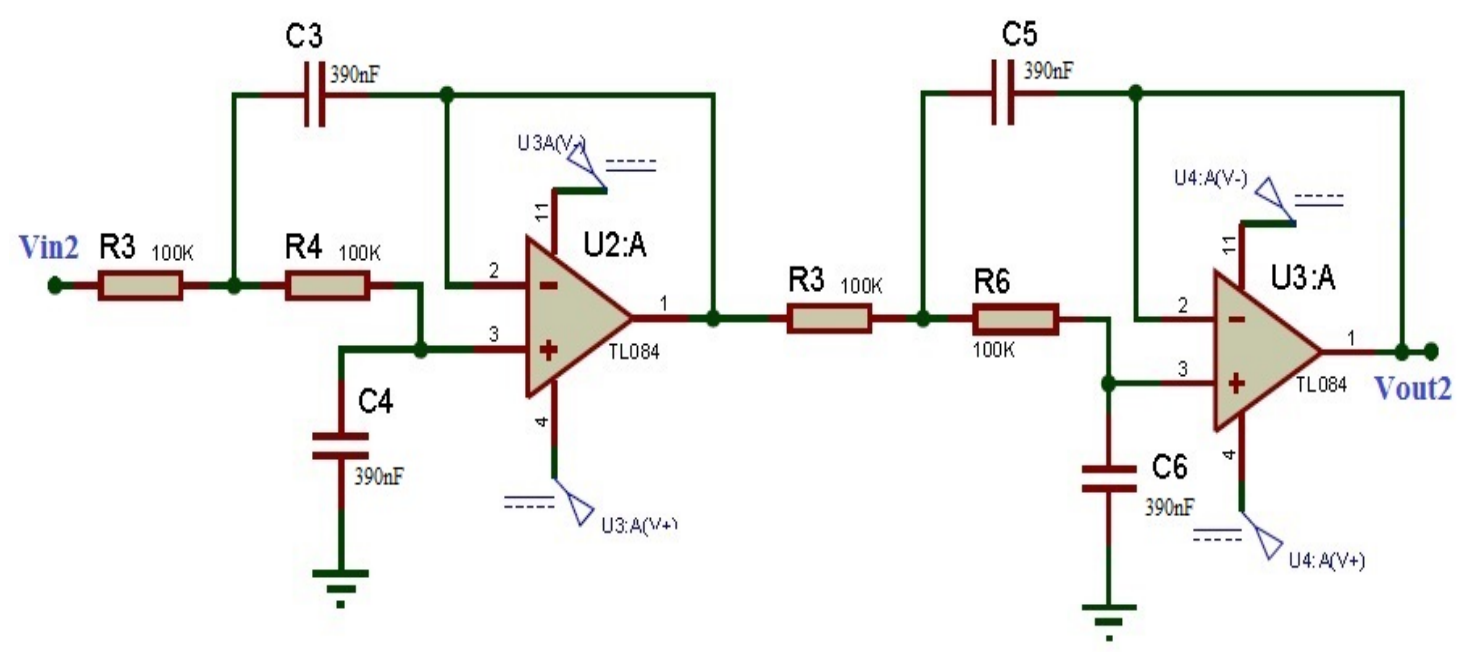

Figura 3.4: Condicionamento - 20 Estágio

Utilizando uma frequência de operação de $3 \mathrm{~Hz}$ e capacitores de $300.10^{-9}$ Farads foi possível calcular os valores dos resistores por meio da equação 3.6. 


$$
f_{c}=\frac{1}{2 \pi \cdot R \cdot C} \Leftrightarrow 3=\frac{1}{2 \pi \cdot R \cdot 390 \cdot 10^{-9}} \Leftrightarrow R \approx 130 \cdot 10^{3} \Omega
$$

O terceiro estágio foi desenvolvido para amplificar os valores de tensão do circuito. Baseou-se na utilização de um amplificador inversor com ganho de amplificação próximo de 150 vezes do valor de tensão de entrada.

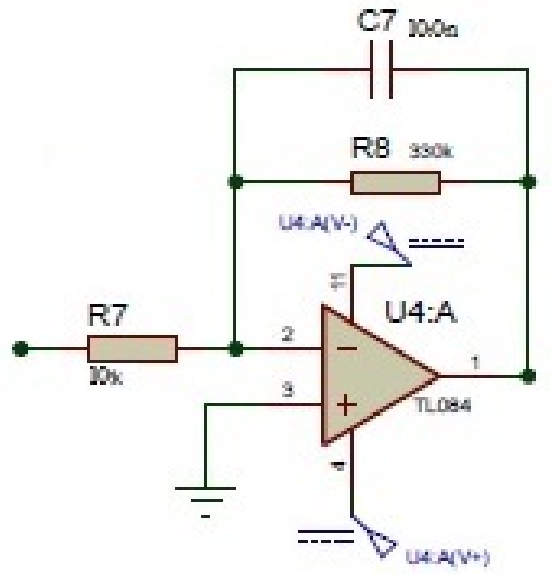

Figura 3.5: Condicionamento - $3^{\circ}$ Estágio

O $4^{\circ}$ estágio teve o objetivo de corrigir a curva pletismográfica para um valor acima do nível zero (0) de referência, criando compatibilidade com a entrada de tensão do microcontrolador. O circuito projetado pode ser visto através da figura 3.6

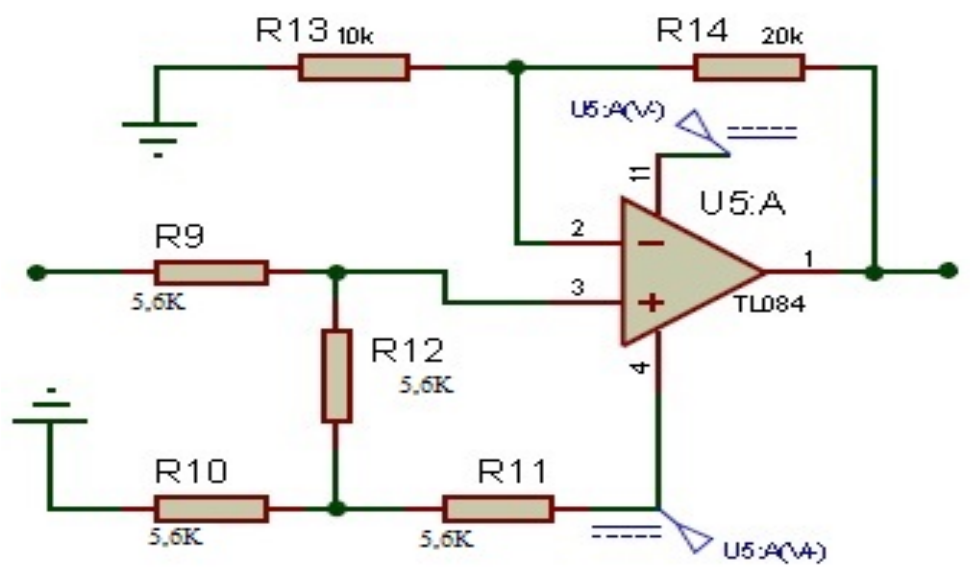

Figura 3.6: Condicionamento - 4º Estágio

O circuito da simulação foi concluído utilizando o microcontrolador PIC 18F452 e o dispositivo LCD que podem ser vistos na figura 3.7. 

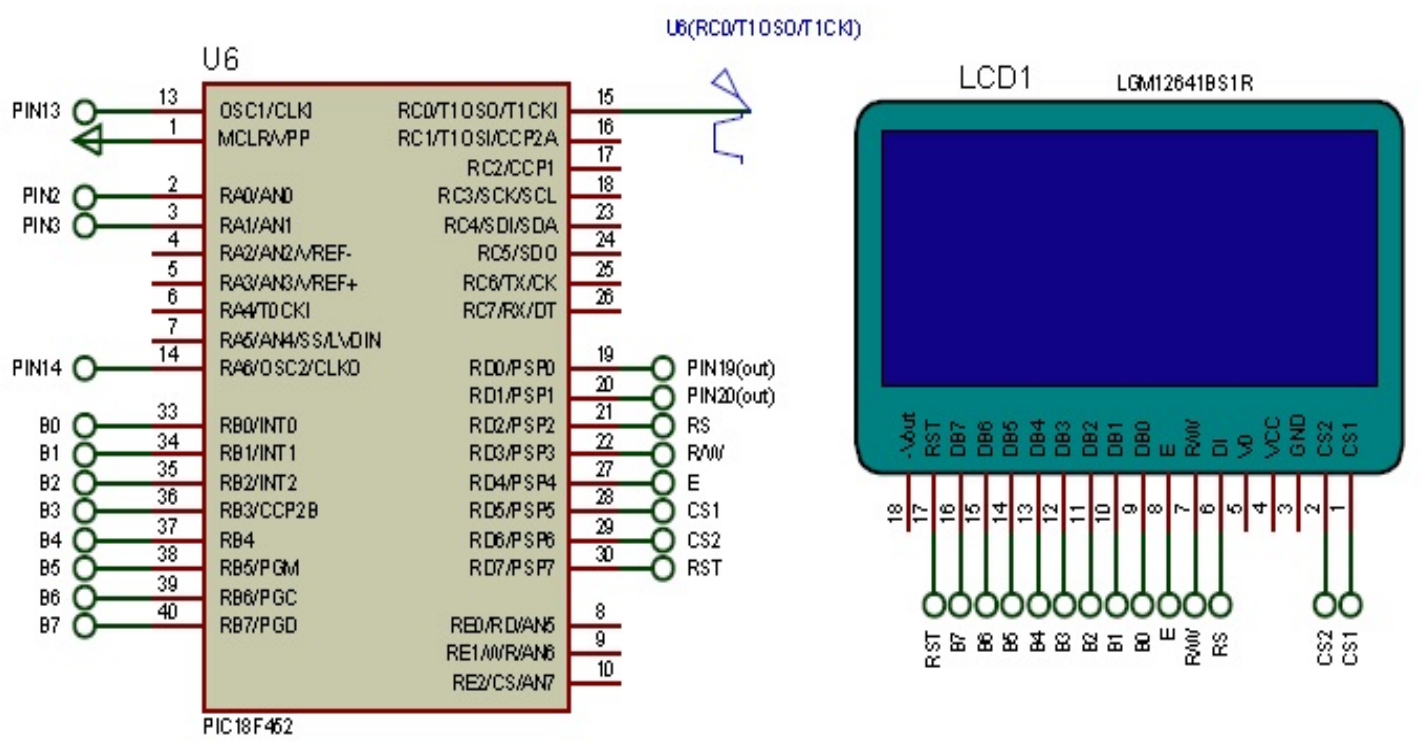

Figura 3.7: Microcontrolador e LCD - Proteus

\subsection{PIC C Compiler e Software Microborn}

Toda a programação foi realizada utilizando a linguagem $\mathrm{C}$ rodando no compilador PIC C Compiler. Utilizou-se para a transferência do programa, gravado em hexadecimal, o software da Microbrn e o hardware K150 que podem ser vistos na figura 3.8 e $3.9[20]$.

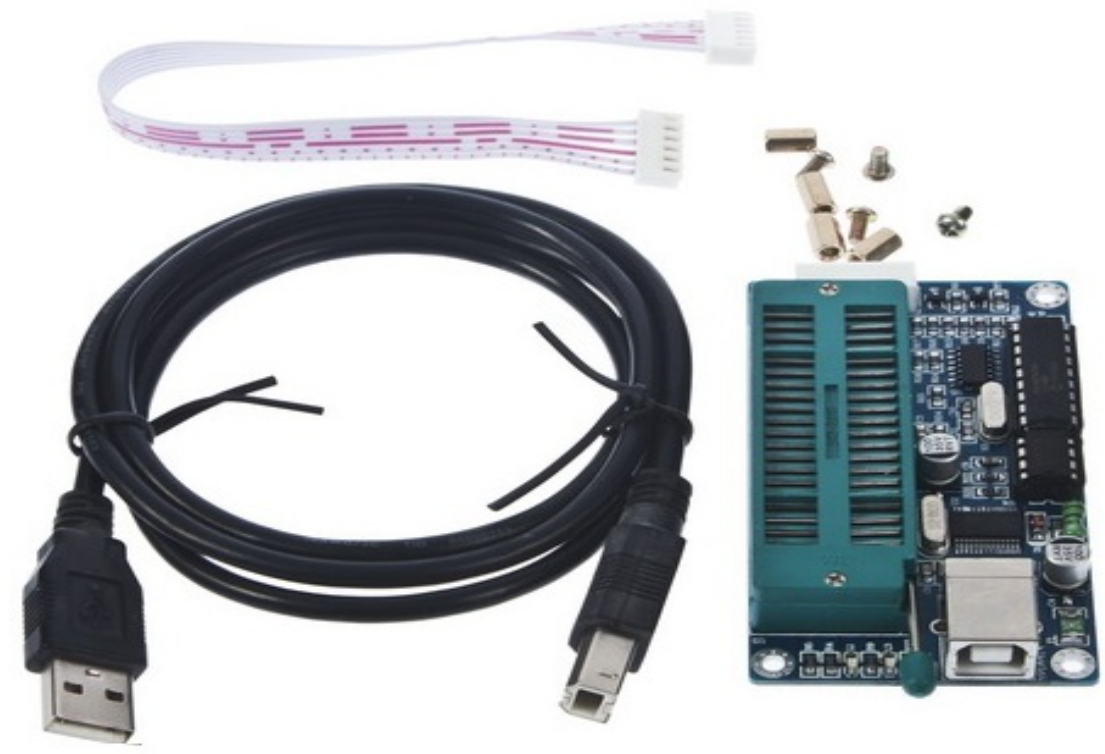

Figura 3.8: Hardware Picburner Usb K150 


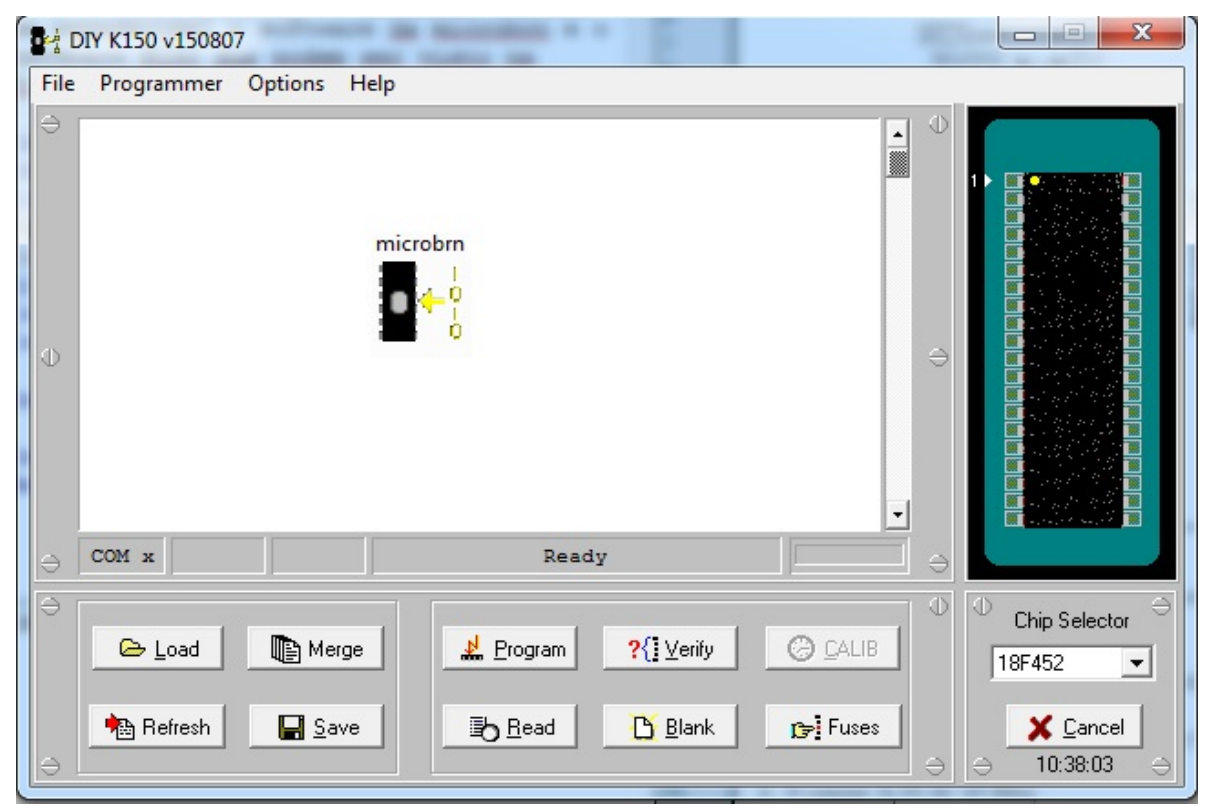

Figura 3.9: Software Microborn

Detalhes do programa principal (main.c) escrito em CCS estão disponíveis no apêndice D.1.

\subsection{Módulo Bluetooth}

O objetivo de inserir a comunicação bluetooth no projeto do oxímetro é proporcionar ao usuário a visualização dos dados via celular smartphone que utilize sistema operacional.

Como solução de hardware, o projeto de oxímetro sem fio utilizou o dispositivo HC-05 visto através das figuras 3.9 e 3.10[21]. Tal elemento é responsável pela comunicação serial por meio da conexão via Bluetooth. Seu fluxo de comunicação (RX / TX) é realizado a partir de 9.600 bps até 115.200 bps. A unidade remota pode ser alimentada por uma faixa de tensão de $3.3 \mathrm{~V}$ até $6 \mathrm{~V}$. Para uma melhor compreensão, as especificações técnicas principais do $\mathrm{HC}-05$ são descritas a seguir:

- Protocolo: EDR especificação Bluetooth v2.0;

- Frequência: banda de 2.4GHz ISM;

- Modulação: GFSK (Gaussian Frequency Shift Keying);

- Potência de emissão: $\leq 4 \mathrm{dBm}$, Classe 2;

- Sensibilidade: $\leq-84 \mathrm{dBm}$ em $0.1 \%$ BER; 
- Velocidade assíncrona: 2.1Mbps (Max ) / 160 kbps, síncronos: 1Mbps / 1Mbps;

- Segurança: Autenticação e encriptação;

- Perfis: Bluetooth porta serial;

- Alimentação: + 3.3VDC 50mA ;

- Temperatura de trabalho: $-20 \sim 75$ graus centígrados

- Dimensão: 26,9 milímetros x 13 milímetros x 2,2 milímetros.

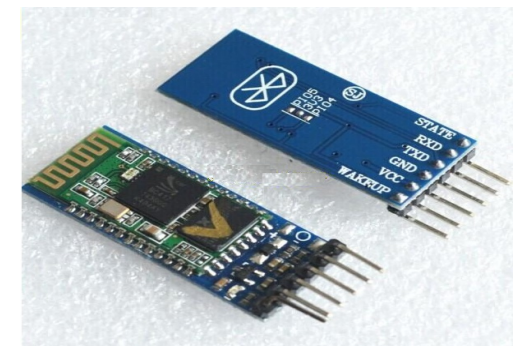

Figura 3.10: Módulo Bluetooth - HC05

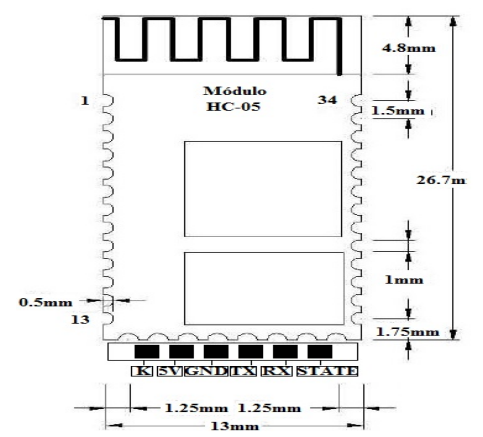

Figura 3.11: Dimensões da Placa HC05

\subsection{APP - Android}

O aplicativo para smartphone teve sua programação desenvolvida com base na linguagem Java usando a plataforma Eclipse. O código principal do aplicativo "Oxímetro com Comunicação Bluetooth"é o programa "MainActivity.java" que está disponível no apêndice " $F$ " desta dissertação. Neste programa, o endereço "MAC" do dispositivo bluetooth identificado na tela do smartphone será reconhecido através da classe "BluetoothDevice".

Ao selecionar um dos itens da lista, a classe "MainActivity.java" realizará todo o direcionamento da comunicação e tratamento das mensagens recebidas. $\mathrm{O}$ arquivo "DeviceList.java"é responsável por listar e conectar os dispositivos bluetooth disponíveis dentro do raio de cobertura do equipamento portátil. Outros códigos envolvidos na elaboração do aplicativo serão apresentados a seguir:

1. device_list.xml, este código é responsável por criar o layout do aplicativo Oxímetro de Pulso com Comunicação Bluetooth. O código está disponível e poderá ser analisado e estudado consultando o apêndice " $E$ ". A figura 3.12 apresenta o design da tela do aplicativo. A imagem do coração mostra os resultados do Batimento Cardíaco e as bolhas de oxigênio os valores da Oxigenação do Sangue. 


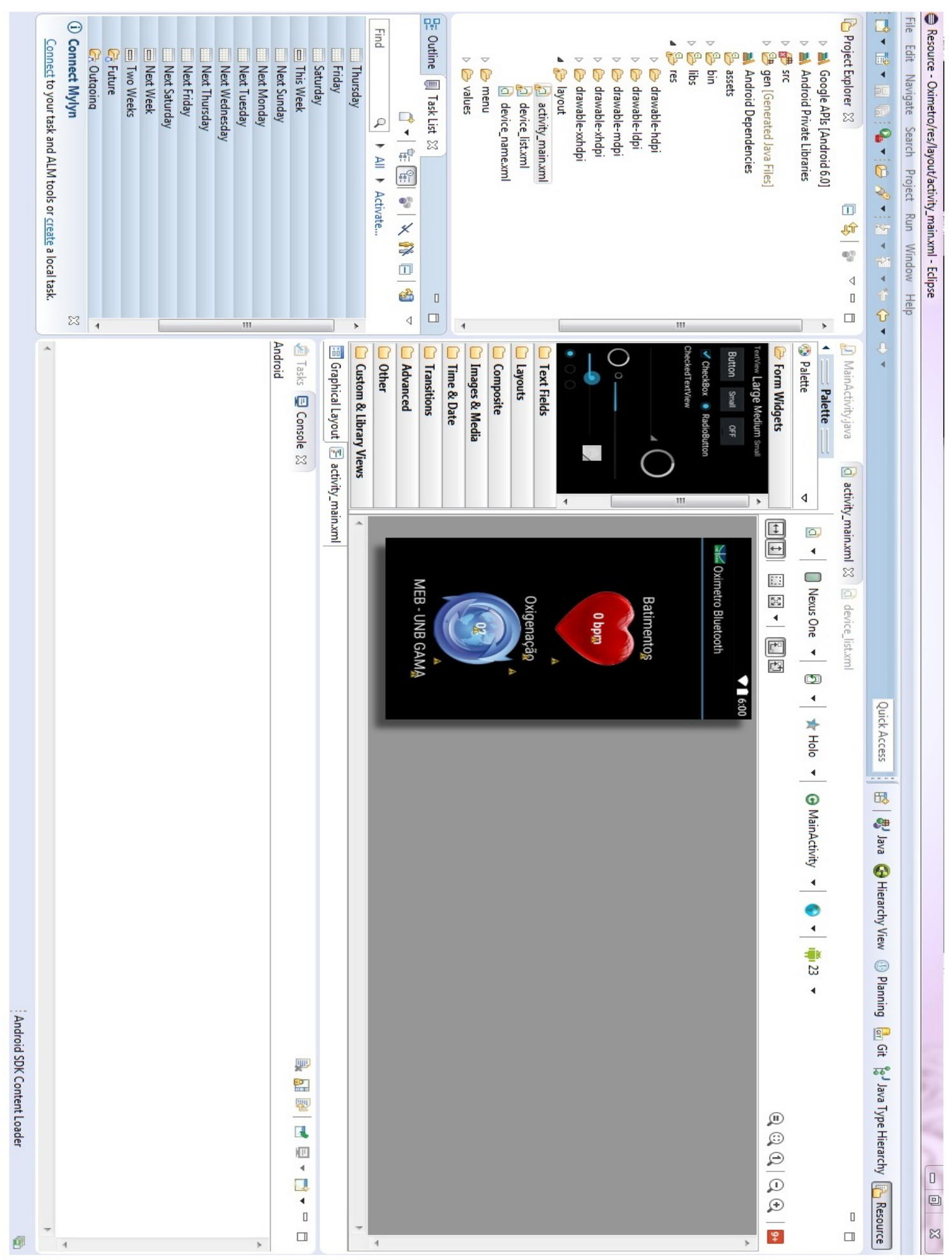

Figura 3.12: Design Aplicativo Android

2. DeviceListActivity.java, este código é responsável por estabelecer o pareamento e a conexão bluetooth entre o protótipo do Oxímetro de Pulso e o dispositivo móvel. Este programa está disponível para analise e estudo no apêndice " $E$ " desta dissertação. O layout do aplicativo pode ser visto pela figura 3.13 que irá 
disponibilizar o acesso a conexão bluetooth.

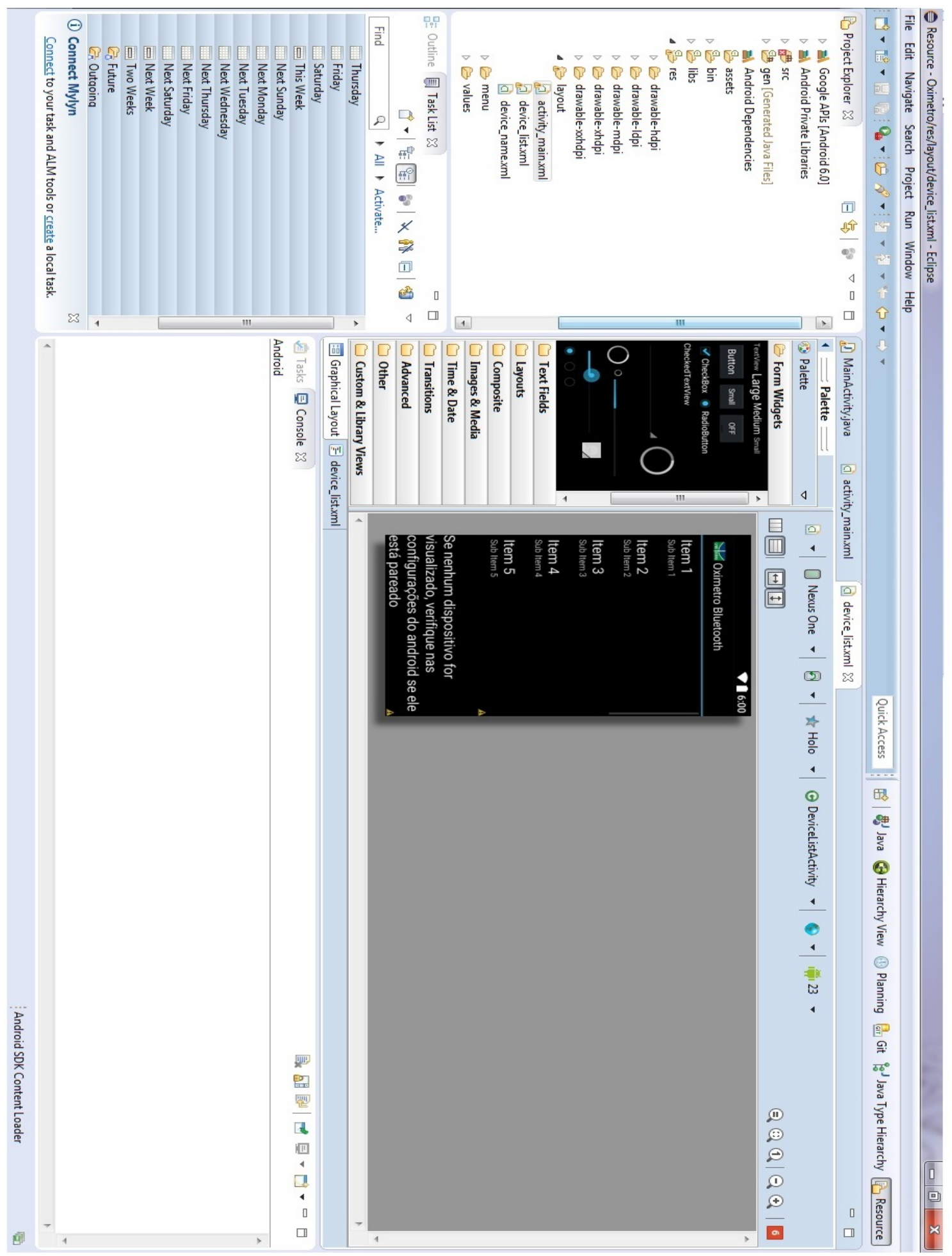

Figura 3.13: Design Conexão Bluetooth

A comunicação com o bluetooth utiliza o método de classe "onResume". Assim, caso o celular entre em modo descanso, a comunicação com o dispositivo bluetooth 
irá parar e não ficará desperdiçando a energia da bateria do celular.

É importante observar que o código "MainActivity.java" realiza a compilação seguindo a ordem apresentada abaixo:

- Separa linha por linha a mensagem recebida, procurando identificar o caractere "|" como identificador referencial da informação. A seguir é apresentado a linha do código "MainActivity.java" responsável por esta função:

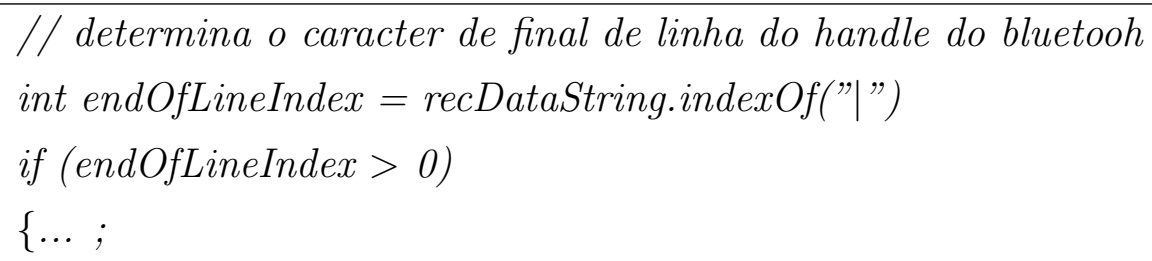

- Separa campo por campo, onde neste caso o caractere identificador é o "\&", cuja linha do código é mostrada a seguir:

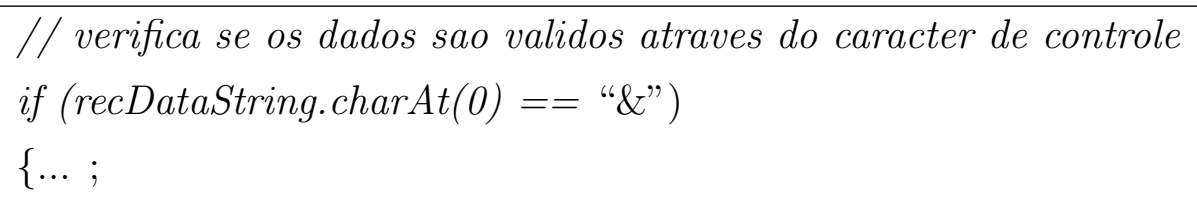

- Relaciona o campo com o sinal recebido, Batimento cardíaco ou Oxigenação. A linha do código que trata esta análise é mostrada abaixo:

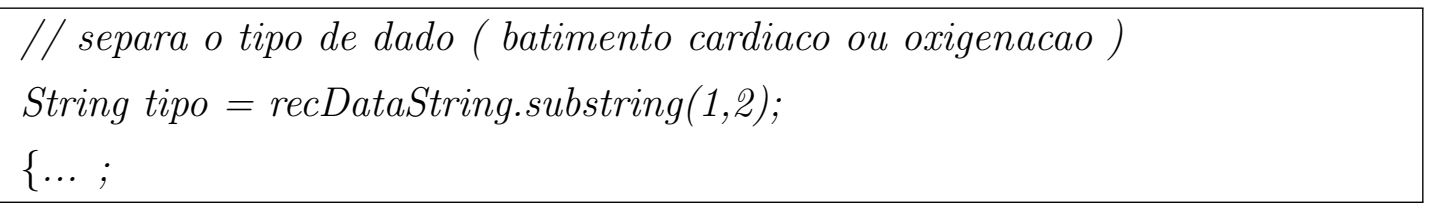

- A cada 30 leituras do sinal recebido, o smartphone envia a informação lida para a página da internet "thingspeak" via http. Para enviar os dados para a nuvem cria-se uma Classe chamada "SendCloud" herdando o comportamento da Classe "AsyncTask".

Este código foi adquirido através da visita a página do desenvolvedor android http://developer.android.com/reference/android/os/AsyncTask.html. Isto facilita a comunicação http que ocorre de forma assíncrona, evitando o travamento do aplicativo. O objeto chamado EasyHttpClient (https://github.com/uscheller/ EasyHttpClient/) facilita a manipulação das requisições HTTP. Com isso, a classe recebe as variáveis "sensorbpm", "sensorspo" que foram inseridas no Handler blue-

tooth montando a url de submissão dos dados com a ajuda do método GET, estabelecendo o envio das informações para o servidor Thingspeak (http://www.thingspeak.com). 


\subsection{Disponibilização dos dados - WEB}

\subsubsection{Configuração}

Criando uma nova conta ThingSpeak [19].

\subsubsection{Criação do canal}

1. Clique no menu no link "Channels" e em seguida Meus Canais [19], ver figura 3.14

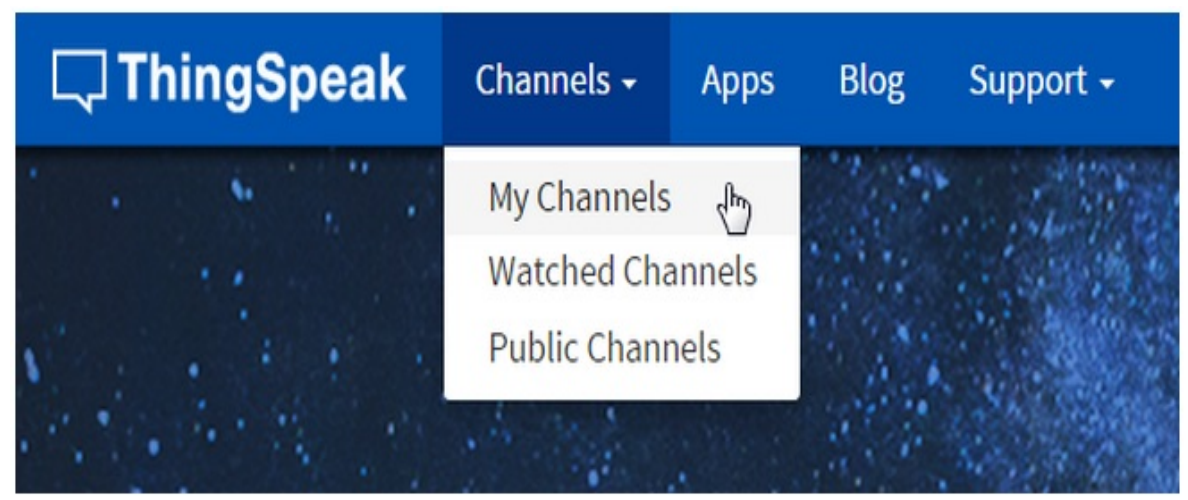

Figura 3.14: Configura o Canal ThingSpeak

2. Na página de Canais, clique em Novo Canal.

3. Especificando os nomes e as propriedades de cada campo:

- Nome: Oxímetro de Pulso - Comunicação Sem Fio / WEB - MEB - UNB.

- Campo 1: bpm.

- Campo 2: SpO2.

A figura 3.15 faz uma referência aos passos da etapa 3. Com isso os dados bpm e SpO2 serão publicados a partir na página do canal ThingSpeak.

4. Por último clique em Salvar. Automaticamente abrir-se-á uma nova página com o endereço https://thingspeak.com/channels/53255/private_show com as informações do projeto, modeladas conforme figura 3.16 [19]. A seguir será apresentado a função das abas adjacentes.

- Ver Privada: Essa guia exibe informações sobre o canal que só você pode ver [19]. 


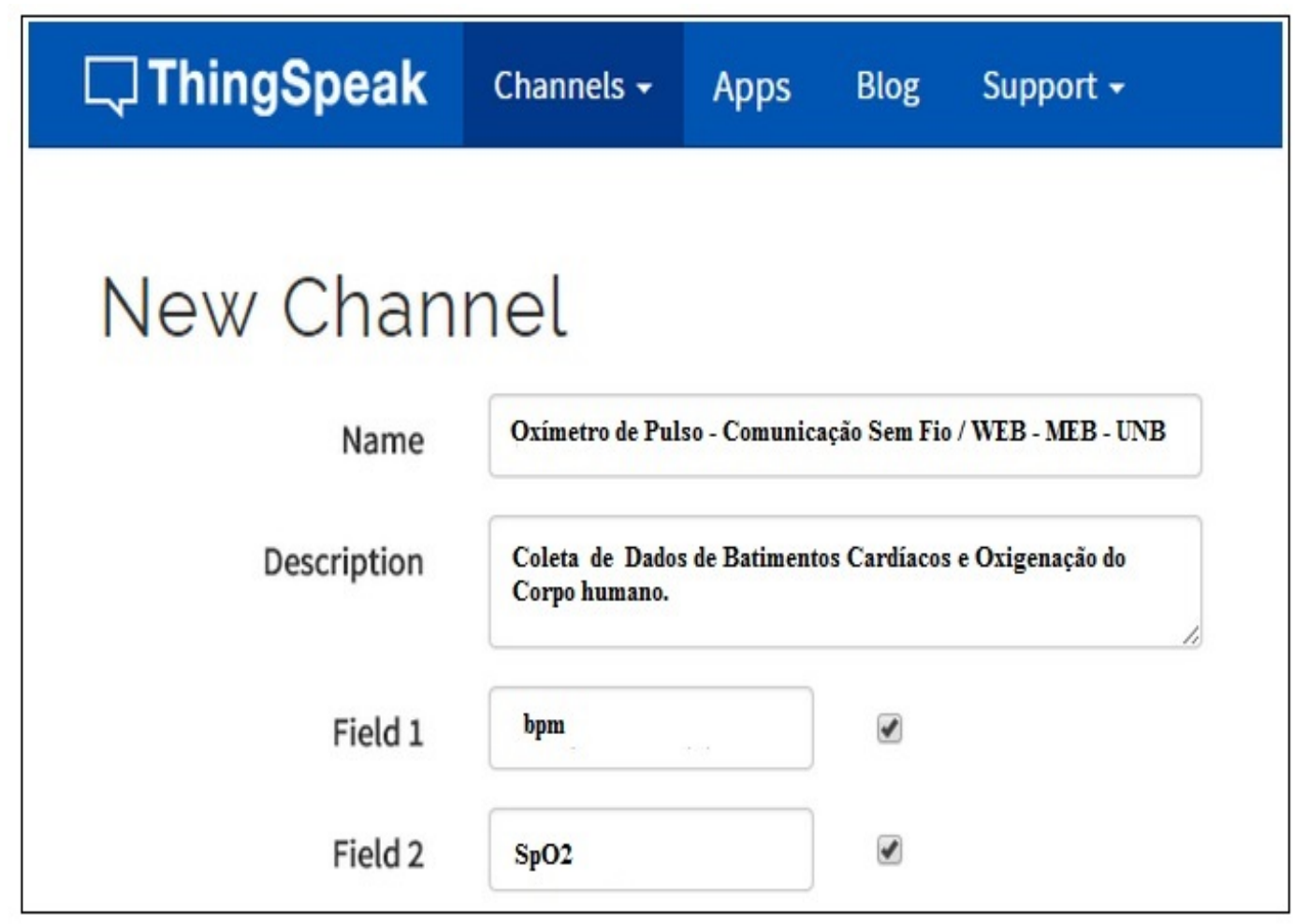

Figura 3.15: Configurando os parâmetros de leitura

- Ver Público: Se você optar por fazer o seu canal disponível publicamente, use este guia para exibir os campos selecionados e visualizações do canal.

- Ajustes do Canal: Este guia mostra todas as opções de canal que você definiu na criação. Você pode editar, apagar ou eliminar o canal a partir deste separador.

- Chaves de API: Este guia apresenta as chaves de API canal. Use as teclas de ler e escrever em seu canal.

- Dados de Importação / Exportação: Essa guia permite importar e exportar dados do canal. 


\begin{tabular}{|c|c|c|c|c|}
\hline ID do canal: & \multicolumn{2}{|l|}{53255} & \multicolumn{2}{|c|}{ Coleta OS Dados de Batimentos Cardiacos e } \\
\hline Autor: & Marcos Aurélio & & Oxigenação do & rpo humano. \\
\hline Acesso: & Privado & & & \\
\hline Ver privado & Ver pública & Configuraçōes de canal & Chaves & Data Import / Export \\
\hline
\end{tabular}

A Adicionar Visualizations Data Export

\begin{tabular}{|l|l|l|}
\hline Análise MATLAB & MATLAB visualizaçāo Aplicativos \\
\hline
\end{tabular}

\section{Estatisticas do Canal}

Criada em 00 days ago

Atualizada 0 days ago

0 Entries
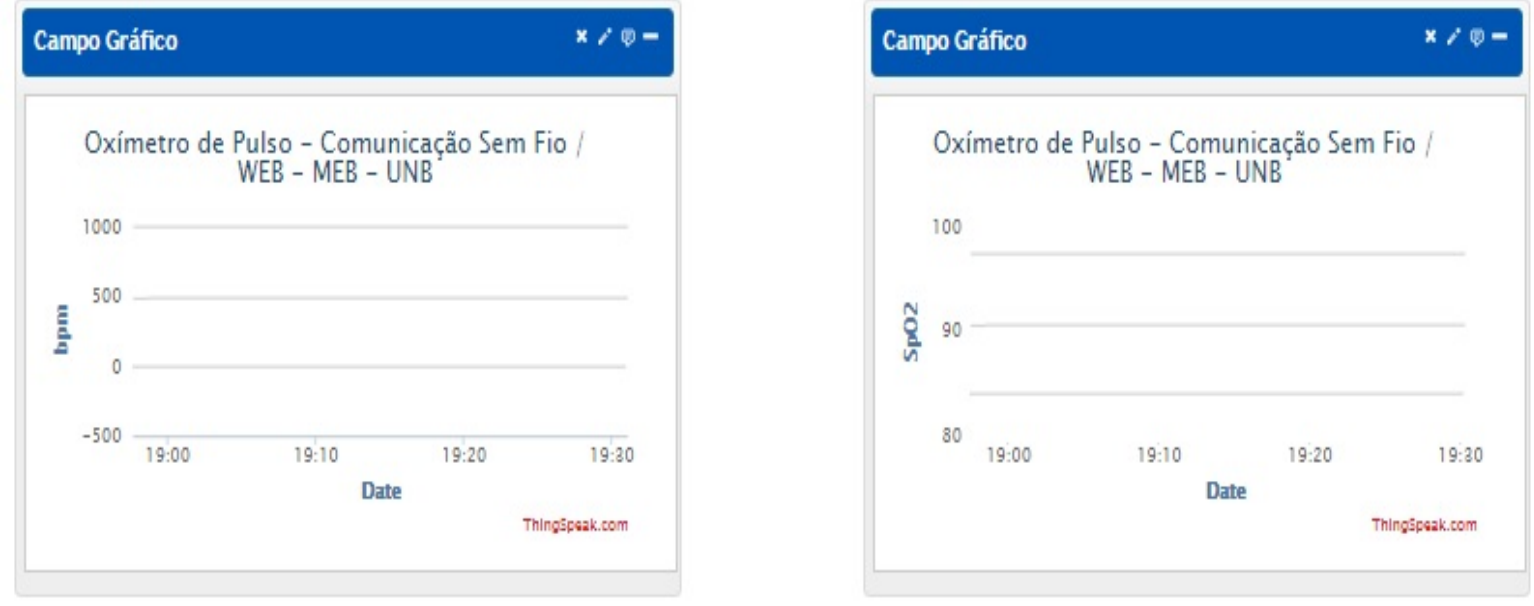

Figura 3.16: Print do canal thingspeak configurado 


\section{RESULTADOS E DISCUSSÕES}

Este capítulo tem por objetivo apresentar os resultados obtidos a partir de testes realizados com o protótipo do oxímetro desenvolvido.

\subsection{Sensor de Dedo}

Após experiências realizadas no laboratório de eletrônica da Escola Técnica de Brasília foi possível validar o perfeito funcionamento do sensor de dedo. A figura 4.1 mostra a representação satisfatória da curva plestimográfica extraída na saída do circuito de amplificação, presente na fase de condicionamento do sinal. Verifica-se que o resultado obtido seguiu fielmente a teoria apresentada no capítulo 2. Para melhor contextualização, a imagem foi extraída da tela de um osciloscópio.

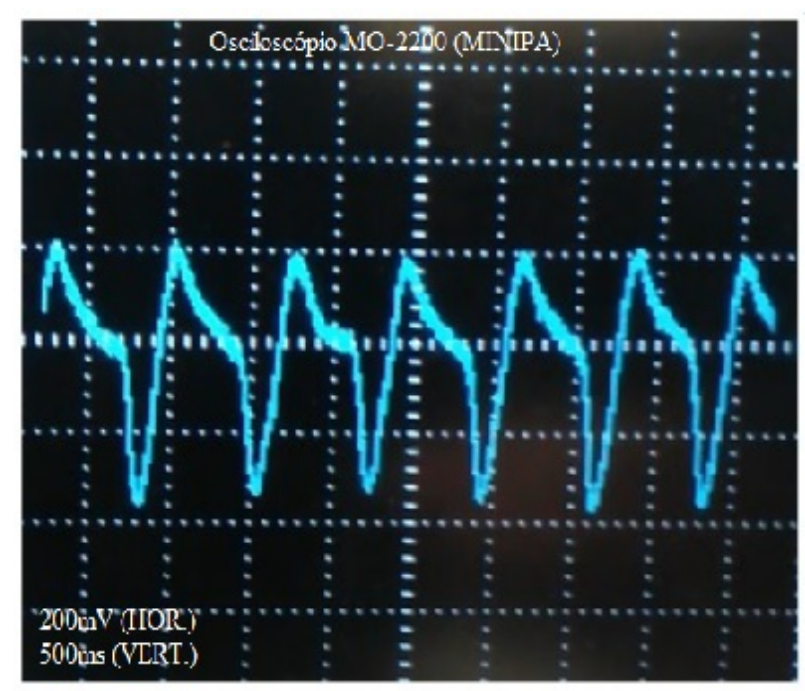

Figura 4.1: Curva pletismográfica vista na tela do osciloscópio

Atualmente, os sensores de dedo custam em torno de $\mathrm{R} \$ 600,00$ no mercado nacional. O modelo do sensor de dedo aplicado nesta dissertação apresentou um custo mais acessível. Modelado e produzido a partir de uma técnica artesanal, tem sua estrutura conjungada a componentes eletrônicos conhecidos por emissores (Leds) e receptores (fotodiodos). Um cabo metálico(UTP-5e) foi utilizado para encaminhamento do sinal e a interface de conexão utilizada foi de conectores RS232 macho e fêmea.

A tabela 4.1 apresenta a relação de gastos envolvidos na confecção do sensor de dedo. 
Tabela 4.1: Custos do Sensor de Dedo

\begin{tabular}{|c|c|c|c|c|}
\hline Material & Quantidade & Unidade & Valor $(R \$)$ & total $(R \$)$ \\
\hline FOTODIODO - BPW34 & 2 & un & 2,74 & 5,48 \\
\hline LED VERMELHO $(5 \mathrm{~mm})$ & 1 & un & 0,46 & 0,46 \\
\hline DIODO INFRAVER.(5mm) & 1 & un & 0,76 & 0,76 \\
\hline CABO UTP 5E & 0,5 & m & 3,00 & 1,50 \\
\hline CONFECÇÃO & 1 & un & 20,00 & 13,48 \\
\hline MÃO DE OBRA & 1 & un & 13,48 & 13,48 \\
\hline \multicolumn{5}{|c}{ Total $(R \$)$} \\
\hline
\end{tabular}

\subsection{Protótipo}

Em relação a leitura e tratamento dos sinais, oxigenação do sangue e batimentos cardíacos, os resultados iniciais apresentaram boa consistência comparados a outros coletados a partir modelos comerciais de oximetro de pulso (FL-100, FraceLake). A comprovação foi registrada através de foto a qual pode ser vista através da figura 4.2.

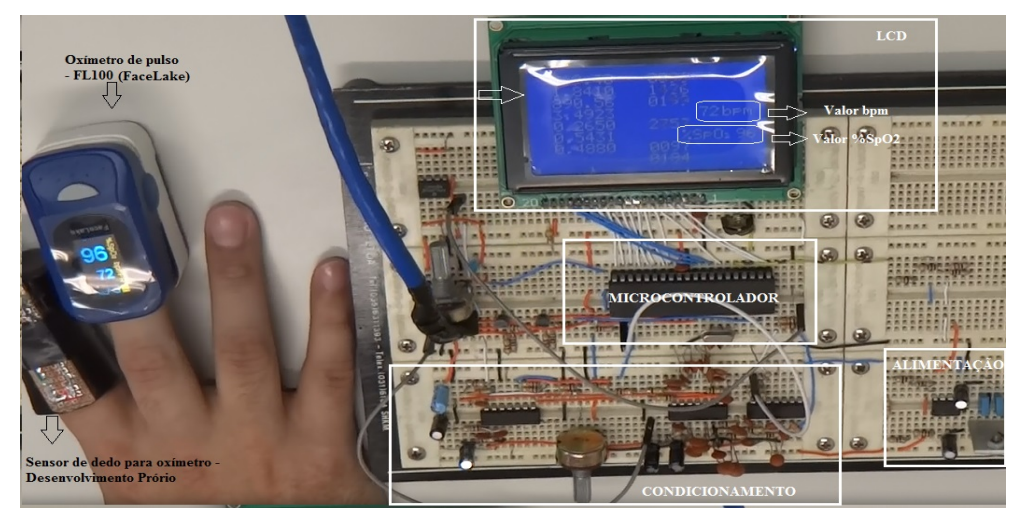

Figura 4.2: Circuito montado em Protoboard

\subsection{Comunicação sem Fio e Aplicativo Android}

A comunicação via bluetooth foi testada levando em consideração o raio de cobertura do dispositivo que alcança até 10 metros. O aplicativo recebeu os dados vistos no LCD do oxímetro com total sincronismo e fidelidade de informação. A figura 4.3 mostra uma foto do teste realizado.

Os oxímetros comercializados atualmente no Brasil não possuem recursos de 


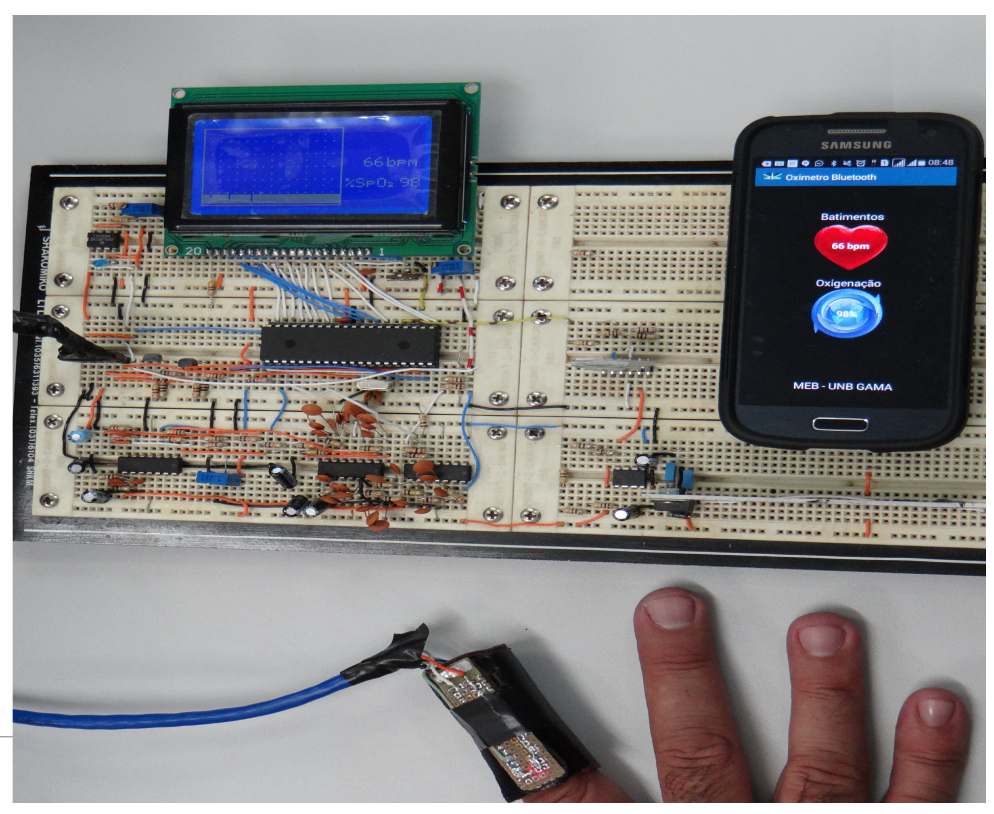

Figura 4.3: Comunicação Bluetooth

comunicação sem fio. Com isso, este equipamento mostra que através da atualização tecnológica é possível desenvolver uma integração entre equipamentos utilizados na Engenharia Biomédica e smartphones.

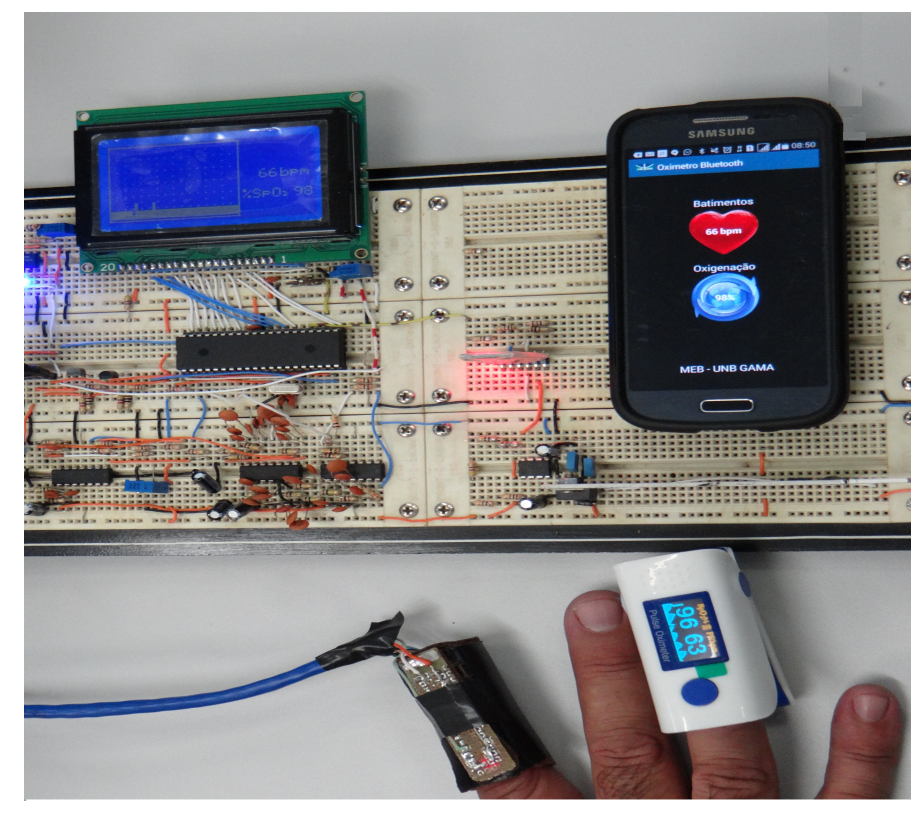

Figura 4.4: Comparação com Finger Pulse Oximeter - Comercial 


\subsection{Internet das Coisas}

Em m-health, o conceito de telemedicina está voltado a mobilidade das informações. Com o objetivo de atender este requisito, o próprio smartphone lê e encaminha os dados, utilizando a página web do aplicativo thingSpeak, o qual é responsável pelo armazenamento no seu servidor.

A figura 4.5 mostra uma imagem da página em que os dados foram disponibilizados para acesso remoto.

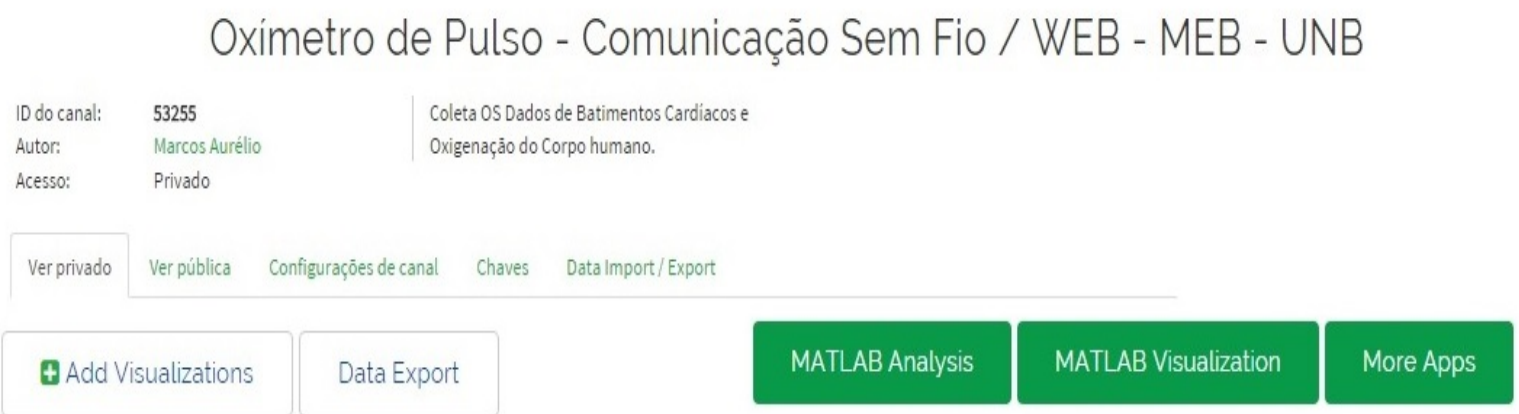

\section{Channel Stats}

Criada em about a month ago

Updated 2 minutesago

152 Entries

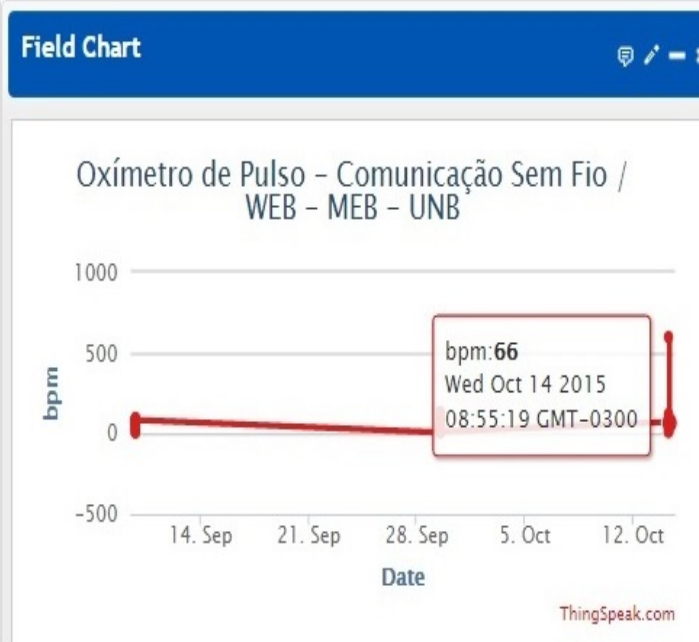

\section{Field Chart}

目i $=x$

Figura 4.5: Imagem do site: https://thingspeak.com/channels 


\subsection{Coleta e Análise de Dados}

A coleta de dados é considerada uma das fases fundamentais desta dissertação de forma a gerar um estudo estatístico. Sem a existência de um grau satisfatório de precisão nos dados obtidos, as fases subsequentes ficariam invalidadas. Os dados coletados serão essencialmente operacionais, referindo-se à obtenção, reunião e registro sistemático de dados. Quanto a origem dos tipos de dados, estes foram considerados primários (dados coletados pelo responsável do projeto).

Os dados coletados classificar-se-ão por meio do processo de amostragem, onde apenas uma parte da população foi pesquisada. Visando ter uma boa fundamentação, cálculos estatísticos foram realizados em torno dos valores de tendência central, como por exemplo: média aritmética da amostra, mediana, moda, quartis, entre outros.

Com o objetivo da testar a eficiência dos dados de oxigenação e batimentos cardíacos aferidos pelo protótipo do oxímetro sem fio com comunicação Bleuetooth foram selecionados cinco indivíduos, onde aparentemente, todos apresentavam condiçoes físicas normais. Como parâmetro de referência, dois outros modelos de oxímetros comerciais foram utilizados para fins comparativos. Os resultados estão registrados através da tabela 4.2 .

Tabela 4.2: Coleta de dados

\begin{tabular}{|c|c|c|c|c|c|c|}
\hline \multirow{2}{*}{ Indivíduo } & \multicolumn{3}{|c|}{ Freq. Card. } & \multicolumn{3}{|c|}{ SpO2 } \\
\cline { 2 - 7 } & $\mathrm{A}$ & $\mathrm{B}$ & $\mathrm{C}$ & $\mathrm{A}$ & $\mathrm{B}$ & $\mathrm{C}$ \\
\hline 1 & 73 & 75 & 72 & 98 & 97 & 96 \\
\hline 2 & 69 & 66 & 66 & 97 & 96 & 96 \\
\hline 3 & 86 & 87 & 84 & 95 & 96 & 96 \\
\hline 4 & 93 & 87 & 96 & 99 & 98 & 96 \\
\hline 5 & 72 & 76 & 78 & 99 & 96 & 95 \\
\hline
\end{tabular}

Nota dos modelos de equipamentos utilizados:
A: FL-100 (Face Lake);
B: Finger Pulse Oximeter;
C: protótipo desenvolvido do Oxímetro de Pulso com Comunicação sem Fio.

\subsubsection{Média Aritmética da Amostra}

A média aritmética da frequência cardíaca dos equipamentos A,B e C foram apresentados na tabela 4.3. Observa-se que a diferença entre as medidas do protótipo 
(C) ficou em torno de $0,77 \%$ em relação os valores medidos pelos equipamentos comerciais (A e B). Já a diferença entre as medidas de \% $\mathrm{SpO}_{2}$ do protótipo (C) ficou com uma variação negativa de 1,6 em relação ao maior valor aferido pelo equipamento (A).

Tabela 4.3: Média Aritmética da Coleta de dados

\begin{tabular}{|c|c|c|c|c|c|c|}
\hline \multirow{2}{*}{ Indivíduo } & \multicolumn{3}{|c|}{ Freq. Card. } & \multicolumn{4}{c|}{ SpO2 } \\
\cline { 2 - 7 } & $\mathrm{A}$ & $\mathrm{B}$ & $\mathrm{C}$ & $\mathrm{A}$ & $\mathrm{B}$ & $\mathrm{C}$ \\
\hline Média Aritmética & 83,3 & 83,3 & 84 & 97,3 & 96,3 & 95,7 \\
\hline
\end{tabular}

\subsubsection{Mediana da Amostra}

A mediana mostra o ponto de equilíbrio dos dados coletados. De acordo com a disposição ordenada dos dados extraídos dos cinco voluntários (ver tabela 4.4) é possível concluir quais os valores são menores ou igual a mediana (Med.), e quais valores são maiores ou iguais a mediana (Med.). Em relação a esta medida de tendência central, verifica-se que a mediana (Med.) está variando entre um valor máximo e mínimo de acordo com as condições de cada voluntário.

Tabela 4.4: Disposição ordenada das amostras para cálculo da mediana

\begin{tabular}{|c|c|c|c|c|c|c|c|c|c|c|c|c|}
\hline Equip. & \multicolumn{4}{|c|}{ Frequência Cardíaca } & Med. FC & \multicolumn{5}{|c|}{ Taxa do $\% O_{2}$} & Med. \% SPO2 \\
\hline A & 69 & 72 & 73 & 86 & 93 & 73 & 95 & 97 & 98 & 99 & 99 & 98 \\
\hline B & 66 & 75 & 76 & 87 & 87 & 76 & 96 & 96 & 96 & 97 & 98 & 96 \\
\hline C & 66 & 72 & 78 & 84 & 96 & 78 & 95 & 96 & 96 & 96 & 96 & 96 \\
\hline
\end{tabular}

\subsubsection{Variância e Desvio Padrão}

A variância e o desvio padrão são duas medidas de variação habitualmete utilizadas que levam em consideração o modo como os dados estão distribuídos, medindo a dispersão média em torno da média aritmética, ou seja, o modo como os valores mais altos flutuam acima dela e o modo como os dados mais baixos se distribuem abaixo dela.

A tabela 4.5 mostra os resultados referentes aos cálculos da variância e desvio padrão da frequência cardíaca dos voluntários através dos oxímetros A, B, C. Observase que os valores variaram entre 11,6 e 12,7 em torno da média aritmética. Também verifica-se que a amplitude do desvio padrão entre os equipamentos está em torno de 1,1 unidade. 
Tabela 4.5: Variância e Desvio Padrão FC

\begin{tabular}{|c|c|c|c|}
\hline \multirow{2}{*}{ Medida } & \multicolumn{3}{|c|}{ Equipamento } \\
\cline { 2 - 4 } & $\mathrm{A}$ & $\mathrm{B}$ & $\mathrm{C}$ \\
\hline Variância & 134,9 & 112,2 & 162,0 \\
\hline Desvio Padrão & 11,6 & 10,6 & 12,7 \\
\hline
\end{tabular}

A tabela 4.6 mostra os resultados referentes aos cálculos da variância e desvio padrão da taxa de oxigenação dos voluntários através dos oxímetros $\mathrm{A}, \mathrm{B}, \mathrm{C}$.

Tabela 4.6: Variância e Desvio Padrão $\% \mathrm{SO}_{2}$
\begin{tabular}{c|c|c|c|}
\hline \multirow{2}{*}{ Medida } & \multicolumn{3}{|c|}{ Equipamento } \\
\cline { 2 - 4 } & $\mathrm{A}$ & $\mathrm{B}$ & $\mathrm{C}$ \\
\hline Variância & 2,9 & 0,9 & 0,3 \\
\hline Desvio Padrão & 1,7 & 1,0 & 0,6 \\
\hline
\end{tabular}

Observa-se que os valores estão variando entre 0,6 e 1,7 em torno da média aritmética. Também verifica-se que a amplitude do desvio padrão entre os equipamentos está em torno de 1,1 unidade. Com isso, ao se comparar o desvio padrão encontrado com o valor em torno da média, é possível comprovar um desvio percentual abaixo de 1\%. Este valor em termos estatísticos é considerado de exelente eficiência. 


\section{CONCLUSÃO E TRABALHOS FUTUROS}

Esta dissertação apresentou um estudo para desenvolvimento de um equipamento biomédico com comunicação bluetooth e aplicações no campo da Telemedicina, e m-health (Saúde Móvel). Especificamente, a pesquisa abordou a coleta de dois sinais importantes do corpo humano: Oxigenação $\left(\% S P O_{2}\right)$ e Batimentos Cardíacos (bpm) que foram coletados através do processo de fotocondução, e posteriormente enviados através da comunicação bluetooth para um celular com sistema operacional Android. Isto permitiu que tais informações pudessem ser disponibilizadas em uma página na internet por meio da conexão de dados da rede celular ou Wi-Fi local.

Os resultados obtidos foram satisfatórios e mostraram que é possível integrar vários tipos de sinais bioelétricos em uma única plataforma de processamento. Para melhorar a precisão dos dados é necessário o aprimoramento do hardware de processamento, porém a metodologia seguida comprova que o uso de um hardware mais robusto e otimizado aumentará a eficiência do equipamento e sinais coletados.

Em termos de protótipo foi possível garantir que a comunicação sem fio poderá estar presente em qualquer dispositivo médico, assim como o que foi implementado no oxímetro de pulso com comunicação bluetooth. Também foi possível garantir a interoperabilidade do equipamento com os meios de comunicação (celulares e internet), que por sinal se torna uma obrigação na inserção do conceito de telemedicina.

É importante ressaltar que o circuito de condicionamento desenvolvido desenvolvido para tratar o sinal recebido do sensor pode ser melhorado e otimizado com o objetivo de prototizar em larga escala uma possível produção. Em relação ao sensor de dedo foi comprovado nesta pesquisa que o desenvolvimento do protótipo permite chegar numa relação de custo/benefício muito mais baixa, comparado, é claro, com os preços em que o mercado brasileiro prática. Técnicas avançadas de modelação com o utilização de impressoras 3D podem ser agregadas para melhorar a acomodação do dedo e dos dispositivos eletrônicos envolvidos na leitura dos sinais fotocondutivos.

Como propostas para trabalhos futuros sugere-se a implementação de módulos adicionais de outros equipamentos biomédicos, tais como: temperatura, eletrocardiograma, pressão arterial, entre outros. A nível de atendimento hospitalar, a integração de vários equipamentos da engenharia biomédica em rede possibilitará o controle centralizado (através de centros de gerência) ou distribuído (acesso remoto). Em relação ao usuário, os dados monitorados por dispositivos móveis e ao mesmo tempo pela internet facilitará o controle e o acompanhamento da saúde. 


\section{REFERÊNCIAS BIBLIOGRÁFICAS}

[1] M. B. Shoemake, "White Paper Coexistence Issues and Solutions for the 2 . $4 \mathrm{GHz}$ ISM Band," no. February 2001, pp. 1-17.

[2] "Oxímetro de pulso para medição da oxigenação periférica e pulsação cardíaca." Disponível em: http://www.tcc.sc.usp.br/tce/disponiveis/18/ 180450/tce-26012015-141909/. Acesso em 10-08-2015.

[3] F. Adochiei, C. Rotariu, R. Ciobotariu, and H. Costin, "A Wireless Low-Power Pulse Oximetry System for Patient Telemonitoring," 7Th International Symposium on Advanced Topics in Electrical Engineering, p. 4, 2011.

[4] K. Li, S. Member, and S. Warren, "Onboard Tagging for Real-Time Quality Assessment of Photoplethysmograms Acquired by a Wireless Reflectance Pulse Oximeter," vol. 6, no. 1, pp. 54-63, 2012.

[5] Y. Mendelson, R. J. Duckworth, and G. Comtois, "A wearable reflectance pulse oximeter for remote physiological monitoring.," Conference proceedings : ... Annual International Conference of the IEEE Engineering in Medicine and Biology Society. IEEE Engineering in Medicine and Biology Society. Annual Conference, vol. 1, pp. 912-5, jan 2006.

[6] M. J. Morón, E. Casilari, R. Luque, and J. A. Gázquez, "A Wireless Monitoring System for Pulse-oximetry Sensors," pp. 0-5, 2005.

[7] F. H.Netter, Atlas Interativo de Anatomia Humana. 2003.

[8] D. Malan, T. Fulford-Jones, M. Welsh, and M. S., "CodeBlue: an adhoc sensor network infrastructure for emergency medical care," Proceedings of the Mobi-Sys 2004 Workshop on Applications of MobileEmbedded Systems, pp. 12-14.

[9] Elsharydah A. and R. Cork, "Blood Gas Measurements, Oximetry," in Encyclopedia of Medical Devices and Instrumentation, pp. 469-476, John Wiley \& Sons Inc., 2006. 
[10] R. G. Seippel, "Transducers, Sensors \& Detectors Hardcover," 1983.

[11] W. Kester, "Practical Design Techniques for Sensor Signal Conditioning," pp. 1-5, 1999.

[12] "Certificação ANVISA - NBR IEC 60601-1 - Ensaio de rigidez dielétrica."

[13] "Certificação ANVISA - NBR IEC IEC 10993-1 - Ensaio de biocompatibilidade."

[14] Jung, Water G., Op Amp applications handbook. 2004.

[15] a. D. Microcontrollers, "Data Sheet High-Performance, Enhanced Flash," Technology, 2006.

[16] E. Andrighetto, "Sistema de processamento de sinais biomédicos : rede wireless ZigBee com aplicação do padrão IEEE 802.15.4," p. 147, 2008.

[17] M. G. Rubinstein, 1, e. J. F. de Rezende, and 2, "Ieee 802.11," pp. 1-18.

[18] F. Carlos and A. Paim, "Desenvolvimento de um sistema de telemetria para aquisição de sinais fisiológicos com aplicação em programas de reabilitação cardíaca," p. 137, 2005.

[19] "ThingSpeak." Disponível em: //thingspeak.com/docsl. Acesso em 14-09-2015.

[20] K. Usb and P. I. C. Programmer, "K150. usb pic programmer," p. 2004, 2004.

[21] "Hc05 bluetooth popular." Disponível em: http://www.aliexpress.com/ popular/hc05-bluetooth.html. Acesso em 22-07-2015.

[22] W. Merkmale and S. Group, "NEU : in SMT und als Reverse Gullwing Silicon PIN Photodiode NEW : in SMT and as Reverse Gullwing BPW 34 BPW 34 S BPW 34 , BPW 34 S BPW 34 S," pp. 1-5, 1998. 
APÊNDICE 


\title{
A Artigo Publicado
}

\section{A.1 Simpósio Engenharia Biomédica - Uberlândia/2015}

\author{
BLUETOOTH PULSE OXIMETER \\ A TELEMEDICINE ORIENTED EQUIPMENT \\ ${ }^{1}$ Mar cos Aur êlio Lim a Neves, 'G eorges Dariel Amvame Nze \\ Universidade de Brasilia (UnB) - C ampus $\mathrm{G}$ ama (FGA) \\ Area Especial 01 - Setor Central - Antigo Fónum do G ama - CEP : $72405-610$-- G ama -- DF -- Brasil \\ ${ }_{\mathrm{m}}$ ar cosnevesetb@gm ail. com, ${ }^{2}$ geor ges@urb.br
}

Resumo - $O$ oxímetro é um equipamento médico não invasivo que extrai dados percentuais de oxigenação (SpO2) e frequência cardiaca $(\mathrm{FC})$ do ser humano. $\mathrm{O}$ processo fisiológico se manifesta por meio do fluxo respiratório e sanguíneo. Atualmente, os oxímetros existentes no mercado nacional não disporibilizam ao paciente ou a equipe médica, as inform ações de frequência cardiaca e percentual de oxigenação utilizando um serviço de telecom unicação. Nos países de $1^{\circ}$ mundo, este cenário já é uma realidade. Com a inserção de conceitos de T elemedicina, dispositivos eletrônicos de com unicação sem fio foram inseridos em equipam entos da área de Engenharia Biomédica possibilitando o envio dos dados coletados para a equipe médica por meio de equipamentos terminais móveis (celular) ou portáteis (tablets e notebooks). Assim, o objetivo deste artigo é apresentar a descrição da análise de um projeto, no nivel de hardware e software, na área da oxím etria voltado no campo da Telem edicina.

Palatras-chave: Sensor, Condicionamento, Amplificador, Microprocessador, Binetooth Sinais Biocondutivos e Monitoramento.

Abstract - The oximeter is a norinvasive medical device that extracts percentage of oxygenation data $(\mathrm{SpO} 2)$ and heart rate (HR) of the human being. The physiological process is marifested by respiratory and blood flow. Currently, existing oxim eters on the national market do not provide to the patient or the medical staff, the heart rate information and percentage of oxygenation using a telecommunications service. In the international market, particularly in 1 st world countries, this scenario is already a reality. With the inclusion of concepts of telemedicine, wireless electronic devices were inserted in Biomedical Engineering equipment enabling the sending of the data collected for the medical staff through mobile terminal equipment (cell phone) or portable (tablets and notebooks). The objective of this paper is to present a description of the analysis of a project, the level of hardware and software in the area of oximetry facing the field of telemedicine.

Keywords: Sensor, Conditioning Amplifier, Microprocessor, Bunetooth, Bio-conductive Signals and Monitoring.

\section{INTRODU CTION}

Clearly, it is known that technology, in a way of another, always provides a support for health. Hence, exploration by apps seeking to improve control and followup medical attention in relation to patients are increasingly pressing for researchers and professionals of related areas [1].

Wireless communication pulse oximeter is an electronic device with transmitter module and low power receiver. Compatible with IEEE 802.15.1, the base of BLUETOOTH technology, can operate at $2.45 \mathrm{GHz}$ transmission range split into classes 1,2 and 3; covering the respective distances of $100 \mathrm{~m}, 10 \mathrm{~m}$ and $1 \mathrm{~m}$.

Through telemedicine it is possible to diagnose, prevent, follow, supervise and moritor innumerable medical procedures and cause the system to become more efficient. The optimization of the Biomedical Engineering resources in electronic projects always seeks to meet the Cost/Benefit ratio for users concerned.

In pursuing this goal this paper introduces a basic analysis of the solution on a project level of a wireless communication oximeter via Bluetooth for centralized operation in the control and moritoring of blood oxygenation and heart rate of hum an beings.

\section{THEORY OF OPERATION}

Regarding the physiological process, the human body oxygen is taken to the body tissues via the blood and respiratory systems. The respiratory system shown in Figure 1 comprises the nasal cavity, mouth, pharynx, larynx, trachea, bronchi: left and right, and lungs represented by the alveoli, which is the system responsible for gas ex change.

The blood system, seen in Figure 2, causes oxygen to circulate through the bloodstream (arterial blood) through the oxygenated hemoglobin molecules ( $\mathrm{HbO2}$ ) to the body tissues. When receiving oxygenation, the body cells absorb much of it and returns through the venous blood de oxygenated hemogiobin molecules ( $\mathrm{Hb}$ ), repeating the process with each heart cycle. Lack of oxygen can lead to problems related to hypoxemia (low concentration of 
oxygen in arterial blood and hypoxia - low availability of oxygen to a specific organi).

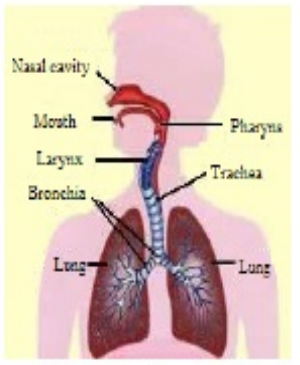

Figure 1-Respiratory System [2]

Monitoring of oxygen saturation rate ( $\mathrm{SpO} 2)$ of the hum an body measured by a pulse oximeter is based on the photo conduction process, which uses light as a process for obtairing oxygenation and heart rate data. Red (range of $600-750 \mathrm{~nm}$ ) and infrared LEDs (range of $850-1000 \mathrm{~nm}$ ) are generating sources of this process.

Based on the Law of Beer-Lambert[4] given by equation 1, spectrophotometry relates the absorption of light by a specific substance and the distance traveled by light beam determined by that body [5].

$$
\begin{aligned}
& I_{1}=I_{0} e^{-\sigma s} \\
& \alpha=\varepsilon(\lambda) \cdot c
\end{aligned}
$$

Where:

$I_{0}=$ Intensity of incident light (W/m2);

$I_{1}=$ Intensity of the transmitted light emerging from the medium (W/m2);

$\alpha=$ Extinction coefficient of a given light beam (cm-1); $J=$ Distance traveled by light in the medium, given in meters (m);

$c=$ Concentration of the substance in the medium (mmol/liter);

$\varepsilon(\lambda)=$ Extinction coefficient of a given light beam.

Through equation 1 it is possible to graphically define the oxygen absorption curves by oxygenated and deoxygenated hemoglobin with respect to wavelengths (seen in Figure 3).

By logarithmically relating the variables of red and infrared signal intensities received at the receiver known as photodiode device, it is possible to extract a ratio $R$ (Equation 3 and Figure 4) within a given interval able to allow the evaluation of the oxygen saturation rate $(0-100 \%)$ received in the body.
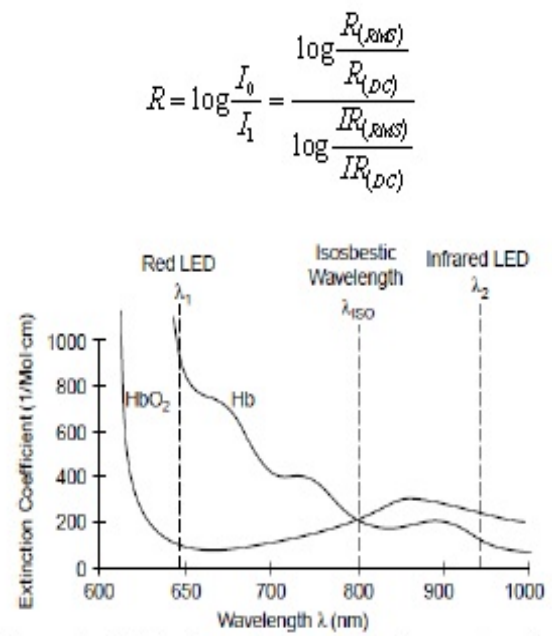

Figure 3 - Light absorption coefficients as a finction of Red and Infrared wavelength [5]

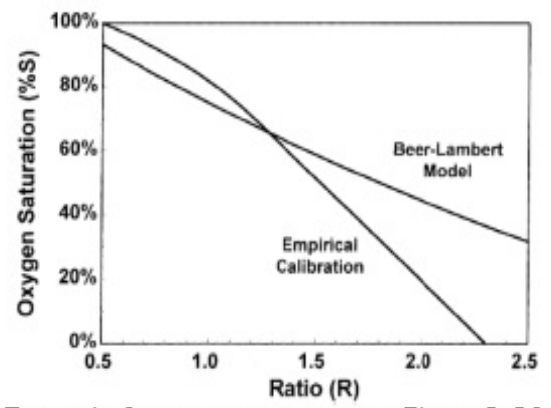

Figure 4 - Correlation between rate $(R)$ and SpOZ[6]

The first pulse oximeters used the Beer-Lambert curve to relate the blood oxygen rate values. N evertheless, it has been observed that for rates below $85 \%$ values presented no precision (in the ratio). For this reason, an empirical curve $w$ as constructed from measurem ents carried out in healthy patients resulting in a more accurate value for the human body oxygenation rate. Equation 4 models the empirical curve

$S p O 2=10.0002 \times R^{3}-52.887 \times R^{3}+26.87 \times R+98.293$

\section{RELATED STUDIES}

In [7], Yitzhak Mendelson, advocates a pulse oximeter design using the telemedicine concept. His research is the development of wireless technology oximetry sensors that can be used in monitoring and controlling vital signs of life-saving professionals, the activities of which are exposed to high levels of strenuous loads of short-term and excessive effort, as well as the im minent danger of carbon dioxide inhalation $(\mathrm{CO})$ at high risk of consciousness loss and death. 
In [8], Felix Adochiei et. al, present a survey wireless oximeter low-cost accomplishment for telemonitoring ( $\mathrm{SpO}$ ) level and heart rate (HR). The use of the proposed system is suitable for moritoring patients who need a diagnosis. The architecture uses micro controllers and low power $R F$ tr ansceiver that commuricates by using the Wi-Fi network or mobile commurication 3G (GSM/ GPRS). Such a prototype was designed, implemented and tested. The hardware used commercially avrilable devices.

In [9], Kejia Li, proposes an evaluation of the oxygenation rate ( $\mathrm{SpO2})$ and the heart rate by sending the plethysmographic curve data (PPG). Li's proposal recuces the transmission of unnecessary data enabling the increase of service life of the power source (batteries) of pulse oximetry. They managed the reduction due to the use of intelligent algorithms that detect the characteristics of edges of PPGs. All information processing $w$ as done on the host receiver. Keija $\mathrm{Li}$ concluded that the results of the algorithm achieved an efficiency of up to $99 \%$ in the interpotetations of PPGs usable.

\section{HARDWARE}

The pulse oximeter electronic structure can be seen by the block diagram of the Figure 5 . In or der to make it easier to understand, its analysis will be discussed in steps shown below.

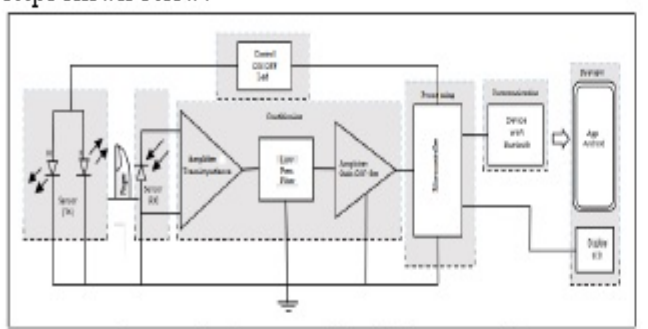

Figure 5- Oximeter Block Diagrams [7]

The first phase, known as the sensing is responsible for detecting the intensity of the absorbed light signals through the body of the finger, identifying the bioconduction signal. In this process, the electroric devices responsible for conveying light signals are light emitting diodes (LED RED and INFRARED) and the receiver element is the photodiode.

Figure 6 shows two methods to capture the signals, known as reflective and transmissive methods.

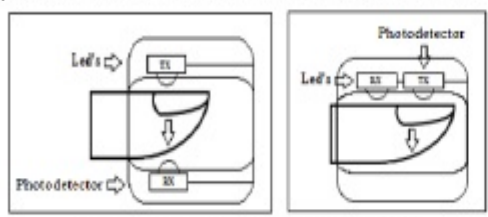

Figure 6-Finger sensors [7][8]
The second phase named conditioring will have the signal handler function. Basically, it consists of stages of: transimpedance, amplification filtering and off set. The transimpedance circuit modeled in the project is shown in Figure 7.

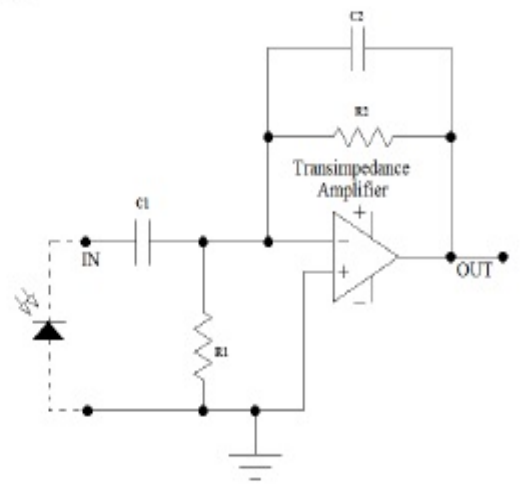

Figure 7- Transimpedance circuit [8]

The third phase is responsible for digital signal processing. The electronic device that performs this process is a microcontroller PIC 30F3014 in which it has the function of digitize the received signals and send them through output UART (Universal Asynchronous Receiver/ Transmitter), as seen in Figure 9.

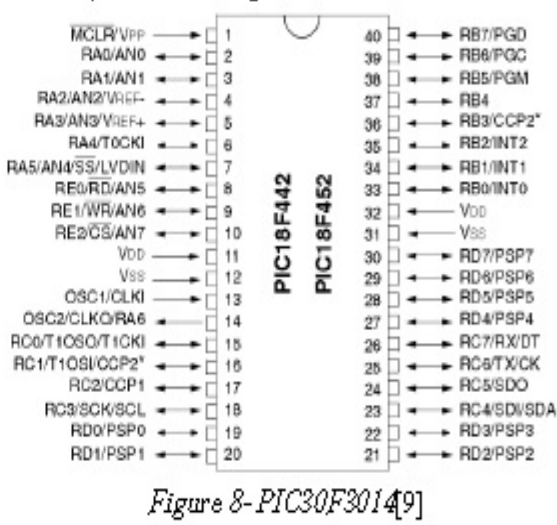

\section{ANDROID APP}

Device HC-05, seen in Figure 9, performs the serial commurication by means of Bluetooth wireless connection. Its communication flow (RX/TX) offers 9,600 bps up to 115,200 bps rates. The Bluetooth comm unication device HC-05 is coupled to UART output port of the microcontroller PIC 18F452. 


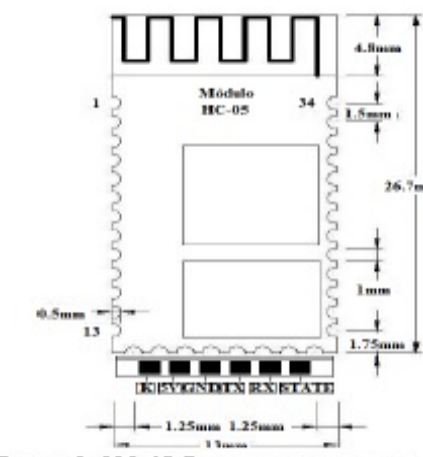

Figure 9- HC-05 Bunetooth moinle [14]

MIT's App Invertor was used to create our mobile application because it offers an integrated developm ent environment for web applications or devices using the Android oper ating system [11]

\section{RESULTS}

Through the first tests carried out, this project has produced satisfactory results in relation to measures of heart $r$ ate, but the oxygenation presented results with values outside the calibration curve. This is probably due to the lack of signal timing at the time of activation of the red and infrared leds.

Despite the smartphone application has not been completed in its entirety, the communication test was successfully performed. Heart rate and oxygenation data were received via data terminal application on mobile devices via Bluetooth connection

\section{CONCLUSION AND FUTURE STUDIES}

This article introduced an architectural solution for the construction of non-invasive medical equipm ent known as Pulse Oximeter. One new feature $w$ as the implementation of wireless comm unication using Bluetooth technology.

As suggestions for future work, we will have the possibility to use mobile processing for resource optimization of hardware and software. Another important contribution would be the creation of a database for monitoring and archiving of static information received by users in real time over the netw ork

\section{REFERENCES}

[1] M. B. Shoem ake, "White P aper Coexistence Issues and Solutions for the $2.4 \mathrm{GHz}$ ISM Band," no. February 2001, pp. 1-17.
[2] "Sistema respiratório. Respiração e componentes do sistem a respiratório - Escola Kids." [Online]. A vailable:http:/Ww/ escolakids com/respiracao.ht m. [Accessed: 09-Dec-2014]

[3] "Entendendo o sistema circulatório :: DR. JONO HUN PARK." [Orline].

A vailable:http://www cirvascular.com/cinugiavascul ar/ertendendo-0-sistem a-circulatorio 2 f [Accessed: 09-Dec-2014].

[4] D. Malan, T. R. . Fulford Jones, M. Welsh, and M. S., "CodeBlue: an adhoc sensot netw otk infrastructure for emergency medical care," Proc. Mobi-Sys 2004 Work. Appl. MobileEmbedded Syst, pp. 12-14

[5] Elsharydah A. and R. C. Cork, "Blood G as Measurements, Oximetry," in Encyclopediz of Medical Devices and Instrumentation, John Wiley \& Sons Inc., 2006, pp. 469-476.

[6] L. Doppler, "Pulse Oximetry," 1860.

[7] Y. Mendelson and D. Ph, "Wearable Wireless Pulse Oximetry for Physiological Moritoring," 2008.

[8] F. Adochiei, C. Rotariu R. Ciobotariu and H. Costin, "A Wireless Low-P ower Pulse Oxim etry System for Patient Telemoritoring," 2011

[9] K. Li, S. Member, and S. Warren, "Onboard Tagging for Real-Time Quality A ssessment of Photoplethysmograms Acquired by a Wireless Reflectance Pulse Oximeter," vol. 6, no. 1, pp. 5463, 2012.

[10] A. Devices, "AN1525-Pulse Oxim eter Design U sing Microchip's dsPIC Digital Signal C ontrollers (DSCs) and Analog Devices," pp. 1-14, 2013.

[11] T. Aoyagi, "1 . 3 Team Work and Hosting Entities," pp. 1-88.

[12] D.S. Controllers, "dsPIC30F3014, dsPIC30F 4013 D ata Sheet," 2004

[13] "App Inventor download - Baixaki." [Online] A vailable:http://ww brix aki.com. br/download/ap p-inventor.htm. [Accessed: 15-Dec-2014]

[14] HC-05 Bluetooth to Serial Port Moctule. Available: http://arduino-ua. com/docs/DS_BluetoothHC05.pdf 


\section{B Diagrama do projeto}

\section{B.1 Oxímetro de Pulso com Comunicação Sem Fio}

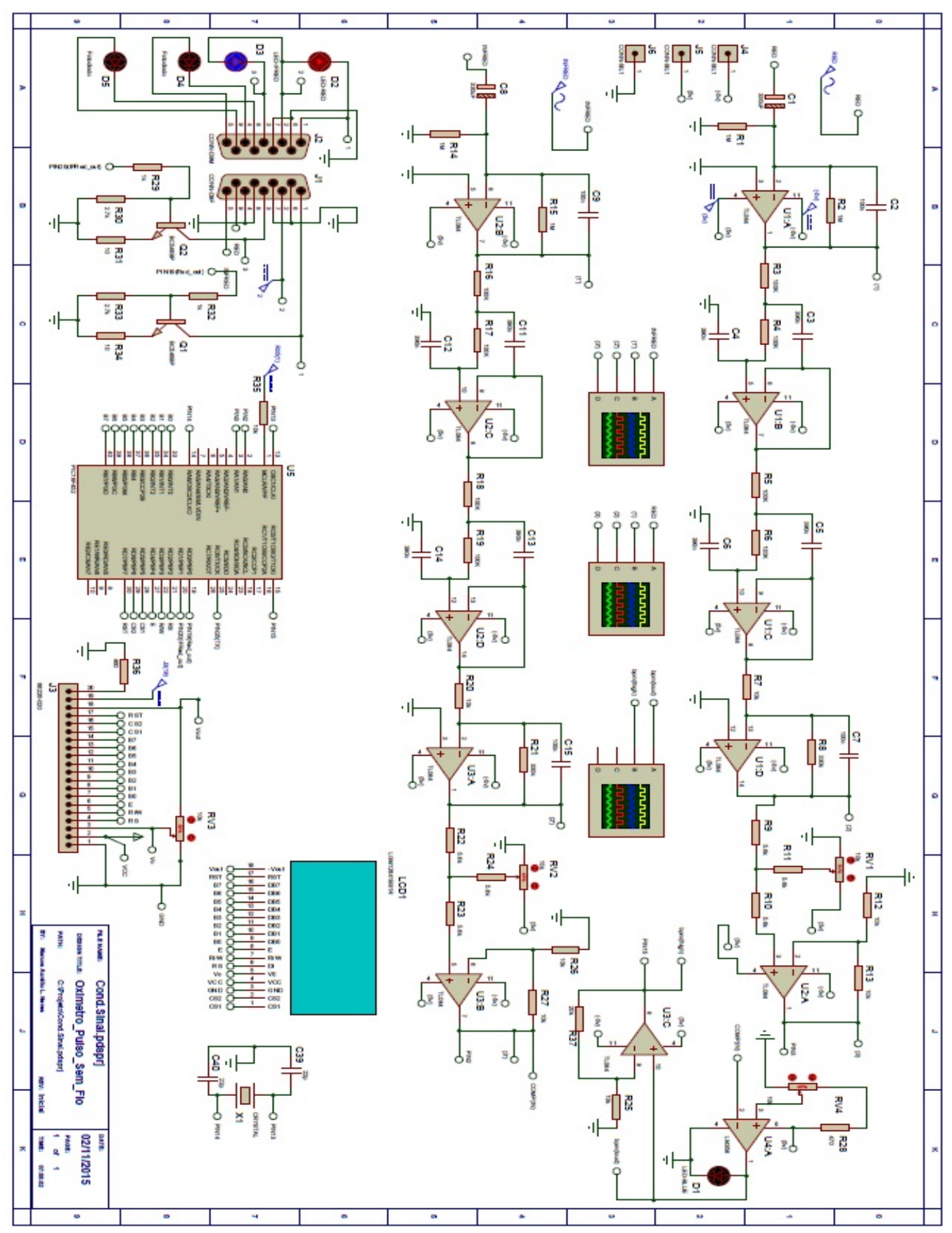

Figura B.1: Diagrama do projeto - Condicionamento e Processamento 


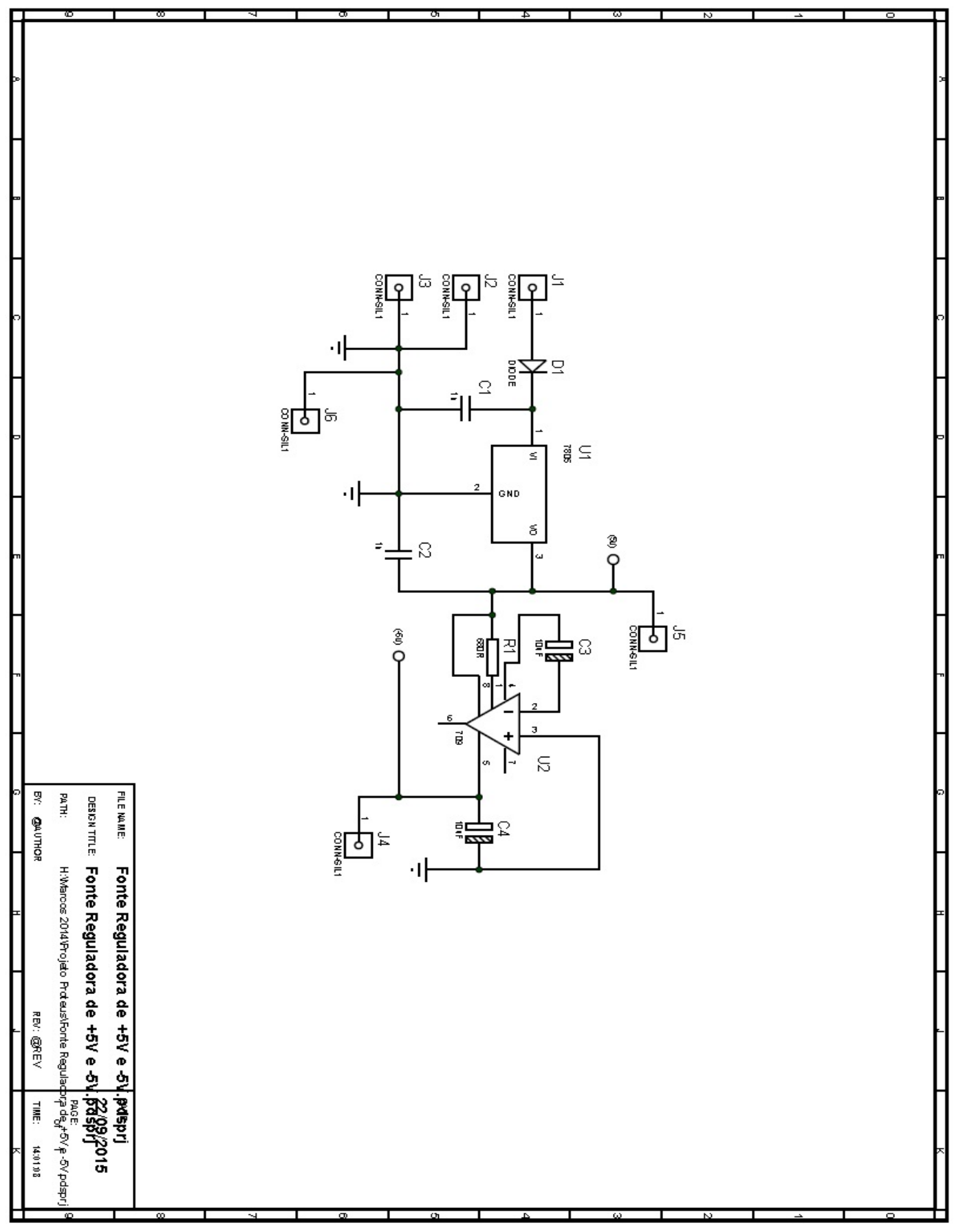

Figura B.2: Diagrama do projeto - Fonte Simétrica 


\section{Especificações Técnicas}

\section{C.1 Foto-Diodo BPW34}

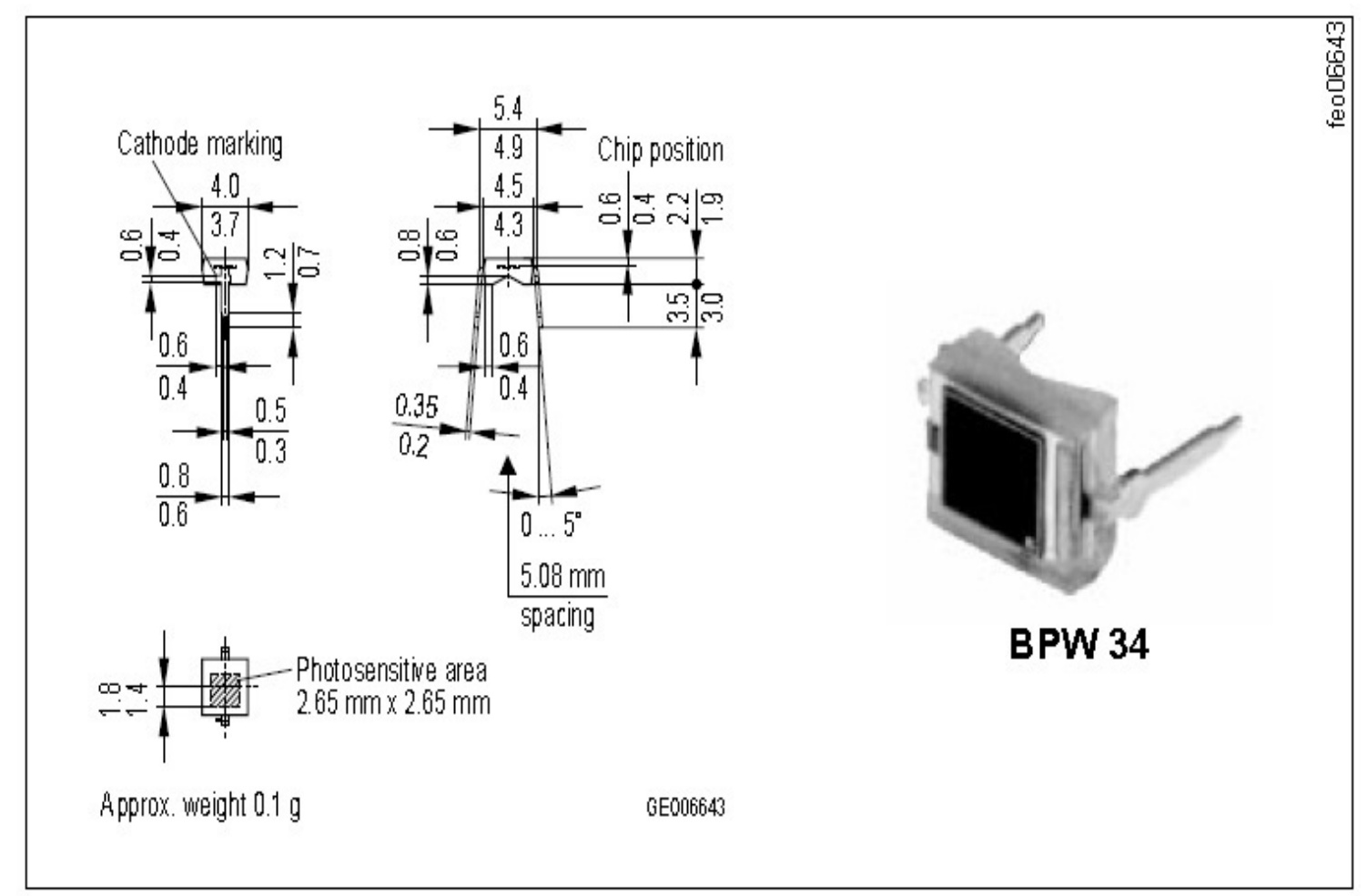

Figura C.1: Dimensões do Fotodiodo BPW34

\begin{tabular}{c|c|c|c}
\hline Descrição & Simbologia & Valor & Unidade \\
\hline Faixa de Temperatura de Operação & $T_{o p}$ & -40 à +85 & $\mathrm{C}$ \\
\hline Tensão Reversa & $V_{r}$ & 32 & $\mathrm{~V}$ \\
\hline Potência Disspada & $P_{t o t}$ & 150 & $\mathrm{~mW}$ \\
\hline Área de Radiação & $\mathrm{A}$ & 7,00 & $\mathrm{~mm}^{2}$ \\
\hline Capacitância IN & $C_{o}$ & 72 & $\mathrm{pF}$ \\
\hline
\end{tabular}

Referência [22]. 


\section{CÓDIGO - PIC18F452}

\section{D.1 Main}

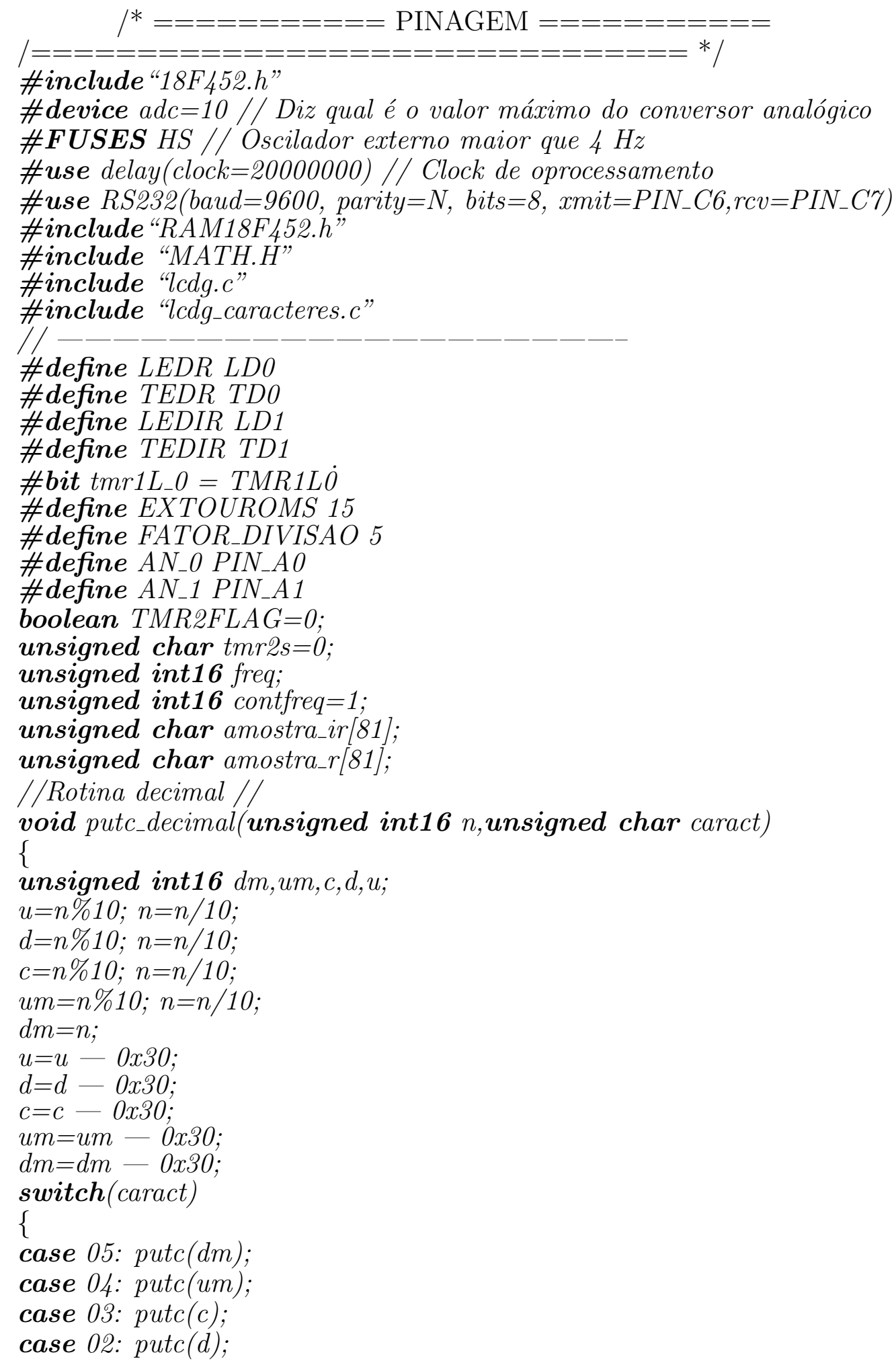




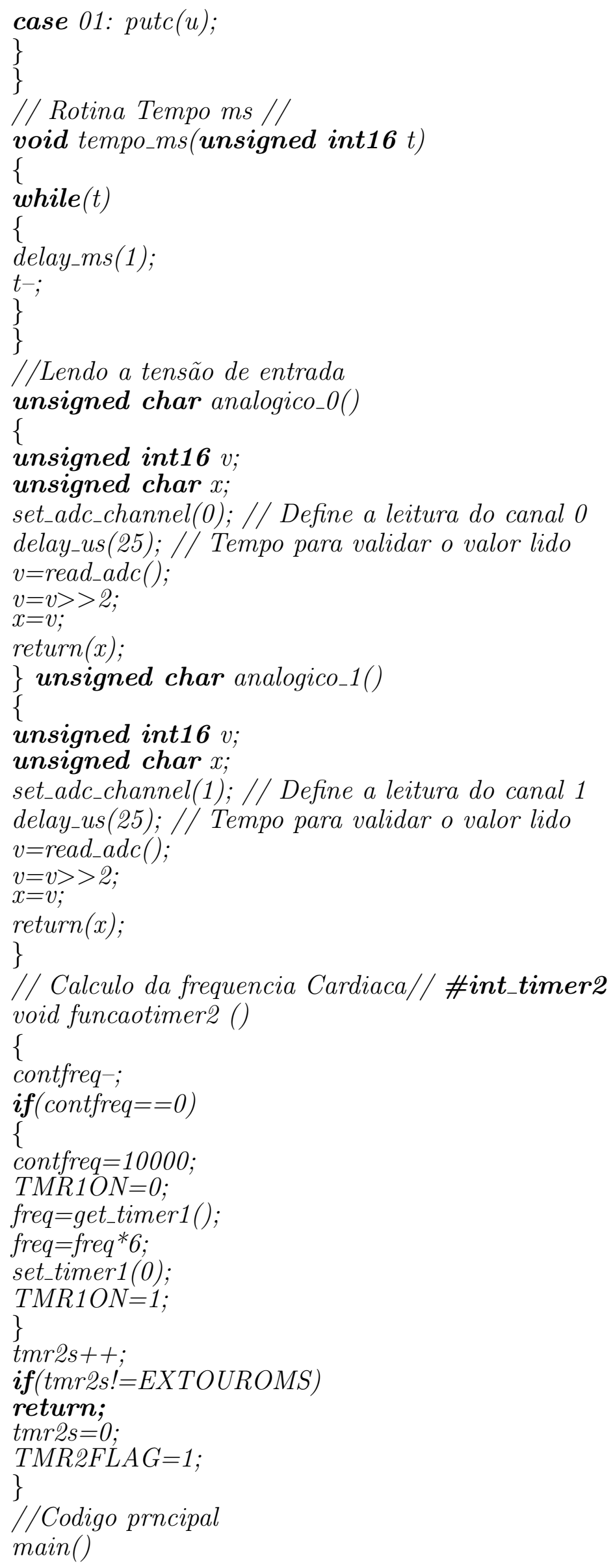


unsigned LONG INT sao2,ir2,ir1,r2,vr,vir, r1; unsigned LONG INT

unsigned int16 g1, g2, grafic1, grafic2,SPO;

unsigned int16 z,anterior,result,anterior_1,result_1, acumulador, acumulador1,total;

float32

fr,fir,mr1,mir1,mr,mir,sao2i,frsao2;

boolean coracao;

unsigned int16 corac $=1$;

unsigned int16 tst;

unsigned int16 $x=2995, y, a 1, a 2$;

float $f x$;

unsigned int16 $i x$;

$L E D I R=0 ; L E D R=0$;

$T E D I R=0 ; T E D R=0 ;$

$l c d g_{-} i n i c i a l i z a() ; l c d g_{-} \operatorname{clr}(0)$;

setup_adc_ports (ALL_ANALOG);// Define as entradas analógicas

setup_adc (ADC_CLOCK_DIV_2); // 2,8 ou 32 - Define a velocidade de conversão

delay_us(25); // Tempo para validar o valor lido

setup_timer_2 (T2_DIV_BY_4,254,5); // $250 \times 4 \times 5=5.000=1 \mathrm{~ms}-$ CONFIGURA

$O$ TIMER 2

enable_interrupts(int_TIMER2); // habilita interrupção do timer 2

enable_interrupts(global); // habilita interrupção geral

setup_timer_1 (T1_EXTERNAL-0-T1_DIV_BY_1);

$z=0 ;$

while(1)

\{

//Acende Led RED

while(!TMR2FLAG);

TMR2FLAG $=0$;

$r \mathscr{2}=r 1$

$L E D R=1$;

tempo_ms(2);

$r 1=$ analogico_O( $)$;

tempo_ms(100);

$/ /$ lcdg_pagcol $(8,65)$;

$/ /$ l lcdg_decimal $(r 1,4)$;

acumulador $=r 1+$ acumulador;

$/ / ! l c d g \_p a g c o l(1,65)$;

//! lcdg_decimal(acumulador,4);

//Imprime imagem do coração no LCD

lcdg_pagcol $(1,100)$;

if $\left(\right.$ tmr $1 L_{-} 0 !=$ coracao $)\left\{\right.$ coracao $=$ tmr $1 L_{-} 0$;

$l c d g_{-} c a r a c t e r e \_e s p e c i a l(1)$;

\}

else

\{

corac-;

if $(\operatorname{corac}==0)$

\{

$\operatorname{corac}=7$;

lcdg_caractere_especial(4);

\}

//Acende Led INFRARED

while(!TMR2FLAG);

TMR2FLAG $=0$; 
$i r 2=i r 1$

$L E D I R=1$;

tempo_ms(2);

ir1=analogico_1();

tempo_ms (1);

//! lcdg_pagcol(2,65);

//! lcdgz_decimal (ir1,4);

acumulador $1=i r 1+$ acumulador 1 ;

$/ / ! l c d g_{-} \operatorname{pagcol}(4,65)$;

//! lcdg_decimal(acumulador1,4);

$g 2=g 1$;

$g 1=r 1 / F A T O R \_D I V I S A O$;

grafic1 $=(g 1-15) * 2$;

$/ /$ ! grafic $2=($ g2 -15$) * 2$;

print_coluna_grafica(z,grafic1,grafic2); $z++$;

//Cáculo Média RED e INFRARED

if $(z==80)$

\{

result=acumulador $/ z$;

//! lcdg_pagcol(6,65);

//! lcdg_decimal $($ result,4);

acumulador $=0$;

result_1=acumulador $1 / z$;

//! lcdg_pagcol( $(7,65)$;

$/ /$ lcdg_decimal $($ result_1,4);

$z=0$;

acumulador $1=0$;

//Cálculo Tensão RED mr=result*4.84;

// putc(10); putc('m'); putc('r'); putc(':');

putc_decimal(result,5);

$/ / !$ lcdg_pagcol $(8,10)$;

$/ / ! \operatorname{lcdg}$ float $(\mathrm{mr})$;

$m r 1=m r / 255$;

// putc(10); putc('t');putc('m'); putc('r');

putc(':');

putc_decimal $($ mr 1,5$)$;

putc(");putc('v');putc('o');putc('t');putc('s')); );

$/ /$ lcdg_pagcol $(1,10)$;

$/ /$ lcdg_float (mr1);

//Cálculo Tensão INFRARED

mir $=$ result_ $1 * 4.84$;

// putc(10); putc('m'); putc('r');putc('i'); putc(':'); putc_decimal(result_1,5);

$/ / !$ lcdg_pagcol $(2,10) ;$

$/ /$ ! lcdg_float(mir);

$\operatorname{mir} 1=\operatorname{mir} / 255$;

//putc(10); putc('t');putc('m');putc('i'); putc('r'); putc(':'); putc_decimal(mir1,5);putc('

');putc('v');putc('o');putc('t');putc('s');

/l! lcdg_pagcol $(3,10)$;

$/ / ! \operatorname{lcdg}$ float(mir1);

acumulador $=0$;

//Rotina de Batimentos de Pulso

lcdg_pagcol(3,88); //envia dados para serial

putc('G');putc('B');putc(':');putc_decimal(freq,3);putc('-');

if $($ freq $>99)$ 


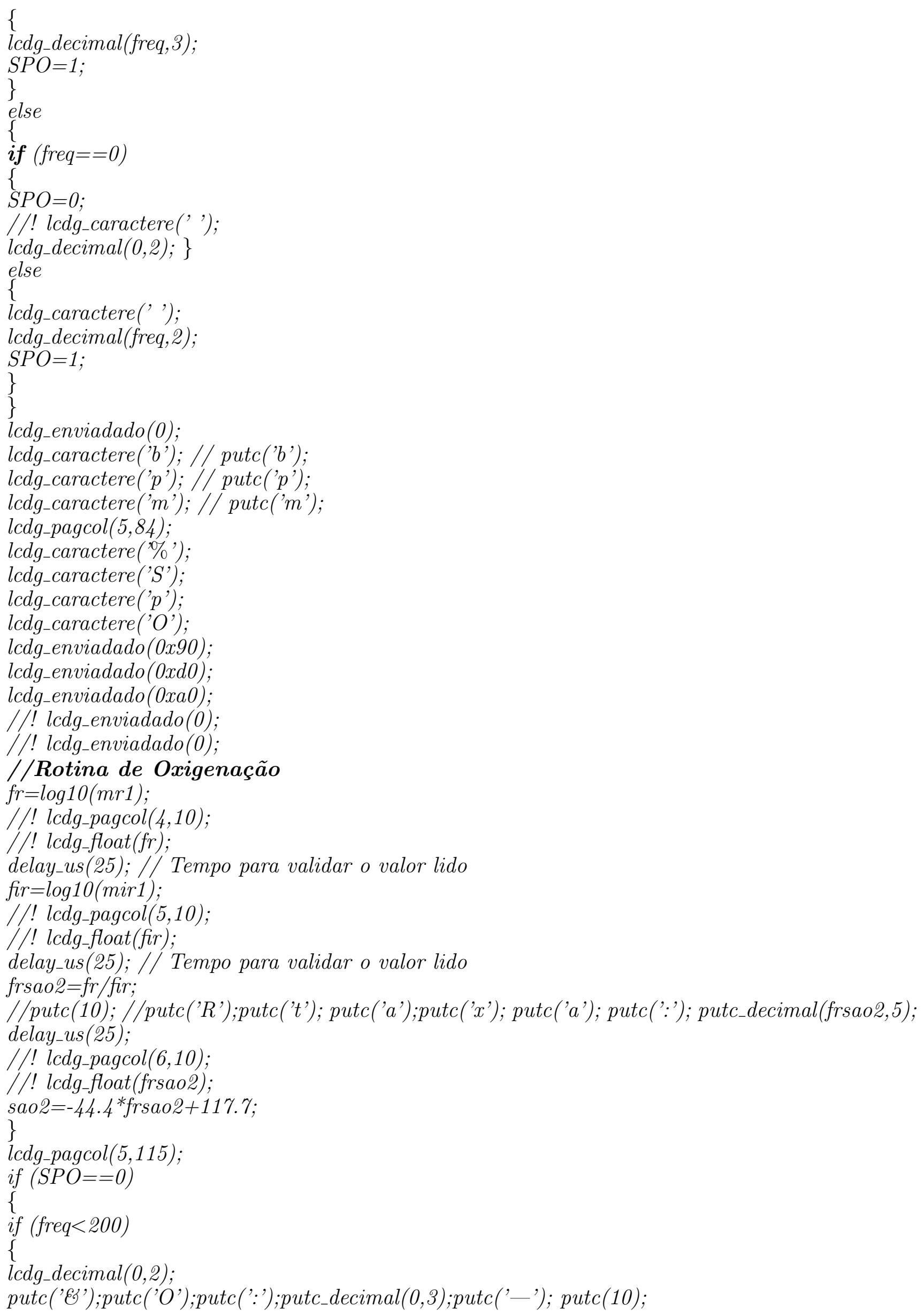




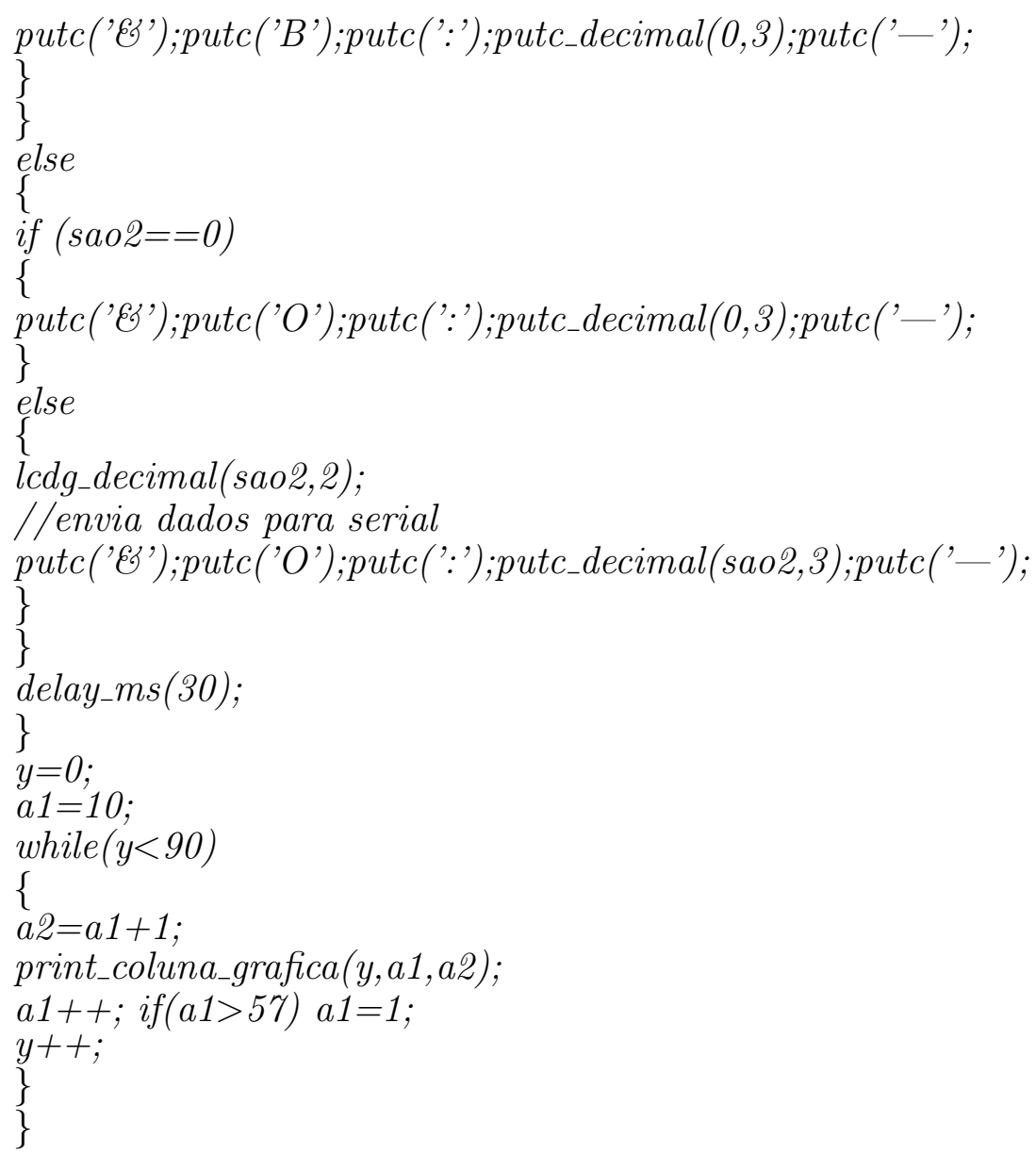




\section{E CÓDIGO - Visualização e Conexão Bluetooth}

\section{E.1 device_list.xml}

$<? \mathrm{xml}$ version="1.0" encoding $="$ utf-8"? $>$

$<$ LinearLayout

xmlns:android="http://schemas.android.com/apk/res/android"

android:orientation= "vertical"

android:layout_width ="match_parent"

android:layout_height="match_parent"

$>$

$<$ TextView

android:id="(Digitar a letra arroba)+id/title_paired_devices"

android:layout_width="match_parent"

android:layout_height="wrap_content"

android:textAppearance= "?android:attr/textAppearanceLarg"

android:text="Selecione o dispositivo:"

android:visibility= "gone"

android:background="\#666"

android:textColor="\#fff"

android:paddingLeft= "5dp""

$>$

$<$ ListView

android:id="(Digitar a letra arroba $)+\mathrm{id} /$ paired_devices"

android:layout_width="match_parent"

android:layout_height= "wrap_content"

android:stackFromBottom="false"

android:layout_weight="1"

$>$

$<$ TextView

android:id="+id/connecting"

android:layout_width="wrap_content"

android:layout_height="wrap_content"

android:textAppearance="?android:attr/textAppearanceLarge"

$>$

$<$ TextView

android:id= "(Digitar a letra arroba $)+i d /$ infoText"

android:layout_width="wrap_content"

android:layout_height="wrap_content"

android:text="Se nenhum dispositivo for visualizado, verifique nas configurações do android se ele está paread"

android:textAppearance $=$ "?android:attr/textAppearanceLarge" $>$

$<$ LinearLayout

android:layout_width="match_parent"

android:layout_height="wrap_content"

android:gravity= "center" >

$</$ LinearLayout $>$

$</$ LinearLayout $>$ 


\title{
E.2 DeviceListActivity.java
}

\author{
package com.oximetro; \\ import java.util.Set; \\ import android.app.Activity; \\ import android.bluetooth.BluetoothAdapter; \\ import android.bluetooth.BluetoothDevice; \\ import android.content.Intent; \\ import android.os.Bundle; \\ import android.util.Log; \\ import android.view.View; \\ import android.widget.AdapterView; \\ import android.widget.ArrayAdapter; \\ import android.widget.Button; \\ import android.widget.ListView; \\ import android.widget. TextView; \\ import android.widget. Toast;
}

import android.widget.AdapterView.OnItemClickListener;

public class DeviceListActivity extends Activity $\{/ /$ Debugging for LOGCAT

private static final String TAG = "DeviceListActivity";

private static final boolean $\mathrm{D}=$ true;

// declare button for launching website and textview for connection status

Button tlbutton;

TextView textView1;

// EXTRA string to send on to mainactivity

public static String EXTRA_DEVICE_ADDRESS = "device_address";

// Member fields

private BluetoothAdapter mBtAdapter;

private ArrayAdapter $<$ String $>$

mPairedDevicesArrayAdapter;

@Override protected void onCreate(Bundle savedInstanceState) \{

super.onCreate(savedInstanceState);

setContentView(R.layout.device_list);

\}

@Override

public void onResume()

\{

super.onResume();

$/ / * * * * * * * * * * * * * * *$

checkBTState();

textView1 = (TextView) findViewById(R.id.connecting);

textView1.setTextSize(40);

textView1.setText(" ");

// Initialize array adapter for paired devices 
mPairedDevicesArrayAdapter $=$ new ArrayAdapter $<$ String $>$ (this, R.layout.device_name);

// Find and set up the ListView for paired devices

ListView pairedListView $=($ ListView $)$ findViewById(R.id.paired_devices);

pairedListView.setAdapter(mPairedDevicesArrayAdapter);

pairedListView.setOnItemClickListener(mDeviceClickListener);

// Get the local Bluetooth adapter

mBtAdapter $=$ BluetoothAdapter.getDefaultAdapter () ;

// Get a set of currently paired devices and append to 'pairedDevices'

Set $<$ BluetoothDevice $>$ pairedDevices $=$ mBtAdapter.getBondedDevices () ;

// Add previosuly paired devices to the array

if (pairedDevices.size ()$>0)\{$

findViewById(R.id.title_paired_devices).setVisibility(View.VISIBLE);//make title viewable for (BluetoothDevice device : pairedDevices) \{

mPairedDevicesArrayAdapter.add(device.getName ()$+$ " $\backslash n "+$ device.getAddress ()$)$; \}

\} else \{

String noDevices $=$ getResources().getText(R.string.none_paired).toString();

mPairedDevicesArrayAdapter.add(noDevices);

\}

\}

// Set up on-click listener for the list (nicked this - unsure)

private OnItemClickListener mDeviceClickListener $=$ new OnItemClickListener ()\{

public void onItemClick(AdapterView? > av, View v, int arg2, long arg3) \{

textView1.setText("Connecting...");

// Get the device MAC address, which is the last 17 chars in the View

String info $=(($ TextView $) \mathrm{v}) \cdot \operatorname{get}$ Text ()$\cdot \operatorname{toString}()$;

String address $=$ info.substring(info.length ()$-17)$;

// Make an intent to start next activity while taking an extra which is the MAC

address.

Intent $\mathrm{i}=$ new Intent(DeviceListActivity.this, MainActivity.class);

i.putExtra(EXTRA_DEVICE_ADDRESS, address); startActivity(i);

\}

private void checkBTState ()\{

// Check device has Bluetooth and that it is turned on

mBtAdapter=BluetoothAdapter.getDefaultAdapter(); // CHECK THIS OUT THAT

IT WORKS!!!

if $(\mathrm{mBt}$ Adapter $==$ null $)\{$

Toast.makeText(getBaseContext(),

"Device does not support Bluetooth", Toast.LENGTH_SHORT).show();

\} else \{

if (mBtAdapter.isEnabled ()$)\{$

Log.d(TAG, “...Bluetooth ON..."); 
\} else \{

//Prompt user to turn on Bluetooth

Intent enableBtIntent $=$ new

Intent(BluetoothAdapter.ACTION_REQUEST_ENABLE);

startActivityForResult(enableBtIntent, 1);

\}

\}

\} 


\section{F CÓDIGO - Main APP}

\section{F.1 MainActivity.java}

package com.oximetro;

import java.io.IOException;

import java.io.InputStream;

import java.io.OutputStream;

import java.util.UUID;

import android.app.Activity;

import android.bluetooth.BluetoothAdapter;

import android.bluetooth.BluetoothDevice;

import android.bluetooth.BluetoothSocket;

import android.content.Intent;

import android.os.AsyncTask;

import android.os.Bundle;

import android.os.Handler;

import android.util.Log;

import android.view.View;

import android.view.View.OnClickListener;

import android.widget.Button;

import android.widget.TextView;

import android.widget.Toast;

public class MainActivity extends Activity \{

Button btnOn, btnOff;

TextView txtArduino, txtString, txtStringLength, sensorView0, sensorView1, sensor-

View2, sensorView3, coracao , sensorbpm , sensorspo ;

Handler bluetoothIn;

final int handlerState $=0 ; / /$ used to identify handler message

int qtd_medicoes $=0$;

int qtd_medicoes_limite $=20$;

String batimento $=" 0 "$;

String oxigenacao $=" 0 "$;

private BluetoothAdapter btAdapter = null;

private BluetoothSocket btSocket = null;

private StringBuilder recDataString = new StringBuilder () ;

private ConnectedThread mConnectedThread;

// SPP UUID service - this should work for most devices

private static final UUID BTMODULEUUID = UUID.fromString("00001101-0000-

1000-8000-00805F9B34FB");

// String for MAC address

private static String address;

(Digitar o símbolo arroba)Override

public void onCreate(Bundle savedInstanceState) \{

super.onCreate(savedInstanceState);

setContentView(R.layout.activity_main);

//Link the buttons and textViews to respective views

$/ /$ btnOn $=$ (Button) findViewById(R.id.buttonOn);

$/ /$ btnOff $=$ (Button) findViewById(R.id.buttonOff $)$;

txtString $=($ TextView $)$ findViewById(R.id.txtString $)$;

txtStringLength $=($ TextView $)$ findViewById(R.id.testView1); 
sensorView0 $=($ TextView $)$ findViewById(R.id.sensorView0 $)$;

sensorView2 $=($ TextView $)$ findViewById(R.id.textView2);

sensorView1 = (TextView) findViewById(R.id.sensorView1);

sensorbpm $=($ TextView $)$ findViewById(R.id.bpm);

sensorspo $=($ TextView $)$ findViewById(R.id.spo);

coracao $=($ TextView $)$ findViewById(R.id.textView1);

$/ /$ sensorView2 $=($ TextView)findViewById(R.id.sensorView2);

$/ /$ sensorView3 $=($ TextView $)$ findViewById(R.id.sensorView3);

bluetoothIn = new Handler ()\{

public void handleMessage(android.os. Message msg)

\{

if (msg.what $==$ handlerState) $\{/ /$ if message is what we want

String readMessage $=($ String $)$ msg.obj; // msg.arg1 = bytes from connect thread rec-

DataString.append(readMessage); //keep appending to string until

int endOfLineIndex = recDataString.indexOf("); // determine the end-of-line

if (endOfLineIndex i 0$)\{/ /$ make sure there data before

String dataInPrint = recDataString.substring(0, endOfLineIndex $) ; / /$ extract string

txtString.setText("Data Received = " + dataInPrint);

int dataLength $=$ dataInPrint.length ()$; / /$ get length of data received

txtStringLength.setText("String Length = " + String.valueOf(dataLength));

Log.v("TAG", "FULL:" + recDataString); //String oxigenacao = recDataString.substring(0, $3)$;

//Log.v("DUMP", "dump:" + recDataString);

if (recDataString.charAt $(0)==$ '\&')

//if it starts with \# we know it is what we are looking for \{

//String dados $=$ recDataString.toString().replace(", ) ;

String tipo $=$ recDataString.substring $(1,2) ; / /$ get sensor value from string between indices $1-5$

Log.v("TIPO", "tipo:" + tipo);

if(tipo.equals("B"))

\{

String batimento = recDataString.substring $(3,6)$;

Log.v("DUMP", "batimento:" + Integer.parseInt(batimento));

//sensorView0.setText("SpO2 = " + Integer.parseInt(batimento) + "\%");

coracao.setText(+Integer.parseInt(batimento)+"bpm");

sensorbpm.setText(+Integer.parseInt(batimento));

if(batimento.equals("000"))

\{

//sensorView0.setText("SpO2 = 0\% ");

sensorView2.setText("0\% ");

\}

if(Integer.parseInt(batimento) $>0$ );

\{

//Log.v("DUMP", "oxigenacao:" + Integer.parseInt(oxigenacao));

qtd_medicoes ++ ;

if(qtd_medicoes $==30)\{/ / \log . v(" D U M P "$, "medicoes:" +qtd_medicoes);

qtd_medicoes $=0$;

new SendCloud().execute(oxigenacao);

\}

Log.v("DUMP", "medicoes:" +qtd_medicoes);

\}

if(tipo.equals( "O")) 


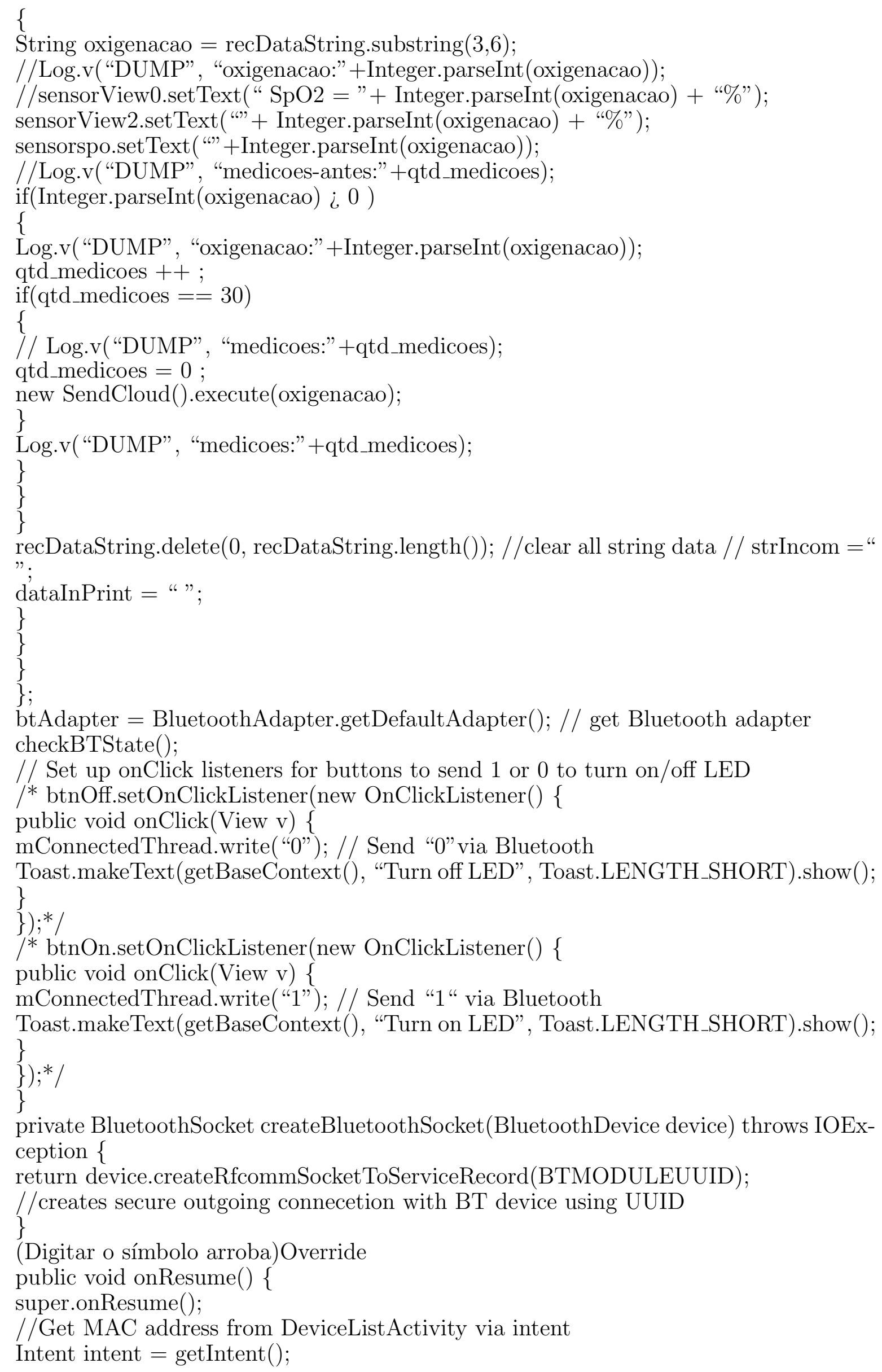


//Get the MAC address from the DeviceListActivty via EXTRA address = intent.getStringExtra(Dev //create device and set the MAC address

BluetoothDevice device $=$ btAdapter.getRemoteDevice(address);

try \{

btSocket $=$ createBluetoothSocket(device);

\} catch (IOException e) \{

Toast.makeText(getBaseContext(), "Socket creation failed", Toast.LENGTH_LONG).show(); \}

// Establish the Bluetooth socket connection.

try

\{

btSocket.connect();

\} catch (IOException e) \{

try

\{

btSocket.close();

\} catch (IOException e2)

\{

//insert code to deal with this

\}

\}

mConnectedThread $=$ new ConnectedThread(btSocket);

mConnectedThread.start();

//I send a character when resuming.beginning transmission to check device is connected

//If it is not an exception will be thrown in the write method and finish() will be called mConnectedThread.write( " $\mathrm{x}$ ");

\}

(Digitar o símbolo arroba)Override

public void onPause()

\{

super.onPause();

try

\{

//Don't leave Bluetooth sockets open when leaving activity

btSocket.close ();

\} catch (IOException e2) \{

//insert code to deal with this

\}

//Checks that the Android device Bluetooth is available and prompts to be turned on if off private void checkBTState ()\{

if(btAdapter $==$ null $)\{$

Toast.makeText(getBaseContext(), "Device does not support bluetooth", Toast.LENGTH_LONG).sh \} else \{

if (btAdapter.isEnabled ()$)\{$

\} else \{

Intent enableBtIntent $=$ new Intent(BluetoothAdapter.ACTION_REQUEST_ENABLE);

startActivityForResult(enableBtIntent, 1);

\}

\{

//create new class for connect thread private class ConnectedThread extends Thread \{ 
private final InputStream mmInStream;

private final OutputStream mmOutStream;

//creation of the connect thread public ConnectedThread(BluetoothSocket socket) \{

InputStream tmpIn = null;

OutputStream tmpOut $=$ null;

try \{

//Create I/O streams for connection

tmpIn = socket.getInputStream () ;

tmpOut = socket.getOutputStream () ;

\} catch (IOException e) \{\}

mmInStream = tmpIn;

mmOutStream $=$ tmpOut;

\}

public void $\operatorname{run}()\{$

byte[] buffer = new byte[256];

int bytes;

// Keep looping to listen for received messages

while (true) \{

try \{

bytes $=$ mmInStream.read(buffer); //read bytes from input buffer

String readMessage $=$ new String(buffer, 0, bytes);

// Send the obtained bytes to the UI Activity via handler

bluetoothIn.obtainMessage(handlerState, bytes, -1, readMessage).sendToTarget();

\} catch (IOException e) \{

break;

\}

\{

//write method

public void write(String input) \{

byte[] msgBuffer = input.getBytes();//converts entered String into bytes

$\operatorname{try}\{$

mmOutStream.write(msgBuffer); //write bytes over BT connection via outstream

\} catch (IOException e) \{

//if you cannot write, close the application

Toast.makeText(getBaseContext(), "Connection Failure", Toast.LENGTH_LONG).show();

finish();

\}

private class SendCloud extends AsyncTaskjString, Void, Stringi \{

(Digitar o símbolo arroba)Override

protected String doInBackground(String... params)

\{

try \{

String url_envio $=$ "https://api.thingspeak.com/update?key=L3DUAQU6AZRCBOCW\&field1=" +

EasyHttpClient envia = new EasyHttpClient();

String retorno $=$ envia.get(url_envio) ;

Log.v("DUMP", "mandando para nuvem:" + retorno);

\} catch (Exception e) \{

// TODO: handle exception

Log.v( (ERRO", "ERRO:" +e.toString()); \}

return "Executed";

\} 
(Digitar o símbolo arroba)Override protected void onPostExecute(String result) \{

$/ /$ TextView txt $=($ TextView $)$ findViewById(R.id.output $)$;

// txt.setText("Executed"); // txt.setText(result);

// might want to change "executed" for the returned string passed

// into onPostExecute() but that is upto you

\}

(Digitar o símbolo arroba)Override

protected void onPreExecute() \{\}

(Digitar o símbolo arroba)Override protected void onProgressUpdate(Void... values) \{\}

\} 